\title{
Cross cultural studies on adolescent cannabis use and psychosis
}

Citation for published version (APA):

Konings, M. (2011). Cross cultural studies on adolescent cannabis use and psychosis. [Doctoral Thesis, Maastricht University]. Maastricht University. https://doi.org/10.26481/dis.20111222mk

Document status and date:

Published: 01/01/2011

DOI:

10.26481/dis.20111222mk

Document Version:

Publisher's PDF, also known as Version of record

\section{Please check the document version of this publication:}

- A submitted manuscript is the version of the article upon submission and before peer-review. There can be important differences between the submitted version and the official published version of record.

People interested in the research are advised to contact the author for the final version of the publication, or visit the DOI to the publisher's website.

- The final author version and the galley proof are versions of the publication after peer review.

- The final published version features the final layout of the paper including the volume, issue and page numbers.

Link to publication

\footnotetext{
General rights rights.

- You may freely distribute the URL identifying the publication in the public portal. please follow below link for the End User Agreement:

www.umlib.nl/taverne-license

Take down policy

If you believe that this document breaches copyright please contact us at:

repository@maastrichtuniversity.nl

providing details and we will investigate your claim.
}

Copyright and moral rights for the publications made accessible in the public portal are retained by the authors and/or other copyright owners and it is a condition of accessing publications that users recognise and abide by the legal requirements associated with these

- Users may download and print one copy of any publication from the public portal for the purpose of private study or research.

- You may not further distribute the material or use it for any profit-making activity or commercial gain

If the publication is distributed under the terms of Article $25 \mathrm{fa}$ of the Dutch Copyright Act, indicated by the "Taverne" license above, 
CROSS CULTURAL STUDIES ON ADOLESCENT CANNABIS USE AND PSYCHOSIS 
(C) Monique Konings, Maastricht 2011

ISBN 9789461591050

Production: Datawyse | Universitaire Pers Maastricht 


\title{
CROSS CULTURAL STUDIES ON ADOLESCENT CANNABIS USE AND PSYCHOSIS
}

\author{
ACADEMIC DISSERTATION \\ to obtain the Degree of Doctor at Maastricht University, \\ on the authority of the Rector Magnificus, \\ Prof. dr. G.P.M.F. Mols \\ in accordance with the decision of the Board of Deans, \\ to be defended in public on \\ Thursday, $22^{\text {nd }}$ December 2011 at 10.00 hrs a.m.
}

by

MONIQUE KONINGS

Born in Hunsel on 15 May 1975

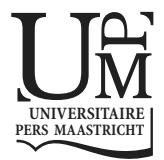




\section{Promotor}

Prof. Jim van Os

\section{Co-promotor}

Dr. C. Henquet

\section{Assessment committee}

Prof. dr. M.W. de Vries, chair

Prof. dr. L. de Haan, Universiteit Amsterdam

Prof. dr. A.M. Korebrits, UM

Dr. L. Krabbendam, Vrije Universiteit Amsterdam

Prof. dr. I. Myin-Germeys, UM 
Voor Antoine 



\section{Table of contents}

$\begin{array}{lll}\text { Chapter I Introduction } & 9\end{array}$

Chapter II Substance abuse in different school systems in Trinidad $\quad 21$ and Tobago: A controlled study of children with disabilities and their drug use

Chapter III Cannabis use and mood disorders: Patterns of clinical 35 presentations among adolescents in a developing country

Chapter IV Validity and reliability of the CAPE: a self-report 51 instrument for the measurement of psychotic experiences in the general population

Chapter V Early exposure to cannabis and risk for psychosis in young 61 adolescents in Trinidad

Chapter VI Evidence from two prospective population-based studies 69 for interaction between cannabis use and childhood trauma on psychosis risk.

Chapter VII Discussion

$\begin{array}{lll}\text { Chapter VIII Summary } & 103\end{array}$

$\begin{array}{lll}\text { Chapter IX samenvatting } & 111\end{array}$

$\begin{array}{ll}\text { Dankwoord } & 119\end{array}$

$\begin{array}{ll}\text { Curriculum vitae } & 121\end{array}$

$\begin{array}{ll}\text { List of publications } & 123\end{array}$ 

CHAPTER I

Introduction 


\section{Phenomenology of psychosis}

The term psychosis was suggested in 1845 by Feuchtersleben as a description of severe mental illness with both psychological and physical symptoms [1]. Kraepelin differentiated between neurosis and psychosis [2] and Schneider introduced the term first-rank symptoms as core symptoms of the diagnostic category schizophrenia [3]. This became the foundation for the definition of schizophrenia and formed the basis of modern classifications such as the Diagnostic and Statistical Manual of Mental Disorders of the American Psychiatric Association (DSM) and International Classification of Diseases (ICD-10). Nowadays, psychosis refers to a mental state in which contact with reality is lost or highly distorted, and where insight into the pathological nature is often absent. Schizophrenia is characterized by multiple psychotic episodes, and includes both positive symptoms, (e.g. bizarre delusions, hallucinations), disorganized behaviour (such as disorganised speech, disorganized and catatonic behaviour) and negative symptoms (flat affect, poverty of thoughts or speech and apathy). In order to fulfil DSM-IV criteria for schizophrenia, these symptoms have to interfere with social and occupational functioning, and may not be due to the acute effects of substance abuse or a medical condition [4]. Prevalence rates for schizophrenia are considered to be one percent worldwide [5]. Systematic reviews however reveal a more complex and varied epidemiological picture where prevalence rates of schizophrenia are higher in certain groups : for example, in men in urban environments and in members of ethnic minority groups, higher rates of schizophrenia have been reported [6, 7].

With the revision of DSM forthcoming, the discussion has arisen whether the old categories of psychotic disorder, in particular schizophrenia, should be retained [8]. Psychotic disorders have long been considered to occur in a dichotomous way where symptoms are "present" or "absent", a view that is inherent with the categorical diagnostic systems used. Psychotic symptoms, however, may not exclusively occur in patient populations in an all-or-none phenomenon. Moreover, there is evidence to suggest that that psychosis exists in the general population as a continuum where the psychosis phenotype is expressed at levels below its clinical manifestation. This broader psychosis phenotype is commonly referred to as psychosis proneness, psychotic experiences or schizotypy [9]. Hanssen and colleagues showed that the incidence of psychotic experiences in the general population was 100 times higher than the incidence of psychotic disorders such as schizophrenia in the general population [10]. Another study showed that $17.5 \%$ of the population sample reported non clinical psychotic symptoms while only $2 \%$ of this sample was diagnosed with a psychotic illness, revealing an incidence rate nearly 50 times higher than the psychosis phenotype in the normal population than that of psychotic diagnoses [11]. 


\section{Aetiology of psychosis}

The etiology of schizophrenia is complex and involves multiple factors. Numerous twin and family studies have shown that part of the vulnerability for the disease is genetic, with heritability rates ranging between 41 and $86 \%$ [12-14]. This genetic liability may not be attributed to a single locus but is more likely due to result from multiple variations in DNA sequence in multiple genes [15-17]. Genetic vulnerability alone, however, is not sufficient to cause the disease. Mounting evidence suggests that multiple environmental risk factors are implicated in the etiology of schizophrenia as well [18] (e.g. infections during pregnancy and delivery [19], ethnic minority [20], trauma at childhood [21] , and urbanicity [22, 23]). Their exact relevance and the neurobiological processes involved however, remain poorly understood [24].

\section{Cannabis as a risk factor for psychosis}

Cannabis is the most commonly used (illegal) drug in the world. In the Netherlands about one in six people between the ages of 15 and 64 years has used cannabis at least once in their lives, especially in the age group of 15-24 years. In the nineties, the use of cannabis considerably increased in Europe, especially amongst young people. In addition, Monshouwer and colleagues showed a doubling in the number of young people using cannabis before the age of 14 between 1992 and 1996 [25]. In patients with a psychotic disorder, the use of cannabis is considerably higher than in the general population (rates vary from 27-42 \%) [26, 27]. Research has shown that in these patients the use of cannabis is associated with a less favourable disease course, with more frequent hospitalizations, more relapses and poorer psychosocial functioning [28-30]. Self report research however, suggests that cannabis use may also have a positive impact on negative [31] and affective symptoms [32]. Patients themselves often report using cannabis for the positive effects of cannabis on mood and social functioning [33, 34].

The French psychiatrist Moreau was the first in 1845 to publish a study on the acute effects of cannabis. He exposed himself and his students to high amounts of THC ( $\Delta$ 9-tetrahydrocannabinol, the psychoactive component of cannabis) and concluded that THC may acutely induce psychotic symptoms [35]. These responses were clearly dependent on the amount of cannabis being administered. Psychotic reactions included paranoid ideas, illusions, hallucinations, depersonalisation and agitation. Later, the psychiatrist and neurologist Ames conducted similar experiments and similarly showed that intoxication with cannabis may result in delusions and hallucinations in healthy volunteers [36]. Favrat and colleagues examined the im- 
pact of cannabis on cognition and driving skills and concluded that the majority of the test cases did not react psychotically to synthetic THC. Two cases of healthy subjects however, developed transient psychotic symptoms (depersonalization, paranoid feelings and derealisation) following the oral administration of cannabis [37]. These different findings suggest that people differ in their sensitivity to cannabis. D'Souza examined differential sensitivity for the acute effect of cannabis by exposing both patients with schizophrenia as healthy controls to THC. The results showed that patients were more sensitive to the acute effects of cannabis and showed more psychotic perceptions and more cognitive impairments after exposure to cannabis than controls [37].

The first study investigating the long term effects of cannabis exposure on psychosis risk was published by Andreasson and colleagues in 1987. In this study 45,000 conscripts aged 18 years were followed over the course of 15 years. The results showed that the risk of developing schizophrenia was 6 times higher for those who had used cannabis at least 50 times at age 18 years, compared to those who had never used cannabis at age 18 years [38]. In the Netherlands the long term effects of cannabis have also been examined using data from the NEMESIS study (Netherlands mental health survey and incidence study). Van Os concluded in this study that in the general population, cannabis use is associated with a three-fold risk of psychosis. This association remained statistically significant after adjusting for possible confounding factors such as ethnicity and growing up in an urban environment [39]. In the Christchurch Health and Development Study in New Zealand 1055 children were examined during childhood and again at age 18, 21 and 25. These results similarly showed that use of cannabis result in an increased risk of developing psychosis later on in life [40]. In this study no relation was found to reverse causality, indicating that psychotic symptoms did not increase the risk of starting to use cannabis (the so called self medication hypothesis). In the German Early Developmental Stages of Psychopathology (EDSP) study including 2437 young people, the self medication hypothesis was further examined, but it was also shown here that psychosis vulnerability at baseline did not predict cannabis use 4 years later [41]. A study in the Netherlands, however, following 1580 young people over a period of 14 years, found that psychotic symptoms at baseline did increase the risk for later cannabis use [40]. Overall, several meta-analyses have now been published, all showing that use of cannabis is associated with a two fold increased risk for psychosis, independent of other risk factors for psychosis or pre-existing psychotic symptoms [41, 42]. It seems clear, however, that cannabis alone may not be a sufficient nor a necessary cause of psychosis, but seems to depend on other factors in order to have a causal impact in the onset of psychotic symptoms 


\section{Childhood trauma as a risk factor for psychosis}

An association between trauma (sexual or physical abuse) and psychosis has been suggested in several studies. Clinical studies have reported increased rates of childhood trauma among patients with a psychotic illness compared to the general population [43, 44]. Furthermore, a study including 200 Community mental-healthcentre clients showed that in patients with a history of childhood abuse, hallucinations were significantly more common compared to patients without a history of childhood trauma. Similarly, another study reported that patients with a psychotic diagnosis and with a history of childhood physical or sexual abuse, reported significantly more severe positive symptoms of schizophrenia [43, 45] and hallucinations $[46,47]$ but not delusions or negative symptoms compared to psychotic patients without exposure to childhood trauma.

In the general population, a relationship between early life traumatic experiences and development of psychotic symptoms later in life has also been noted. [48, 49]. For example, subjects in a large general population sample, who reported experiencing abuse frequently during childhood, had an estimated 30 times greater chance of developing psychosis compared to those who did not report childhood abuse. Less frequent abuse was associated with an estimated five times greater risk of developing psychosis compared to those without any exposure to childhood abuse [50]. In another non patient sample, it was shown that the $70 \%$ of the persons who reported hearing voices had first experienced hallucinations following a traumatic event [51] . A dose response relationship between trauma and psychotic symptoms has also been found with greater exposure to trauma being associated with progressively greater risk for psychotic symptoms [21, 52-54]. Also peer victimization in early childhood was shown to be associated with psychotic symptoms, with more severe victimization being associated with a greater risk [55]. A very recent study by Arsenault and colleagues showed that children who experienced maltreatment by an adult or peer victimization had more risk of developing psychotic symptoms than those children who had not experiences these traumas. When children were exposed to these traumas early in life, the risk of developing psychotic symptoms was higher than those who had been exposed to maltreatment later in life [56].

Thus, both cannabis use and childhood trauma have consistently been found to be associated with psychosis risk. The pathway, by which both environmental factors may lead to adult psychotic illness, however remains poorly understood and is in urgent need of further investigation. 


\section{Cultural aspects of psychosis}

Few studies have investigated the incidence of psychotic disorders in non-western or developing countries [57]. A possible explanation for this is that good quality medical infra structure is absent in non developed countries. Also, a substantial proportion of patients with psychosis is known to seek treatment in alternative services, in which methods based on non-biomedical beliefs or other pathways of care are commonly applied $[58,59]$. A study conducted in Malaysia showed that the majority of patients with psychiatric complaints consulted traditional healers (73\%) [60]. Thus, in non-western countries, the prevalence rates of psychotic disorder may often be underestimated [61]. Studies investigating psychosis rates among ethnic minorities in western societies, however, systematically showed increased incidence rates among migrant and minority ethnic populations $[62,63]$. The incidence of psychosis, for example, was found to be significantly higher in African-Caribbean and Black African groups living in the UK than in the White British population [64, 65]. Also in the Netherlands, incidence of psychotic disorder was found to be higher among ethnic minorities (non native Dutch people). Here it was found that the variation in the incidence of psychosis in the different minority groups varied by degree of perceived discrimination: the more intense the perceived discrimination, the higher the incidence of psychotic disorders in that group compared to the other minority groups. [66]. Clearly, more information on the prevalence of psychotic symptoms in non-western societies and ethnic minority is needed, as well as the role of culture specific environmental factors that moderate the risk for psychosis.

\section{Adolescence}

The onset of psychotic disorders occurs typically early in adult life. Studies on the onset of the disease consistently show an increase in the incidence and prevalence of the disorder from the age of 15 onwards [67] whereas an onset before the age of 12 years rarely occurs. Age of onset differs between sexes, with a peak incidence in men between 10 and 25 years and in women 25 and 35 years [68]. Similarly, the more broadly defined psychosis phenotype, psychotic experiences, is much more common in young people and declines with age $[11,69]$. Adolescence is also a period during which young people start experimenting with drugs such as cannabis. There is evidence to suggest that an early onset of cannabis use increases the risk of using cannabis more frequently and for longer periods of time, as well as using drugs other than cannabis later in life [70]. In a mid-secondary school where adolescents were followed for 10 years, it was found that the heavier the use of cannabis and the earlier the onset, the higher the risk of developing drug related problems, delinquency and juvenile offending, school dropout and difficulties in interpersonal 
relationships at age 24 years [70-72]. With respect to psychosis, there are two studies showing that early exposure to cannabis (before the age of 15 years) increases the risk of developing psychotic symptoms or psychotic illness later in life $[73,74]$

Adolescence and early adulthood, thus seem to be a critical developmental period in which exposure to toxic substances, such as cannabis, may be more detrimental than exposure during later adult life. Pharmacological and gene knock-out studies have demonstrated that the central effects of THC are mediated via partial agonism at cannabinoid 1 (CB1) receptors, the primary binding site of endogenous cannabinoids [75]. Experimental studies on animals have shown that the CB1 receptor binding reaches maximum values around puberty. In humans, this progressive increase in $\mathrm{CB} 1$ receptor binding potential has been shown in several brain regions as well [76]. This progressive increase of CB1 receptor binding potential may thus reflect the final manifestation of complete functional maturity of the endocannabinoid system. Given that the endocannabinoid system acts in close interaction with the dopamine system, and dysregulation of the dopamine system has been suggested as playing an import role in the development of psychotic symptoms; cannabis exposure during adolescence specifically may increase the risk of developing psychosis later in life.

\section{Aims of the thesis}

The overall aim of the thesis was to investigate the association between cannabis and psychiatric diseases, mainly psychosis, and to test whether an association between cannabis and psychosis is also present in a non-western society. This thesis furthermore aimed at exploring whether early traumatic experiences moderate the long-term psychosis inducing effects of cannabis use later in life in population based samples.

Chapter II provides a review on substance use during adolescence and discusses patterns of substance use in the Caribbean area. In addition, the prevalence of alcohol and cannabis use during adolescence was investigated including different school systems in Trinidad. Chapter III describes a series of case-studies on cannabis using psychiatric patients in Trinidad, in order further to investigate patters of clinical presentations of affective and psychotic symptoms as well as suicidal ideation in relation to cannabis use. Chapter IV discusses the reliability and validity of the Community Assessment of Psychic Experiences (CAPE42), an instrument to assess psychotic experiences in general. In chapter $\mathbf{V}$ the CAPE was then used to investigate the association between adolescent exposure to cannabis and the risk of developing psychosis in a sample of school students in Trinidad. In chapter VI, interac- 
tion between childhood trauma and cannabis was investigated in two independent population-based samples to establish whether early traumatic experiences moderate the long-term psychosis inducing effects of cannabis use later in life. The final chapter provides a summary and discusses the main findings presented in this thesis.

\section{References}

1. Beer, M.D., The dichotomies: psychosis/neurosis and functional/organic: a historical perspective. Hist Psychiatry, 1996. 7(26 Pt 2): p. 231-55.

2. Beer, M.D., Psychosis: from mental disorder to disease concept. Hist Psychiatry, 1995. 6(22 Pt 2): p. 177-200.

3. Ihara, K., et al., The prevalence, diagnostic significance and demographic characteristics of Schneiderian first-rank symptoms in an epidemiological sample of first-episode psychoses. Psychopathology, 2009. 42(2): p. 81-91.

4. AmericanPsychiatricAssociation, Diagnostic and Statistic Manaul of Mental Disorders. 2000, Washington DC: American Psychiatric Association.

5. Jablensky, A., et al., Schizophrenia: manifestations, incidence and course in different cultures. A World Health Organization ten-country study. Psychological Medicine, Monograph. Supplement 1992. 20: p. 1-97.

6. McGrath, J., et al., A systematic review of the incidence of schizophrenia: the distribution of rates and the influence of sex, urbanicity, migrant status and methodology. BMC Med, 2004. 2: p. 13.

7. Saha, S., D. Chant, and J. McGrath, Meta-analyses of the incidence and prevalence of schizophrenia: conceptual and methodological issues. Int J Methods Psychiatr Res, 2008. 17(1): p. 55-61.

8. van Os, J., 'Salience syndrome' replaces 'schizophrenia' in DSM-V and ICD-11: psychiatry's evidencebased entry into the 21st century? Acta Psychiatr Scand, 2009. 120(5): p. 363-72.

9. van Os, J., et al., A systematic review and meta-analysis of the psychosis continuum: evidence for a psychosis proneness-persistence-impairment model of psychotic disorder. Psychological Medicine, 2009. 39(2): p. 179-95.

10. Hanssen, M., et al., The incidence and outcome of subclinical psychotic experiences in the general population. British Journal of Clinical Psychology 2005. 44(Pt 2): p. 181-91.

11. van Os, J., et al., Strauss (1969) revisited: a psychosis continuum in the general population? Schizophrenia Research, 2000. 45(1-2): p. 11-20.

12. Faraone, S.V., L. Taylor, and M.T. Tsuang, The molecular genetics of schizophrenia: an emerging consensus. Expert Rev Mol Med, 2002. 4(14): p. 1-13.

13. Tienari, P., et al., Genotype-environment interaction in schizophrenia-spectrum disorder. Long-term follow-up study of Finnish adoptees. Br J Psychiatry, 2004. 184: p. 216-22.

14. McGuffin, P., Nature and nurture interplay: schizophrenia. Psychiatr Prax, 2004. 31 Suppl 2: p. S18993.

15. van Os, J., B.P. Rutten, and R. Poulton, Gene-Environment Interactions in Schizophrenia: Review of Epidemiological Findings and Future Directions. Schizophrenia Bulletin, 2008.

16. van Winkel, R., et al., Genome-Wide Findings in Schizophrenia and the Role of Gene-Environment Interplay. CNS Neurosci Ther, 2010: p. 1-8.

17. Schwab, S.G. and D.B. Wildenauer, Update on key previously proposed candidate genes for schizophrenia. Curr Opin Psychiatry, 2009. 22(2): p. 147-53.

18. van Os, J., et al., The schizophrenia envirome. Current Opinion in Psychiatry, 2005. 18(2): p. 141-5.

19. Mittal, V.A., L.M. Ellman, and T.D. Cannon, Gene-environment interaction and covariation in schizophrenia: the role of obstetric complications. Schizophrenia Bulletin, 2008. 34(6): p. 1083-94. 
20. McGrath, J.J., Variations in the incidence of schizophrenia: data versus dogma. Schizophrenia Bulletin, 2006. 32(1): p. 195-7.

21. Spauwen, J., et al., Impact of psychological trauma on the development of psychotic symptoms: relationship with psychosis proneness. British Journal of Psychiatry, 2006. 188: p. 527-33.

22. Marcelis, M., et al., Urbanization and psychosis: a study of 1942-1978 birth cohorts in The Netherlands. Psychologica Medicine, 1998. 28(4): p. 871-9.

23. Bak, M., et al., Early trauma may increase the risk for psychotic experiences by impacting on emotional response and perception of control. Acta Psychiatr Scand, 2005. 112(5): p. 360-6.

24. Tandon, R., M.S. Keshavan, and H.A. Nasrallah, Schizophrenia, "Just the Facts" What we know in 2008. 2. Epidemiology and etiology. Schizophrenia Research, 2008. 102(1-3): p. 1-18.

25. Monshouwer, K., et al., First cannabis use: does onset shift to younger ages? Findings from 1988 to 2003 from the Dutch National School Survey on Substance Use. Addiction, 2005. 100(7): p. 963-70.

26. Green, B., D.J. Kavanagh, and R.M. Young, Reasons for cannabis use in men with and without psychosis. Drug Alcohol Rev, 2004. 23(4): p. 445-53.

27. Ringen, P.A., et al., Illicit drug use in patients with psychotic disorders compared with that in the general population: a cross-sectional study. Acta Psychiatr Scand, 2008. 117(2): p. 133-8.

28. Grech, A., et al., Cannabis use and outcome of recent onset psychosis. European Psychiatry, 2005. 20(4): p. 349-53.

29. Linszen, D.H., P.M. Dingemans, and M.E. Lenior, Cannabis abuse and the course of recent-onset schizophrenic disorders. Archives of General Psychiatry, 1994. 51(4): p. 273-9.

30. Zammit, S., et al., Effects of cannabis use on outcomes of psychotic disorders: systematic review. British Journal of Psychiatry, 2008. 193(5): p. 357-63.

31. Compton, W.M., et al., Prevalence of marijuana use disorders in the United States: 1991-1992 and 2001-2002. JAMA, 2004. 291(17): p. 2114-21.

32. Dixon, L., et al., Drug abuse in schizophrenic patients: clinical correlates and reasons for use. Am J Psychiatry, 1991. 148(2): p. 224-30.

33. Addington, J. and V. Duchak, Reasons for substance use in schizophrenia. Acta Psychiatr Scand, 1997. 96(5): p. 329-33.

34. Spencer, C., D. Castle, and P.T. Michie, Motivations that maintain substance use among individuals with psychotic disorders. Schizophr Bull, 2002. 28(2): p. 233-47.

35. Moreau, J.J., Hashish and Mental Illness. 1973, New York: Raven Press.

36. Ames, F., A clinical and metabolic study of acute intoxication with Cannabis sativa and its role in the model psychoses. J Ment Sci, 1958. 104(437): p. 972-99.

37. Favrat, B., et al., Two cases of "cannabis acute psychosis" following the administration of oral cannabis. BMC Psychiatry, 2005. 5: p. 17.

38. Andreasson, S., et al., Cannabis and schizophrenia. A longitudinal study of Swedish conscripts. Lancet, 1987. 2(8574): p. 1483-6.

39. van Os, J., et al., Cannabis use and psychosis: a longitudinal population-based study. American Journal of Epidemiology, 2002. 156(4): p. 319-27.

40. Ferdinand, R.F., et al., Cannabis use predicts future psychotic symptoms, and vice versa. Addiction, 2005. 100(5): p. 612-8.

41. Henquet, C., et al., Prospective cohort study of cannabis use, predisposition for psychosis, and psychotic symptoms in young people. British Medical Journal, 2005. 330(7481): p. 11.

42. Arseneault, L., et al., Causal association between cannabis and psychosis: examination of the evidence. British Journal of Psychiatry, 2004. 184: p. 110-7.

43. Ross, C.A., G. Anderson, and P. Clark, Childhood abuse and the positive symptoms of schizophrenia. Hospital \& Community Psychiatry 1994. 45(5): p. 489-91.

44. Mueser, K.T., et al., Trauma and posttraumatic stress disorder in severe mental illness. Journal of Consulting \& Clinical Psychology 1998. 66(3): p. 493-9.

45. Kilcommons, A.M. and A.P. Morrison, Relationships between trauma and psychosis: an exploration of cognitive and dissociative factors. Acta Psychiatrica Scandinavica, 2005. 112(5): p. 351-9. 
46. Hammersley, P., et al., Childhood trauma and hallucinations in bipolar affective disorder: preliminary investigation. British Journal of Psychiatry, 2003. 182: p. 543-7.

47. Read, J., et al., Sexual and physical abuse during childhood and adulthood as predictors of hallucinations, delusions and thought disorder. Psychology and Psychotherapy, 2003. 76(Pt 1): p. 1-22.

48. Lim, C., S.A. Chong, and R.S. Keefe, Psychosocial factors in the neurobiology of schizophrenia: a selective review. Annals Academy of Medicine Singapore 2009. 38(5): p. 402-6.

49. Morgan, C. and H. Fisher, Environment and schizophrenia: environmental factors in schizophrenia: childhood trauma--a critical review. Schizophrenia Bulletin, 2007. 33(1): p. 3-10.

50. Janssen, I., et al., Childhood abuse as a risk factor for psychotic experiences. Acta Psychiatrica Scandinavica, 2004. 109(1): p. 38-45.

51. Romme, M.A., Esscher, A.D., Hearing voices. Schizophr Bull, 1989. 15: p. 209-16.

52. Scott, J., et al., Association between trauma exposure and delusional experiences in a large community-based sample. British Journal of Psychiatry, 2007. 190: p. 339-43.

53. Shevlin, M., et al., Cumulative traumas and psychosis: an analysis of the national comorbidity survey and the British Psychiatric Morbidity Survey. Schizophrenia Bulletin, 2008. 34(1): p. 193-9.

54. Hirsch, S., et al., A one year prospective study of the effect of life events and medication in the aetiology of schizophrenic relapse. British Journal of Psychiatry, 1996. 168(1): p. 49-56.

55. Schreier, A., et al., Prospective study of peer victimization in childhood and psychotic symptoms in a nonclinical population at age 12 years. Archives of General Psychiatry, 2009. 66(5): p. 527-36.

56. Arseneault, L., et al., Childhood trauma and children's emerging psychotic symptoms: A genetically sensitive longitudinal cohort study. Am J Psychiatry, 2011. 168(1): p. 65-72.

57. Bresnahan M, et al., Geographical variation in incidence, course and outcome of schiozphrenia: a comparison of developing and developed countries. , in The epidemiology of schizophrenia., J.P. Murray RM, Susser E, et al. (eds), Editor. 2003, Cambridge University Press: Cambridge. p. 18-33.

58. Chaturvedi, S.K., Duration of untreated psychosis in LAMI countries. Br J Psychiatry, 2009. 194(2): p. 188; author reply 189.

59. Razali, S.M. and A.M. Yassin, Complementary treatment of psychotic and epileptic patients in malaysia. Transcult Psychiatry, 2008. 45(3): p. 455-69.

60. Salleh, M.R., The consultation of traditional healers by Malay patients. Med J Malaysia, 1989. 44(1): p. 3-13.

61. Naqvi, H.A., et al., Pathways to care: duration of untreated psychosis from Karachi, Pakistan. PLoS One, 2009. 4(10): p. e7409.

62. Allardyce, J. and J. Boydell, Review: the wider social environment and schizophrenia. Schizophrenia Bulletin, 2006. 32(4): p. 592-8.

63. Morgan, C., et al., Migration, Ethnicity, and Psychosis: Toward a Sociodevelopmental Model. Schizophrenia Bulletin, 2010. may 30.

64. Cooper, C., et al., Perceptions of disadvantage, ethnicity and psychosis. Br J Psychiatry, 2008. 192(3): p. $185-90$.

65. Fearon, P., et al., Incidence of schizophrenia and other psychoses in ethnic minority groups: results from the MRC AESOP Study. Psychol Med, 2006. 36(11): p. 1541-50.

66. Veling, W., et al., Discrimination and the incidence of psychotic disorders among ethnic minorities in The Netherlands. Int J Epidemiol, 2007. 36(4): p. 761-8.

67. Bailly, D., [Adolescence and schizophrenia]. Encephale, 2009. 35 Suppl 1: p. S10-9.

68. Sadock J., S.V.A., Ruiz P., Kaplan H.I. et al. , Kaplan and Sadock's comprehensive textbook of psychiatry 9th edition ed. Vol. 1. 2009, Philadelphia: Wolters Kluwer Health/Lippincott Williams \& Wilkins.

69. Verdoux, H., et al., Is early adulthood a critical developmental stage for psychosis proneness? A survey of delusional ideation in normal subjects. Schizophrenia Research, 1998. 29(3): p. 247-54.

70. Degenhardt, L., et al., Outcomes of occasional cannabis use in adolescence: 10-year follow-up study in Victoria, Australia. British Journal of Psychiatry, 2010. 196: p. 290-5.

71. Fergusson, D.M., M.T. Lynskey, and L.J. Horwood, The short-term consequences of early onset cannabis use. J Abnorm Child Psychol, 1996. 24(4): p. 499-512. 
72. Fergusson, D.M. and L.J. Horwood, Early onset cannabis use and psychosocial adjustment in young adults. Addiction, 1997. 92(3): p. 279-96.

73. Arseneault, L., et al., Cannabis use in adolescence and risk for adult psychosis: longitudinal prospective study. British Medical Journal, 2002. 325(7374): p. 1212-3.

74. Stefanis, N.C., et al., Early adolescent cannabis exposure and positive and negative dimensions of psychosis. Addiction, 2004. 99(10): p. 1333-41.

75. Pertwee, R.G., The pharmacology of cannabinoid receptors and their ligands: an overview. Int J Obes (Lond), 2006. 30 Suppl 1: p. S13-8.

76. McLaughlin, C.R., et al., Cannabinoid receptors in developing rats: detection of $m R N A$ and receptor binding. Drug and Alcohol Dependence 1994. 36(1): p. 27-31. 



\section{CHAPTER II}

\section{Substance abuse in different school systems in Trinidad and Tobago: A controlled study of children with disabilities and their drug use}

Monique Konings, $\mathrm{MD}^{1,2}$ and Hari D Maharajh, BscHons, MBBS, FRCPsych, Dip Clin Neuro, LLB Hons, $\mathrm{CMT}^{2}$

${ }^{1}$ Psychiatric Unit, Mental Health Care, Oost Brabant, the Netherlands and ${ }^{2}$ Psychiatry Unit, Department of Clinical Medicine, University of West-Indies, Trinidad

Int J Disabil Hum Dev 2007;6(1):3-10 


\begin{abstract}
Substance use is a worldwide problem with increasing use among children and adolescents in the school systems. This study investigated the lifetime and current use of cannabis and alcohol in two contrasting school systems in Trinidad: Government Secondary Schools (GSS) and Servol Vocational Schools (SVS). A questionnaire was administered to 468 students (age 12-23 years) at three grammar-styled schools and two vocational schools in north, central and south Trinidad. Demographic data was collected on age, gender, family structure, religion, and peer -group effect. Twenty-eight percent reported lifetime cannabis use and sixty-one percent lifetime exposure to alcohol. Current rates of cannabis use was almost four and a half times more common among vocational school students. Both alcohol and cannabis was more commonly used by males in both school systems $(95 \% \mathrm{Cl} 43.6-56.4, \mathrm{p}=$ $0.004)$. The age of onset of cannabis and alcohol use was statistically lower in government-assisted school students (T 2.36, df 95, p < 0.05, T 5.06, df 253, p < 0.001 and $\mathrm{T} 3.07$, df $118, \mathrm{p}<0.01$ respectively). Cannabis use was positively correlated with peer group usage, increased with age, and positively correlated with a nonintact family $(X 2=7.451, d f=1, p=0.006)$. Alcohol and cannabis were more prevalent in vocational school systems, where cannabis was excessively used. Important contributory factors were family dysfunction, gender, age, and peer pressure. It is imperative that the Ministry of Education be sensitized about this growing problem and appropriate educational and preventative programs instituted.
\end{abstract}

Keywords: adolescence, cannabis, alcohol, school, vocational, grammar, disabilities, Trinidad, Tobago

Correspondence: Monique Konings, MD, Psychiatry unit, Mental Health Care/GGZ Oost Brabant, Helmond, the Netherlands. E-mail-address: konings164@zonnet.nl.

Submitted: July 03, 2006. Revised: August 08, 2006. Accepted: August 08, 2006. 


\section{Introduction}

Substance abuse, especially tobacco, alcohol, and cannabis is becoming more prevalent among adolescents. Internationally, the pattern is changing among youths, with an increasing use of cannabis (1) and alcohol $(2,3)$. Lifestyle changes associated with the use of these recreational drugs have resulted in more social problems (4) and criminal violence (5). In addition, recent reports have linked cannabis use with poor performance at school and the risk of using other illicit drugs (6). Alcohol and cannabis use have been implicated as trigger factors in precipitating anxiety states, mood disorders, and suicidal behaviour (7-9).

The rates of cannabis use among adolescents who have used this substance at least once in their lifetime range from $32.5 \%$ to $43.0 \%(10,11)$. The lifetime incidence ranges from $3.5 \%$ to $8 \%$ cannabis use to $2.2 \%$ to $7 \%$ cannabis dependency $(12,13)$. The incidence rates of alcohol, tobacco, and cannabis use were even higher in youths with disabilities (14), who reported signifi-cantly more exposure to risk factors and fewer protective factors (15). Studies in developing countries have also reported high rates of cannabis use with a prevalence of $17 \%$ among male students and $8 \%$ among girls in the Seychelles (16) and 3.4\% in Nigeria (17). The pattern is changing worldwide, with more frequent use of cannabis (10) and earlier onset of use. The age of initial use has decreased to a mean of 12 years (18). Contributory factors associated with cannabis use were identified as peer pressure, negative family atmosphere, school difficulties, co-morbid psychopathology, and male gen$\operatorname{der}(19,20)$.

The prevalence rates of the current use of alcohol among adolescents ranges from $14.5 \%$ (17) to $47.5 \%$ (21). In many developed countries, high rates of alcohol use has been reported among adolescents, with a rate of $71 \%$ in Portugal (22). In an eight year study among adolescents the Baltic states, increased rates of weekly point prevalence drinking were found, with $25 \%$ of the boys drinking weekly (23). In London $32 \%$ of $14-16$ year-old schoolchildren reported at least one episode of excessive drinking, defined as the consumption of 10 or more units of alcohol per drinking occasion (24). Factors associated with the consumption of alcohol were similar to those found in studies of adolescent cannabis use, namely peer norms, peer relationships, school difficulties, family history of alcohol use, and use of alcohol by parents. In addition, positive associations with were found male gender $(19,22,25)$. A high co-morbidity with cigarette smoking was seen in schoolchildren and students $(24,26)$.

Increasing rates of alcohol and cannabis use among adolescents have also been reported in Caribbean countries. Over a period of 15 years, a threefold increase from $8 \%$ in the rates of cannabis use has been observed in Trinidad (27-29). The use of drugs in Trinidad was related to traditional values, low self esteem, and low educational expectations (30). A survey of secondary school students between the ages 
of $12-18$ years in Jamaica revealed that $60.7 \%$ of 394 students tested admitted to the use of one or more drugs (31). Alcohol was the most commonly used drug, with $50.2 \%$ of females having tried a psychoactive drug compared with $63 \%$ of the males.

Gordon (32) and Sharma (33) surveyed students in secondary schools in urban Jamaica almost two decades later and reported increased use, with alcohol remaining the most popular drug. Twenty percent of the students surveyed believed there was no risk in taking drugs and half of the students who took drugs had initiated drug use before the age of 10 years. According to Douglas (34), between 1987 and 1997, the use of marijuana significantly increased overall from $19.8 \%$ to $26.9 \%$ for lifetime use and $4.15 \%$ to $7.7 \%$ for current use. Mari-juana use represented $80.0 \%$ of illicit drug use. Again in Jamaica, prevalence rates of $50.2 \%$ for alcohol and $16.6 \%$ for tobacco were reported (35), with higher prevalence among male students, urban students, and children of professionals.

The aims of the present study were to investigate patterns of lifetime prevalence and current use of drug exposure in two contrasting school systems in Trinidad, one system being Servol, which has mainly disability students, and to determine possible contributory factors.

\section{Methods}

Trinidad and Tobago are twin islands located in the southern Caribbean Sea, just off the coast of Venezuela. The islands have a population of 1.3 million, $49.9 \%$ females and $50.1 \%$ males. The ethnic composition is $40.3 \%$ Indo-Trinidadian, $39.6 \%$ AfroTrinidadian, $18.4 \%$ mixed, and $1.7 \%$ others (CSO 2004).

In Trinidad and Tobago, the school system comprises either a grammar-styled or a vocational school system. Schools in the former are government or government-assisted schools (GAS), both at the primary and the secondary levels. At the secondary level, the schools are classified as government secondary, assisted secondary, junior secondary, senior comprehensive, and composite schools. The government-assisted secondary schools, which are managed by denominational boards, are generally considered the more prestigious schools, whereas the others are categorized as non-prestigious schools. In 2001, 111,781 students were enrolled in the secondary level schools; with 22,251 in government-assisted secondary schools (36).

Several vocational training centers are located in Trinidad and Tobago; the best known of these centers is SERVOL. The SERVOL schools were established in 1974 in Trinidad and Tobago in an effort to address dropouts from the grammar-styled school and those so disadvantaged due to poor performance. SERVOL has a population of approximately 5,000 students, with ages ranging from 13 to 20 years. Many 
of these students come from disadvantaged homes and abusive situations, some have learning disabilities, and others may have psychiatric pathology.

Two SERVOL schools (SVS) in north and central Trinidad were randomly assigned and visited. . Three vocational schools in north and central Trinidad were also included in this study. The schoolchildren were randomly selected in these different schools and their ages ranged from 12 to 23 years. The students who volunteered were asked to fill in a 15 item questionnaire under the supervision of their teachers.

\section{Statistical analyses}

All data were analyzed using the of SPSS (Statistical Package for the Social Sciences, Version 11.0). The independent samples $T$ test and the Levene's Test for Equality of Variances were done to compare whether the different means of both groups were equal to each other.

\section{Results}

Of the 472 students participating in this study, $45.3 \%$ were male $(n=214)$ and 53.8 $\%(n=254)$ female. Four students were omitted from this study because of insufficient information (0.8\%) (see table 1 ). The mean age of this population was 16.05 years with a standard deviation of 1.94 and a mean of 16.0 years (range 1223 years). The majority of children $(38.6 \%, n=182)$ were of African descent, $25.2 \%$ $(n=119)$ of Indo-Trinidadian origin and $27.3 \%(n=129)$ of mixed origin. One person was mentioned as white $(0,2 \%)$ and 41 children $(8.7 \%)$ could not specify their descent.

\section{Demographics vocational schools}

One hundred and forty seven students (147) from two vocational schools in North and Central Trinidad were interviewed by means of a 15 -item questionnaire (see table 1). Of this cohort $68.3 \%(n=99)$ were males, $31.7 \%(n=46)$ females. The mean age was 17.4 years (SD 1.44, median 17.0 years, range $14-23$ years). The majority of children were of African-Trinidadian descent, $51.2 \%(n=76)$ and only a minority ( $n=11,7.5 \%$ ) of Indian-Trinidadian descent. Most of them ( $n=84,57.1 \%$ ) were living in a non-intact family, defined here as living with only one parent, living with family members, living with step family and some living on their own. The majority belonged to the Roman Catholic religion ( $n=34,23.1 \%$ ) or were Pentecostal ( $n=25,17.0 \%$ ). 
Table 1: Demographics vocational schools and government-assisted schools in Trinidad

\begin{tabular}{|c|c|c|c|c|}
\hline & \multicolumn{2}{|c|}{ Vocational schools } & \multicolumn{2}{|c|}{ Government assisted } \\
\hline Mean age (SD) & \multicolumn{2}{|c|}{17.4 y (1.44) } & \multicolumn{2}{|c|}{15.4 y (1.82) } \\
\hline \multirow[t]{2}{*}{ Median (range) } & \multicolumn{2}{|c|}{17.0 y $(14-23)$} & \multicolumn{2}{|c|}{16.0 y $(12-19)$} \\
\hline & No. & $\%$ & No. & $\%$ \\
\hline Boys & 99 & 67.3 & 115 & 35.4 \\
\hline Girls & 46 & 31.3 & 208 & 64.0 \\
\hline African descent & 76 & 51.2 & 106 & 32.6 \\
\hline Indian descent & 11 & 7.5 & 108 & 33.2 \\
\hline Other/mixed & 32 & 21.8 & 98 & 30.2 \\
\hline Family: intact & 41 & 27.9 & 192 & 59.1 \\
\hline not intact & 84 & 57.1 & 131 & 40.3 \\
\hline Roman Catholic & 34 & 23.1 & 57 & 17.5 \\
\hline Muslim & 13 & 8.8 & 18 & 5.5 \\
\hline Hindu & 3 & 2.0 & 70 & 21.5 \\
\hline Pentecostal & 25 & 17.0 & 65 & 20.0 \\
\hline Presbyterian & 2 & 1.4 & 13 & 4.0 \\
\hline Jehova's & 3 & 2.0 & 11 & 3.4 \\
\hline Baptist & 9 & 6.1 & 34 & 10.5 \\
\hline Anglican & 9 & 6.1 & 18 & 5.5 \\
\hline Other & 13 & 6.5 & 37 & 11.4 \\
\hline TOTAL & 147 & & 325 & \\
\hline
\end{tabular}

\section{Demographics government-assigned schools}

A total of 325 students completed the questionnaire in the Government assigned schools of Central and South Trinidad. Among this group 64.6\% ( $n=208)$ were female and $35,4 \%(n=115)$ male (see table 1$)$. The mean age was 15.4 years with a standard deviation of 1.82 , median age of 16 years and a range from 12 to 19 years. $32.6 \%$ ( $n=106)$ were of African-Trinidadian descent, 33.2\% $(n=108)$ of IndianTrinidadian origin and $30.1 \%(n=98)$ of other and mixed origin. Most of the students from this school came from an intact family ( $n=192,59.1 \%)$. Hindu ( $n=70$, $21.5 \%$ ), Pentecostal ( $n=65,20.0 \%$ ) and Roman Catholic ( $n=57,17.5 \%$ ) were the most common religions.

\section{Life time cannabis and alcohol use}

The lifetime prevalence of cannabis use was found to be $31.7 \%(n=40)$ in the vocational schools (see table 2 and figure 1). The life time cannabis use in vocational schools was higher than the schoolchildren, who ever used cannabis in the other schools ( $n=84,26,2 \%)$ This was not a statistically difference $(19 \%, 95 \% \mathrm{Cl} 19,5$ $38,5, p=0,06)$. There was no significant difference in lifetime alcohol use between 
the GAS and SVS $(n=78,61,9 \%$ and $n=196,61,1 \%$ respectively, $61,5 \%, 95 \% \mathrm{Cl}=$ $51,4-71,6, p=0,09)$.

\section{Current cannabis and alcohol use}

The current use of cannabis was significantly more prevalent with 4.4 times greater in vocational schools than in the GAS and as many as 28 schoolchildren of vocational schools reported using cannabis versus 17 children in the other schools. There was no significant difference in current alcohol use between the students of vocational schools or government schools (see table 2 and figure 2)

Table 2: Substance use in different school systems in Trinidad.

\begin{tabular}{|c|c|c|c|c|c|c|c|}
\hline \multirow[t]{2}{*}{ Substance use } & \multicolumn{2}{|c|}{ Vocational schools } & \multicolumn{2}{|c|}{ Government assisted } & & & \\
\hline & $\mathrm{N}$ & $\%$ & $\mathrm{~N}$ & $\%$ & & & \\
\hline Past & 126 & - & 321 & - & & & \\
\hline cannibis & 40 & 31.7 & 84 & 26.2 & & & \\
\hline alcohol & 78 & 61.9 & 196 & 61.1 & & & \\
\hline Present & 120 & - & 319 & - & & & \\
\hline cannibis & 28 & 23.3 & 17 & 5.3 & & & \\
\hline alcohol & 25 & 20.8 & 65 & 20.4 & & & \\
\hline First age of use & $\mathrm{N}$ & Age $\pm S D$ & $\mathrm{~N}$ & Age $\pm S D$ & & & \\
\hline cannibis & 50 & $13.8 \pm 2.29$ & 45 & $12.69 \pm 2.28$ & t 5.06 & df 253 & $\mathrm{p}<0.001$ \\
\hline alcohol & 74 & $13.66 \pm 2.5$ & 181 & $11.3 \pm 3.32$ & 2.36 & df 93 & $\mathrm{p}<0.05$ \\
\hline cigarettes & 42 & $13.5 \pm 2.66$ & 76 & $11.84 \pm 3.05$ & t 3.07 & df 116 & $p<0.01$ \\
\hline other drugs & 9 & $14.44 \pm 2.92$ & 15 & $13.93 \pm 1.87$ & t 0.47 & df 22 & $p>0.01$ \\
\hline
\end{tabular}

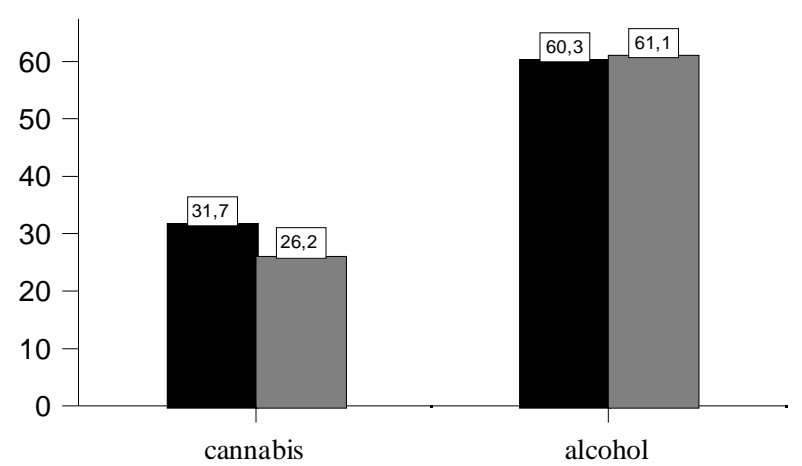

$$
\begin{aligned}
& \text { vocational schools } \\
& \square \text { government assisted schools }
\end{aligned}
$$

Figure 1: Life time cannabis and alcohol use 


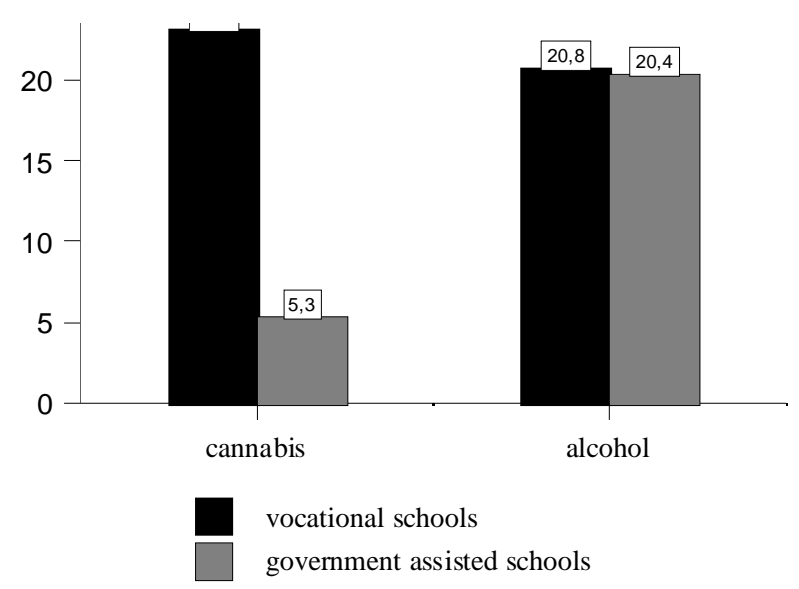

Figure 2: Current cannabis and alcohol use

\section{Substance use and gender}

With respect to gender differences among these schools (see figure 3 ) there was a predominance of male students using alcohol and cannabis in both schools $(50.0 \%$, $95 \% \mathrm{Cl} 43.6$ - 56.4, $\mathrm{p}=0.004)$.

\section{Substance use and age}

Analysis of the ages of onset of different drug use in the two school systems with the independent Sample T-Test showed that the age of onset of alcohol consumption and cannabis use were statistically different (see table 2). The age of onset of alcohol use in non-vocational schools was significantly lower compared to age of onset in vocational students (T 5.06, df 253, p < 0.001). Also students of government assisted schools started to use cannabis at an earlier age than the other students ( $T$ 2.36, df $95 \mathrm{p}<0.01)$.

Age and present use of cannabis and alcohol was calculated and a trend of increase use over age was seen for cannabis. Use of alcohol was more or less stable over the different ages (see figure 4). 


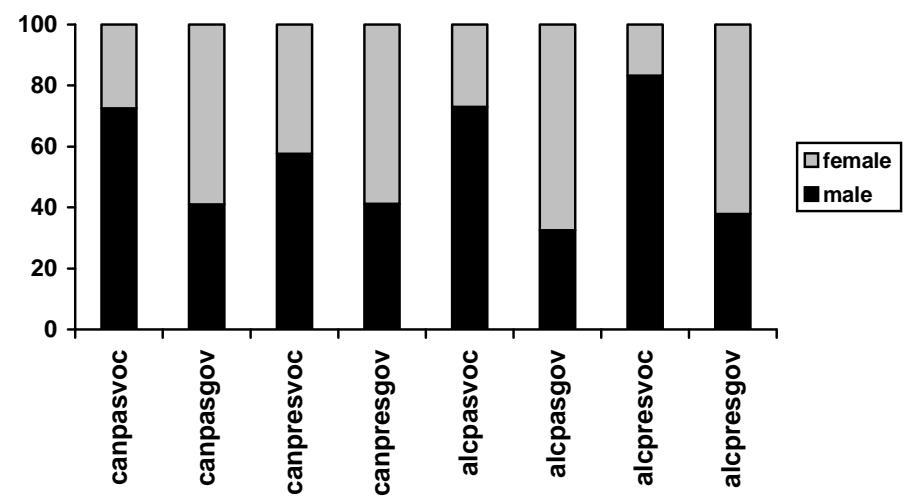

Figure 3: Gender differences in cannabis and alcohol life time and present use in the two different school systems

Vocational schools: canpasvoc - past use cannabis; canpresvoc - present use cannabis; alcpasvoc - past use alcohol; alcpresvoc - present use alcohol; Government schools:canpasgov - past use cannabis; canpresgov - present use cannabis; alcpasgov - past use alcohol; alcpresgov - present use alcohol

Table 3: Present use of cannabis and use of cannabis among friends

\begin{tabular}{lcccc}
\hline How many friends are using? & \multicolumn{4}{c}{ Cannabis use in schools } \\
\cline { 2 - 5 } & \multicolumn{3}{c}{ Vocational } & \multicolumn{2}{c}{ Government assisted } \\
\cline { 2 - 5 } & Present users & Non-users & Present users & Non-users \\
\hline None & 1 & 20 & 19 & 72 \\
$1-2$ & & 4 & 10 & 13 \\
$3-4$ & & 1 & 5 & 2 \\
more than 4 & 16 & 23 & 46 & 17 \\
\hline
\end{tabular}

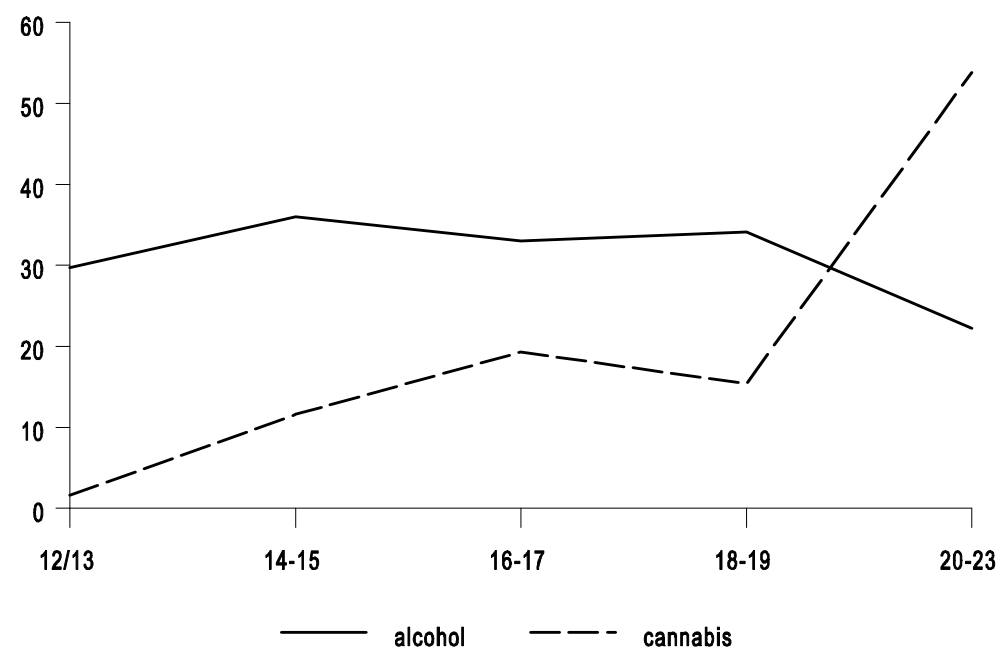

Figure 4: Percentage of cannabis and alcohol use in both school systems in the different ages 


\section{Substance use among peer groups}

Response on the questionnaire to "how many of your friends were also using drugs" indicated that cannabis use was seen with more frequent use by friends. Students who did not use any drugs also had many friends who did not use at all also (see table 3). The students in the vocational schools who were non users were confronted with many friends using cannabis. Students in vocational schools who were using cannabis were shown to have less contact with students who were NOT using cannabis $(4.1,95 \% \mathrm{Cl} 1.0-7.1, \mathrm{p}=0.05)$. This situation was also found in Government Assisted schools and this difference was statistically significant $(37.5,95 \% \mathrm{Cl}$ 26.9 - 48.0, $p<0.001)$. Sixteen $(94.1 \%)$ students in government schools said they had more than one friend using cannabis compared with students (58.3\%) in vocational schools. This difference was almost statistically different $(13.0,95 \% \mathrm{Cl} 9.9$ $16.0, p=0.05)$. Sixty-one (76.3\%) students in government schools who used cannabis said they had at least one friend who used cannabis. Of the 104 governmental students who never used cannabis, $32(30.8 \%)$ said they had friends using cannabis. This was statistically significant $(42.9,95 \% \mathrm{Cl} 32.6-53.2, \mathrm{p}<0.001)$.

Table 4: Cannabis use and none use in different family systems

\begin{tabular}{lccl}
\hline Cannabis & \multicolumn{3}{c}{ Family status } \\
\cline { 2 - 4 } Use & Intact & Not intact & \multicolumn{1}{c}{ Statistics } \\
\hline Present & 24 & 47 & $X^{2}=7,451, d f=1$. \\
& 91 & & $P=0,006$ \\
None & 41 & $X^{2}=39,035, d f=1$. \\
& & & $P<0,001$ \\
\hline
\end{tabular}

\section{Substance use and family structure}

When 'use of cannabis' and 'non use' was measured in two different types of families, statistically significance differences were seen between cannabis use and a non intact family and no use of drugs at all and living in an intact family (table 4). [numbers are in table 4]

\section{Discussion}

Students of three government high schools $(n=323)$ and two vocational schools ( $n$ $=145$ ) participated in this study in Trinidad. The students were questioned about their cannabis and alcohol use. Analysis of the demographic data of the two school types showed a slight gender difference between the schools with $68.3 \%(n=99)$ boys in the two vocational schools and $35.4 \%(n=115)$ males in the government schools. Differences in age were also seen between these two school types. A total 
of 325 students completed the questionnaire in the government-assigned schools, with a mean age of 15.4 years (SD 1.82, median age of 16 years, range 12-19 years) and 145 students filled in the questionnaire to age in the vocational schools (mean age 17.4 years (SD 1.44, median 17.0 years, range $14-23$ years). The mean age of students in the vocational schools was higher than that of students of the government schools. Another difference in demographic data was ethnicity; most students in the vocational schools were of African-Trinidadian descent in contrast with the government schools in which the majority were of Indian-Trinidadian descent (30.1\%). Most students of the vocational schools $(57.1 \%, n=84)$ were living in a non-intact family, whereas most government assigned school students were living with an intact family $(59.1 \%, n=192)$.

The use of alcohol in the past and present was high in both school types. Lifetime alcohol use was around $60 \%$ in both school types, and current alcohol use was around $20 \%$ in both school types. Both parameters showed no statistically significance differences between the school types $(61.5 \%, 95 \% \mathrm{Cl}=51.4-71.6, \mathrm{p}=0.09$ for life time alcohol use and 20.6\%, 95\% Cl $12.1-29.1$, $p>0.05$ for current alcohol use. These rates are high, but comparable with world literature. These studies show a wide range in rates of lifetime, about $50 \%$ to $60 \%(37,38)$ and about $20 \%(39)$ and $17.9 \%(40)$ in current alcohol use.

Cannabis use in the past was very common in both school systems. About one third of the students had ever used cannabis $(31.7 \%, n=40$ in the vocational schools versus $26.2 \%, \mathrm{n}=84$ in the government assisted schools, $19 \%, 95 \% \mathrm{Cl} 19.5$ $38.5, p=0.06)$. Current cannabis use was more than four times more often reported in vocational school students $(23.3 \%, n=28$ versus $5.3 \%, n=17)$, which was statistically significant $(14.3 \%, 95 \% \mathrm{Cl} 6.3-22.3, \mathrm{p}=0.002)$. Possible explanations for this difference could lie in the older age of children visiting vocational schools, presence of more family problems, and possible psychiatric problems among their students, because vocational schools accept students who fail in the other schools, who fail on "common entrance", and many of these students come from disadvantaged homes and abusive situations. These factors can be risk factors in increasing drug use. Many of these vocational schoolchildren come from non-intact families, with parenting by single parents and family members. Cannabis use in these social situations showed a significant increase among non intact family homes $(X 2=7.451, \mathrm{df}=$ $1, p=0.006)$. This relationship between growing up in a single parent family and more commonly use of cannabis is supported in another study by Rey (39), who found that cannabis use increased rapidly with age and was more common in adolescents living with a sole parent.

When the age of onset of cannabis and alcohol use was analyzed, the results showed a lower age of onset in the government assisted schools, which showed statistical significance. An hypothesis for the later age of onset of cannabis use among vocational school students and still higher prevalence of cannabis use could 
be that the vocational students start to use cannabis at a higher age (albeit still young: 13.8 years, SD 2.29) and use it more and longer than do the other students (see above; differences in age between different school systems. This may be a possible confounder in the found results).

Different patterns of cannabis use can result in different psychiatric symptoms and behavior (41). When the ages of cannabis use were analyzed, the results showed that cannabis use seemed to increase with age.

When the possible influence of peer groups on drug use was analyzed, the results showed that use of cannabis was positively associated with the use of cannabis by friends, these differences were almost significant $(13.0,95 \% \mathrm{Cl} 9.9-16.0, \mathrm{p}=$ $0.05)$. Such influence of the peer group on drug use among adolescents has been discussed in the literature, and a recent study by van den Bree and Pickworth (42) revealed three risk factors for adolescent cannabis use: own and peer involvement with substances, delinquency, and school problems.

The present study has many limitations. The division of the school system into two different systems is a global division and has certain limitations. There are many differences in the two school systems we analyzed, like age (children in the vocational schools a higher age) and social situation (more non-intact families in the vocational students). The differences in gender between the two schools, with male gender being more prominent in the vocational schools, may cause a bias, because men are known to have a higher prevalence of drug use than do women. Additionally, the higher age of the school students in the vocational schools may lead to a bias. Cannabis use is known to increase with age, which may be an explanation for the increased rate of cannabis use in the older vocational students. The vocational schools that were visited were located in the more northern area of Trinidad, which is more urban than the southern part of Trinidad, which is more rural. One of the three government-assigned schools visited were located in the southern part. Another limitation was that much data were missing on the questions about drug use. Not all the schoolchildren filled in these questions, maybe because of the presence of teachers, while filling in, but still there were many data left, which were used (see table 2) for analysis.

Despite these limitations, this study provided insight into cannabis and alcohol use in schools in Trinidad. When the two school systems were compared, differences in alcohol and cannabis use was found. Alcohol and cannabis use is highly prevalent in both systems, but present cannabis use was far more prevalent in the vocational schools. More males were using cannabis when analyzed in both school systems $(50.0 \%, 95 \% \mathrm{Cl} 43.6-56.4, \mathrm{p}=0.004)$. Several factors associated with drug use were found-peer involve-ment, male gender, and age. Alcohol use was prevalent in both schools and at all ages, whereas cannabis use seemed to increase with age. Alcohol and cannabis use was a common problem in Trinidad with high prevalence rates in both genders. 
Since alcohol and cannabis use is associated with psychic problems and behavior problems, school teachers should be aware of this and government should support and assist preventive programs for drug use in schools, while treatment for alcohol and drugs addiction should be aimed at this young, specific population.

\section{References}

1. Rossow I, Groholt, Wichstrom L. Intoxicants and suicidal behaviour among adolescents: changes in levels and associations from 1992 to 2002. Addiction 2005;100(1):79-88.

2. Berggren $F$, Nystedt $P$. Changes in alcohol con-sumption: an analysis of self-reported use of alcohol in a Swedish national sample 1988-89 and 1996-97. Scand J Public Health 2006;34(3):304-11.

3. Poelen FA, Scholte RH, Engels RC, Boomsma DI, Willemsen G. Prevalence and trends of alcohol use and misuse among adolescents and young adults in the Netherlands from 1993 to 2000. Drug Alcohol Depend 2005;79(3):413-21.

4. Javier Alvarez F, Fierro I, Carmen del Rio M. Alcohol-related social consequences in Castille and Leon, Spain. Alcohol Clin Exp Res 2006; 30(4):656-64.

5. Haggard-Grann U, Hallqvist J, Langstrom N, Moller J. The role of alcohol and drugs in triggering criminal violence: a case-crossover study. Addiction 2006;101(1):100-8.

6. Hall WD. Cannabis use and the mental health of young people. Aust N Z J Psychiatry 2006;40(2): 105-13.

7. Nishimura ST, Goebert DA, Ramisetty-Mikler S, Caetano R. Adolescent alcohol use and suicide indicators among adolescents in Hawaii. Cultur Divers Ethnic Minor Psychol 2005;11(4):309-20.

8. Ferdinand RF, Sondeijker F, van der Ende J, Selten JP, Huizink A, Verhulst FC. Cannabis use predicts future psychotic symptoms, and vice versa. Addiction 2005;100(5):612-8.

9. Fergusson DM, Horwood LJ, Ridder EM. Tests of causal linkages between cannabis use and psychotic symptoms. Addiction 2005;100(3):354-66.

10. Perkonigg A, Lieb R, Hofler M, Schuster $P$, Sonntag $H$, Wittchen HU. Patterns of cannabis use, abuse and dependence over time: incidence, progression and stability in a sample of 1228 adolescents. Addiction 1999;94(11):1663-78.

11. Black S, Casswell S. Recreational drug use in New Zealand. Drug Alcohol Rev 1993;12(1):37-47.

12. Coffey C, Carlin JB, Degenhardt L, Lynskey M, Sanci L, Patton GC. Cannabis dependence in young adults: an Australian population study. Addiction 2002;97(2):187-94.

13. Kohn L, Kittel F, Piette D. Peer, family integration and other determinants of cannabis use among teenagers. Int J Adolesc Med Health 2004;16(4): 359-70.

14. Hollar D. Risk behaviours for varying categories of disability in NELS: 88. J Sch Health 2005; 75(9):350-8.

15. Blum RW, Kelly A, Ireland M. Health-risk behaviours and protective factors among adolescents with mobility impairments and learning and emotional disabilities. J Adolesc Health 2001; 28(6):481-90.

16. Faeh D, Viswanathan B, Chiolero A, Warren W, Bovet P. Clustering of smoking, alcohol drinking and cannabis use in adolescents in a rapidly developing country. BMC Public Health 2006; 6(1):169.

17. Abdulkarim AA, Mokuolu OA, Adeniyi A. Drug use among adolescents in Ilorin, Nigeria. Trop Doct 2005;35(4):225-8.

18. Von Sydow K, Lieb R, Pfister H, Hofler M, Sonntag H, Wittchen HU. The natural course of cannabis use, abuse and dependence over four years: a longitudinal community study of ado-lescents and young adults. Drug Alcohol Depend 2001;64(3):347-61.

19. Rumpold G, Klingseis M, Dornauer K, Kopp M, Doering S, Hofer S, Mumelter B, Schussler G. Psychotropic substance abuse among adolescents: a structural equation model on risk and protective factors. Subst Use Misuse 2006;41(8):1155-69. 
20. Ljubotina D, Galic J, Jukic V. Prevalence and risk factors of substance use among urban adolescents: questionnaire study. Croat Med J 2004;45(1):88-98.

21. Afiah MZ, Hejar AR, Kulanthaven KC, Fadhilah J, Law TH. Prevalence of smoking and drinking habits among Form Six students in Petaling District, Selangor. Med J Malaysia 2006;61(1):41-7.

22. de Souza DP, Areco KN, da Silveira Filho DX. Alcohol and alcoholism among Brazilian adolescent public-school students. Rev Saude Publica 2005; 39(4):585-92. [Portuguese]

23. Zaborkis A, Sumskas L, Maser M, Pudule I. Trends in drinking habits among adolescents in the Baltic countries over the period of transition: HBSC survey results, 1993-2002. BMC Public Health 2006;15;6:67.

24. Best D, Manning V, Gossop M, Gross S, Strang J. Excessive drinking and other problem behaviours among 14-16 year old schoolchildren. Addict Behav 2006;24: [Epub ahead of print]

25. Yeh MY. Factors associated with alcohol consumption, problem drinking, and related con-sequences among high school students in Taiwan. Psychiatry Clin Neurosci 2006;60(1):46-54.

26. Weitzman ER, Chen YY. The co-occurrence of smoking and drinking among young adults in college: national survey results from the United States. Drug Alcohol Depend 2005;80(3):377-86.

27. Singh $H$, Maharaj HD, Shipp M. Pattern of substance abuse among secondary school students in Trinidad and Tobago. Public Health 1991; 105(6):435-41.

28. Maharajh, H.D. . Cannabis-head cause of psychosis. Trinidad Guardian, 21 February 2005: 25.

29. Maharajh HD, Konings M. Suicidal behaviour and cannabis-related disorders among adolescents. In: Merrick J, Zalsman G, eds. Suicidal behavior in adolescence. An international perspective. Tel Aviv, Israel: Freund, 2005;119-29.

30. Singh $\mathrm{H}$, Mustapha $\mathrm{N}$. Some factors associated with substance abuse among secondary school students in Trinidad and Tobago. J Drug Educ 1994;24(1):83-93.

31. Chung PK. Drug abuse in Jamaican urban secondary educational institutions; a survey in four schools. Master thesis. Mona, Jamaica: Univ West Indies, 1986.

32. Gordon F. Drug abuse in all-age schools. Master thesis. Mona, Jamaica: Univ West Indies, 1995.

33. Sharma KLD. Present trends in drug use and abuse in new secondary schools in the Kingston Metropolitan Area. Master thesis. Mona, Jamaica: Univ West Indies, 1995.

34. Douglas K-G. Patterns of substance use and abuse among post-primary students in Jamaica: National Adolescent Students' Drug Survey 1997/1998. Jamaica: Planning Inst Jamaica, Policy Dev Unit Work Paper, 2000.

35. Soyibo K, Lee MG. Use of illicit drugs among high-school students in Jamaica. Bull World Health Organ 1999;77(3):258-62.

36. Central Statistical Office Trinidad Tobago 2005. Web: www.cso.gov.tt

37. Taylor M, Jinabhai CC, Naidoo K, Kleinschmidt I, Dlamini SB. An epidemiological perspective of substance use among high school pupils in rural KwaZulu-Natal. S Afr Med J 2003;93(2):136-40.

38. Brook U, Tepper A. Consumption, knowledge and attitudes of high school pupils towards alcohol and alcoholism: the Israeli experience. Patient Educ Couns 2002;47(2):115-9.

39. Rey JM. Martin A. Krabman P. Is the party over? Cannabis and juvenile psychiatric disorder: the past 10 years. Am Acad Child Adolesc Psychiatr 2004;43(10):1194-205.

40. McDermott RJ, Clark-Alexander BJ, Westhoff WW, Eaton DK. Alcohol attitudes and beliefs related to actual alcohol experience in a fifth-grade cohort. J Sch Health 1999;69(9):356-61.

41. Konings M, Maharajh HD. Cannabis use and mood disorders: patterns of clinical presentations among adolescents in a developing country. Int J Adolesc Med Health 2006;18(2):221-33.

42. van den Bree MB. Pickworth WB. Risk factors predicting changes in marijuana involvement in teenagers. Arch Gen Psychiatry 2005;62(3):311-9. 


\section{CHAPTER III}

Cannabis use and mood disorders: Patterns of clinical presentations among adolescents in a developing country

M Konings, MD and Hari D Maharajh, MD

Int J Adolesc Med Health 2006; 18(2):221-233. 



\title{
Cannabis use and mood disorders: Patterns of clinical presentations among adolescents in a developing country
}

\author{
M Konings, MD and Hari D Maharajh, MD \\ Psychiatric Hospital PMS Vijverdal, Maastricht, the Netherlands and Psychiatry \\ Unit, Department of Clinical Medicine, University of West-Indies, Champs Fleur, \\ Trinidad
}

\begin{abstract}
Notwithstanding the increase use of cannabis among adolescents in both developing and developed countries, few studies have looked at cannabis use and mood disorders. In a series of case studies, this researeh project secks to investigate patterns of clinical presentations seen among cannabis users in psychiatric outpatients in Trinidad. Five clinical patterns of presentations are identified among cannabis users and abusers based on variables of dosing, age of initial use, duration of use, tolerance and reverse tolerance and poly-drug abuse. All patients in these case studies were standardized for method of use and potency of cannabis used. Patients were screened by urine tests to determine co-morbid use of other substances. Other variables such as environmental factors and genetic vulnerability were reviewed as far as possible from historical accounts of family members. The five patterns described are low, controlled use with mild euphoria and heightened awareness, moderate use with mixed depressive symptoms and suicidal behaviour, heavy, short term use with manic symptoms, long term incremental use with psychotic symptoms due to the trumping of depressive symptoms and cannabis mixed with other substances resulting in florid psychosis. Mood disorders appear to be a common finding among adolescents using cannabis. Sensitization to symptomatic presentation and early detection of cannabis use in young adolescents are necessary. Further research is needed on the effect of cannabinoids on emotions, behaviour and thinking and its relationship to mental disorders. This study is useful as a guideline for the implementation of public health strategies and legislation concerning the use of cannabis in youths.
\end{abstract}

Keywords: adoleseents, cannabis, mood disorders, descriptive, Trinidad

Correspondence: Hari D Maharajh, Psychiatry Unit, Department of Clinical Medicine, University of the West Indies, Champs Fleurs, Trinidad (WI). Tel: 1-868 6623968 / 1-868 665 3119, Fax: 1-868 662 3968. E-mail: drharim Qtarib-link net

Recelved: May 24, 2005, Revlsed; June 07, 2005. Accepted: June 08, 2005.

\section{INTRODUCTION}

The association of cannabis use and psychiatric disorders is an area of nosological uncertainty. DSM-IV-TR classiffcation (1) system does not include mood disorders as an effect of cannabis use or induced disorders as is categorized for alcohol (291.84), cocaine (292.84), amphetamines (292.84), opioids (292.84) and hallucinogens (292.84). This omission of cannabis induced mood disorder is rather puzzling, since cannabis is also classified as a hallucinogen, which according to the DSM-IV can induce mood disorders. Similarly, few studies have looked at cannabis use and its relation to bipolar and other mood disorders.

A strong association between cannabis 
use and schizophrenia is described in numerous studies $(2,3)$. The co-occurrence of cannabis use and major depressive disorders or depressive symptoms has been reported in some studies (3-7). Cannabis use in patients with bipolar disorder has been less extensively investigated. Bipolar patients are prone to abuse substances and in one study (8), $25 \%$ of a cohort with bipolar disorder was found to be substance abusers, mostly alcohol, cocaine or cannabis. In Jamaica, $27 \%$ of patients who were known cannabis users were diagnosed as having hypomania (9). Another study from Jamaica reported no statistical diff. erences in abnormalities in affective symptomatology between cannabis users and non cannabis users (10).

Clinical observations have indicated that patients who use cannabis show more symptoms of hypomania with euphoric mood and agitation when compared to a group of non-cannabis users $(11,12)$. Grinspoon and Bakalar (13) presented case histories showing that some patients use cannabis as a mood stabilizer in bipolar disorder. The research literature on cannabis use and mood disorder appear to be non-conclusive and there is a need for further investigations.

Cannabis use in adolescents is common and has been associated with a world wide increase and a changing pattern of consumption (14). The frequency of use has increased (15) and the age of initial use has dropped considerably to a mean of 12 years (16). In Belgium, a recent study reported that the prevalence rate of weekly cannabis use increased from $1.2 \%$ in 1990 to $9.2 \%$ in 1994 and was still increasing in 1998 (11). In two well-designed cross sectional school surveys among Norwegian students in 1992 and 2002, cannabis use increased from $5.1 \%$ to $13.5 \%$ among boys and 3.9 to $9.3 \%$ among girls. In addition, there was a significant increase of the mean scale on the depression score in both genders (14). Two thirds of all adolescents and young adults have had at least a single lifetime exposure to cannabis $(15,17,18)$. Lifetime incidence of cannabis abuse ranges from $3.5 \%$ to 8 $\%$, with cannabis dependence ranging from $2.2 \%$ to $7 \%(11,16,18,19)$. In the Caribbean region, no comprehensive study of cannabis use among adolescents has been conducted. In 1991 the use of cannabis among secondary school students in Trinidad and Tobago was reported as $\mathbf{8 \%}$ (19). This has increased over the last 15 years to $20 \%$ (20).

The association between bipolar disorder and cannabis is an important public health concern, since the comorbidity of drugs and bipolar disorder is associated with impaired outcome of the bipolar illness (21). The length of a manic episode seems to be related to the duration of use of cannabis with a longer duration of the manic period. Cannabis use is also associated with an increase in noncompliance to medication and an earlier onset of affective symptoms resulting in more hospitalizations $(22,21)$. This results in spiraling cost and burden to the health care system.

\section{METHODS}

Five patients representing different patterns of cannabis use were selected from the outpatients clinics in Trinidad. Patients were assigned to different categories based on clinical presentations, age of first use, duration of use and toxicity. Duration of use and toxicity were determined by selfreports, which were later confirmed by interviews with the family members.

Toxicity or degree of cannabis use/ abuse was determined as follows: Each patient was interviewed on three occasions individually and together with a family member to determine the quantity of cannabis used. During these introviews 
clinical assessments were recorded and random urine screens for cannabis were done.

The method of cannabis use/abuse was standard. It was a locally contrived system of buying pieces of 'bamboo paper' from the shops at the cost of 50 cents (Trinidad and Tobago (TT) currency - one US dollar is approximately six TT dollars) and wrapping locally grown and dried marijuana leaves, seeds and stems into a cigarette. They are prepared in two sizes, namely "a five piece or joint" and "a ten piece or post". A "joint" is the diameter of a standard cigarette and measures two and a half inches and is sold at five dollars on the streets and a "post" is twice the length and sold at ten dollars. One end of the sticky bamboo paper is attached to a normal cigarette and lighted from the cannabis end drawing through the tobacco end.It should be noted that one 'post' is equivalent to two' joints'.

The first category is the light, controlled use of cannabis, meaning one to two cigarettes (joints) per week, for more than a year. The second pattern is moderate, longterm use of one year or more of two to six cigarettes per week. The third pattern seen is one of heavy use of cannabis of more than six cigarettes per week over a short period of time of less than three months. The fourth pattern is one of light use followed by increasing use over time. The last category is a combination of cannabis use with other psychotropic substances mostly alcohol, cocaine and other stimulants. All patients were screened for poly-substance abuse through urine testing. Tobacco use was common in all categories due to the method of cannabis use.

An Abott Laboratories AxSYM 5.0 utilizing Fluorescence Polarization Immunoassay technology with an improved aatomatic immunoassay system was used to analyze the presence of cannabinoids in the urine. The AxSYM system was used to detect alcohol, cocaine or other drugs in urine and the Immulite analyzer was used to detect nicotine in urine.

\section{RESULTS}

Five cases representing different patterns of cannabis use are described [Tables 1-3]. Clinical presentations of psychiatric symptoms appear to be determined by dosages, frequency, duration and poly-drug use. All cases were interviewed by a senior consultant (HDM), while files and notes were reviewed by both authors. Informed consent was obtained from all patients over eighteen and the parents of those under eighteen. Permission was obtained from the heads of the sectors to do this study.

\section{Case 1. Recreational and controlled use of cannabis}

A 20 year old foreign female medical student sought treatment for cannabis use at the university psychiatric service following advice from her boyfriend. She stated that she smoked two rolled cannabis cigarettes per week during midweek and on weekends which 'increased her interpersonal skills allowing her to socialize better." Her boyfriend had become concerned about her over-friendliness, talkativeness and interactions with complete strangers. She has been using marijuana since the age of 16 years while at boarding school in the United States. At that time she smoked with other students, mostly at weekend parties, and claimed she had no problems except on one occasion, when she was caught and her father was informed. She was born and raised in London, England and later sent to school in America. Her father was a specialist medical doctor in London and her mother was a housewife. Her relationship with her father was strained and she described him as an alcoholic and distant and rarely communicated with hirn; she 
Table 1. Screening for stubstances isolated in patient's tarine

\begin{tabular}{cccccc}
\hline cases & cannabis & alcohol & cocaine & nicotine & other \\
\hline 1 & + & - & - & + & - \\
2 & + & - & - & + & - \\
3 & + & - & - & + & - \\
4 & + & - & - & + & - \\
5 & + & - & + & + & - \\
\hline
\end{tabular}

Table 2. Described cases in relation to different factors in adolescent cannabis use

\begin{tabular}{|c|c|c|c|c|c|c|}
\hline case & $\begin{array}{l}\text { age of } \\
\text { onset of } \\
\text { use }\end{array}$ & duration & frequency & toxicity & symptoms & $\begin{array}{l}\text { family } \\
\text { history }\end{array}$ \\
\hline 1 & 16 & 4 years & regularly & light & increased artistic ability & none \\
\hline 2 & 14 & 1 year & regularly & moderate & $\begin{array}{l}\text { increased energy level, } \\
\text { increased speech, } \\
\text { grandiose ideas }\end{array}$ & $\begin{array}{c}\text { alcohol } \\
\text { dependence }\end{array}$ \\
\hline 3 & 19 & 10 days & regularly & heavy & $\begin{array}{l}\text { decreased need for sleep, } \\
\text { disruptive, increased } \\
\text { energy }\end{array}$ & none \\
\hline 4 & 14 & 3 years & infrequent & heavy & $\begin{array}{c}\text { paranoid, agitated, } \\
\text { hallucinations, overvalued } \\
\text { ideas }\end{array}$ & not known \\
\hline 5 & 17 & 7 years & regularly & $\begin{array}{l}\text { moderate } \\
\text { with } \\
\text { other drugs }\end{array}$ & $\begin{array}{c}\text { hallucinations, formal } \\
\text { thought disorders, } \\
\text { delusions }\end{array}$ & none \\
\hline
\end{tabular}

* light toxicity is defined as smoking 1 to 2 cigarettes of cannabis a week moderate is defined by smoking $2-6$ ciganettes use a week

heavy use is defined by smoking more than 6 cigarettes a week

Table 3. Oufcome factors in adolescent cannabis use

\begin{tabular}{llll}
\hline Environmental factors & Genetic factors & Personal factors & Cannabis factors \\
\hline Peer or group pressure & Familial & Personality traits & Frequency \\
Parental drug use & predisposition & Depressive symptoms & Age of initial use \\
Cultural beliefs & Polygenic effect & Suicidal thoughts & Dosage \\
Social acceptance & Dominant / recessiveComorbidity & Duration \\
Family problems & inheritance & Constitution & Availability \\
Delinquent peers & & & \\
\hline
\end{tabular}


however spoke to her mother on a regular basis. Her pattern of drug use was two cannabis cigarettes per week for the past five years; she used no other drug but also smoked ten cigarettes of tobacco daily.

Clinically, she was not depressed, anxious, agitated or deluded. She had never experienced suicidal thoughts or abnormal perceptions and cognitive testing was normal. Her speech was of normal flow, spontaneous, not circumstantial without evidence of formal thought disorder. She was advised to do the normal baseline laboratory tests of full blood count, urea and electrolytes, thyroid function tests, liver and renal functions and urine analysis. All findings were normal except the urine analysis that tested positive for tobacco and marijuzana.

The sessions were aimed at the relationship with her father and bad experiences in the past. She stopped her cannabis use and her relationship with her father significantly improved. She started to use cannabis again, stating that the use of marijuana makes her more creative and makes it easier for her to do exams.

\section{Case 2. Moderate long term use of cannabis}

A 15-year-old, form four secondary school student was brought to an outpatient clinic by his mother and aunt who became extremely concerned about his recent and abrupt change of personality. Approximately one year ago, following his promotion from junior to senior secondary school, his mother noticed that he began behaving strangely with social withdrawal and unpredictable emotional changes ranging from aggression to inappropriate happiness. On investigation from neighbours and friends, they found out that he was hanging out 'with the wrong kind of people' and smoking marijuana.

His mother and aunt related that he is more talkative than usual with inflated self esteem and expansive ideas. His teachers have complained that he is distractible and disruptive at school: he is unable to sit still, not concentrating or following instructions. He has a decreased need for sleep, feeling rested with a maximum of five hours of sleep at night. He has now become sexually active and in addition, over the past few weeks he has been stealing money. When confronted by his relatives about his antisocial behaviour, he became extremely irritable and aggressive threatening to commit suicide. He developed suicidal thoughts after quarrels with his parents about his behaviour, substance abuse and sexual indiscretions.

In his premorbid personality, the relatives described him as a nice, friendly and obedient child of a quiet disposition who got along well with everyone. His recent behaviour was puzzling and they did not know what to do about their only child.

On interview, he was tall, lanky and euphoric and admitted that he was using marijuana since he started at this new school. He said that he had succumbed to peer pressure in order to gain acceptance into the new environment. $\mathrm{He}$ used approximately four locally made marijuana joints (cigarettes) per week and on occasions will consume two glasses of beer. When asked about his change of behaviour, he noted that his use of marijuana gave him increased energy. He has the foeling that "I can do everything when 1 am smoking". The tempo of his speech was increased with no flight of ideas or evidence of thought disorder. He had little insight into his problem, smiling fatuously while his relatives related their troubles.

There is a strong family histery of alcohol dependency, both with the father and mother. There was no history of physical diseases and examination was normal. He was treated with low doses of 
an atypical antipsychotic and referred to an adolescent group for further psychological treatment. Further family sessions were arranged.

\section{Case 3. Short term heavy episodic use of cannabis}

A 19-year-old cash crop farmer was forcefully brought to the psychiatric clinic by his father and brother. The father stated that he was no longer controllable at home, did not sleep all night, pacing and playing music loudly, being disruptive to the houschold and neighbourhood and talking. nonsense. His family requested his admission to the psychiatric hospital through the Mental Health Act on the grounds that he: was a danger to himself and others. His. father stated that over the last ten days, after selling his garden products, he utilized all this money to buy marijuana. He had not: been working but had been continuously smoking 'the fatman', that is a giant size cigarette (three times the size of a cigar). He smoked on the street comers with friends and in his room at home and had not: been eating or taking care of his personal hygiene. He played music and sang all night long, disturbing the neighborhood. He was an educated and well spoken young man who had attained seven passes at the Ordinary Level of the Caribbean Examination Council. He came from a religious background with no history of substance abuse of mental illness. After leaving school at the age of seventeen years, he worked for one year as a salesman in a manufacturing company and was successful. After one year he became tardy, did not meet his quota and was warned for frequent absenteeism. This coincided with the onset of his use of marijuana. He later abandoned his job and went into gardening which facilitated a ready source of 'herbs' (marijuana).

On examination he was tatty in dress, unshaven and unkempt with an elevated and expansive mood for more than eight days. His speech was spontaneous, pressured and circumstantial, breaking into extemporary calypsoes about the psychiatrist. He showed distractability with his attention drawn to the medical charts on the wall, where in a grandiose manner he demonstrated his knowledge of biology. He had a decreased need for sleep and requested that 'doc hurry up with your ting', since he had important business to attend to. He had no insight into his behavior and denied heavy use of drugs stating that he used 'a little herb to cool the head'. There was no family history for psychiatric illnesses. His relatives were given a letter of urgent admission to the hospital.

\section{Case 4. Progressive incremental use of cannabis}

A 14-year-old male secondary school student began using marijuana with friends during school hours. He would leave home in the morning and not attend school but would join older friends in an abandoned house where they smoked cannabis cigarettes. He lived with his grandmother who had no idea that he was absconding from school until she was informed by the school authority. His mother had migrated to the United States and supported him by sending him 'barrels of items' which he sold to maintain his habits.

After being away from school for one term he was expelled and the school guidance officer sought psychiatric help. He was detoxified and treated with individual therapy for six months. Through the school authorities, arrangements were made to reinstate him into the school system. After one month he again joined the street users and continued his previous hubits. On this occasion, he had doubled his previous use of marijuana from one to three cigarettes per week to two to six Fer week. 
He again defaulted from school and was asked to leave because of his influence on other students. Subsequently, he was admitted to a psychiatric unit where after three days he broke out and returned to the streets. He continued his use of marijuana. The following year having abandoned his schooling at the age of 17, he was held in a police raid after he was involved with other cannabis users in allegations of house breaking. He was sentenced to one year's imprisonment at the Youth Prison.

Following his release he continued using marijuana on a daily basis and according to him he smoked "as much as 1 can lay my hands on". He continued smoking in large amounts for the next two years until his mother returned on a holiday from the United States with the intention of returning with him.

When brought to the psychiatrist he was found to be paranoid, agitated and quoting fluently from the bible. He paced the examination room looking at the ceilings and smiling fatuously. He spoke of the "plight of the black man" and was interested in their welfare. He spoke philosophically of the universe and of man's purpose in it. He held overvalued ideas of himself and felt that he was placed on earth to help the poor and suffering. He admitted to using at least four to six marijuana cigarettes on a daily basis. Despite his psychotic state the psychiatrist noted "that be was not aggressive, pleasantly amusing, voluble and incoherently intelligent". Family history was not known since his parents moved away and his grandmother could not give much information about it.

\section{Case 5. Mixed use of drugs}

A 24-year-old unemployed man was referred to a psychiatrist from the Magistrate Court following charges of possession and use of illicit drugs, marijuana and cocaine.
He was concurrently referred to a forensic detoxification and rehabilitation center on a court order for a period of two years with three-monthly follow up by a psychiatrist. In his family history his father died when he was 17 years of age and he was looked after by an older brother and his wife. There was no personal or family history of substance abuse or mental diseases. In his drug history he began using tobacco while at secondary school at the age of 15 , with occasional binges of alcohol. This was followed by cannabis use two years later. He graduated to cocaine use at the age of 19. Over the last four years he has used combinations of all four drugs, with marijuana and cocaine being his drugs of choice. He used three 'black cigarettes', that is, a combination of marijuana and cocaine cigarettes, five times per week. This involved removing the tobacco from a normal cigarette, adding marijuana and chips of rough cocaine and heating it over a flame until the cocaine melted and blended with the marjjuana, resulting in a 'black cigarette.'

On mental status examination he was illogical and incoherent, not oriented in time and place. His speech was plentiful, ascetic, tangential and circumstantial with poverty of ideation. He experienced visual hallucinations where he saw objects coming out of the ground. He was not aggressive, but seemed suspicious of the interviewer and at times, he left the examination room, would peep through the window in search of policemen. His affect was blunt with little changes in his emotional state. He was diagnosed as suffering from a drug induced psychosis. He was treated with high doses of a typical antipsychotic which has cleared his mental state. Urine testing for drugs one month ago tested positive for cannabis only. The patient denied the use of drugs in prison. 


\section{DISCUSSION}

The use of cannabis during the adolescent period may result in anxiety states, mood disorders and psychoses. The phenomenological presentations are determined by genetic factors, environmental factors and personal factors [table 3]. The latter includes age of first use, toxicity of preparations, duration of use and drugcombination usage. In this study five patterns of cannabis use/abuse are presented which represent the psychiatric outcome of youths using marijuana in the local culture. These patterns are not inclusive of all clinical presentations, but focus on expressions of mood disorders associated. with cannabis use [Figure 1].

There is no consensus on the association between cannabis use and depression. In a. twin study, a modest association between early onset adolescent cannabis use $(<17$ years) and suicidal attempts, but not for major depressive disorders was reported (4). However, other studies have reported an association with heavy cannabis use and depressive disorders $(5,6)$. Case 2 in our study, with moderate use of cannabis. presented with mixed symptoms of both dysthymia and hypomania (DSM IV 2000) with suicidal behaviour. Suicidal behaviour in this case may not be a direct effect of the use of cannabis, but seems to be a maladaptive response to the dysfunction within the family following disclosure of his drug related behaviour.

As is demonstrated in case 1, light of controlled use of cannabis seldom results in diagnostic problems. Long term, low dose of cannabis may result in a mild euphoria. and is related to increased artistic ability (23). Among adolescents, medicinal marijuana is more a defense in the magistrate's court rather than a therapeutic agent. In more than two decades of clinical practice, one of the authors (HDM) has never seen a genuine case of the medicinal use of marijuana among adolescents though it is a common defense in the law [figure 1].

The third pattern of cannabis use described (case 3 ) is characterized by heavy use defined as more than six joints or cigarettes per week over a short period of time that is, with a duration of less than a three- month period. This may be continuous or episodic and results in bipolar disease. This finding is supported by Rottanburg et al (12), who compared two groups of non-cannabis users and cannabis users in which the latter group showed more hypomanic symptoms and agitation compared to the group who did not use cannabis. Acute intoxication or increased use of cannabis with an accumulation of cannabinoids will result in psychotic reactions not unlike schizophrenia. This must be differentiated from drug induced delirium.

A rapidly resolving psychosis with marked hypomanic features was reported when patients with psychosis continued using the cannabis (12). The clinical presentation of case 3 underlines the difficulty in differentiating the nosological differences between schizophrenia and mania especially in Caribbean patients where we have observed an excess of affective symptoms among patients diagnosed with psychoses. Case 4 depicts the long term $\alpha$ incremental use of cannabis use with a clinical presentation of a conduct disorder, anxiety symptoms, paranoid delusions and psychosis.

There is an absence of affective symptoms. A number of hypotheses may be proffered: firstly, that the progressive use of cannabis trumps depression, thereby delaying the onset of elinically diagnosable psychiatric disorders in patients without a genetic predisposition to mental cisorders. This theory finds support in studies by Grinspoon and Bakalar (13), who reported the use of marijuana for the stabilization of 


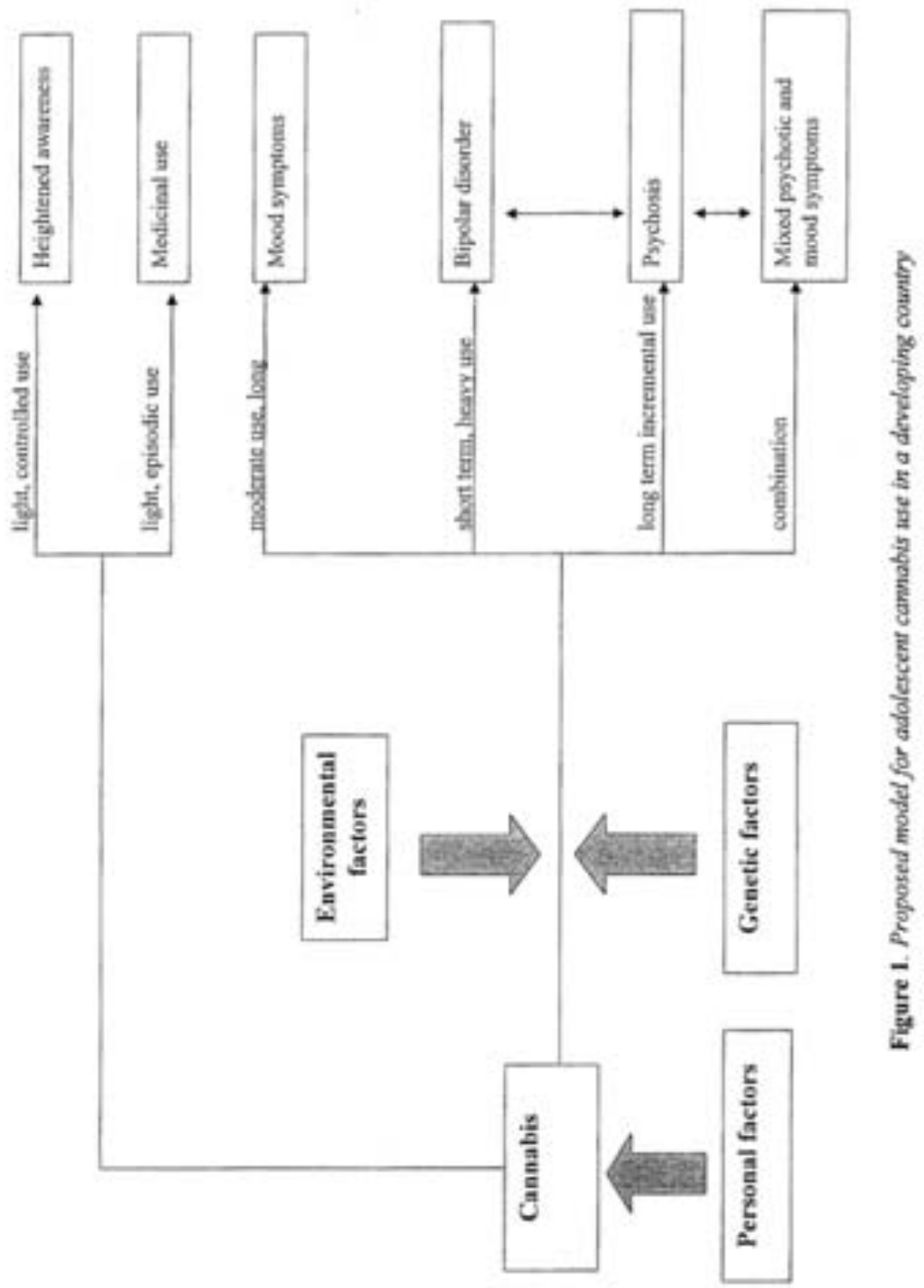


bipolar disorder. Secondly, that the evolution and manifestation of psychiatric symptoms is supportive of the theory of a continuum in which psychiatric symptoms like psychotic symptoms are present in the general population as a continuum rather than as an all or non phenomenon $(24,25)$. This continuum does not have to be limited to psychotic features but through the broad range of DSM syndromes (26). The expressions and experiences of individuals thought, emotions and behaviour during the adolescent period is determined by different patterns of cannabis use. An individual can therefore move interchangeably from one stage to another (12).

The use of cannabis mixed with other stimulants and hallucinogens provides a useful model for the study of drug comorbidity. As is described in case 5, drug use begins in early age with the use of gateway licit drugs such as nicotine and alcohol graduating later to illicit drugs such as cannabis and cocaine. Clinical presentations in these cases with mixed use are generally of a florid psychotic nature of mixed symptoms. Visual hallucinations are common with identifiable paranoid symptoms such as 'peeping' or looking out for the police in the case of cocaine use (case 5). The psychoses seen in cannabis abusers are for the most part non-florid. Many patients are amotivated and without an adequate history can be diagnosed as schizophrenia with negative symptoms. Phenomenological differences are differences in the possession, form and content of their speech. There is a preoccupation with philosophical, religious and social issues. As in case 4, despite his psychotic state, the psychiatrist noted "that he was not aggressive, pleasantly amusing, voluble and incoherently intelligent". The active ingredient of cannabis is a psychoactive substance identified as delta-9-tetrahydrocannabinol (delta-9-THC). More than 60 other cannabinoids have been identified $(13,27)$. These metabolites may contribute directly or indirectly to psychiatric symptoms. Cannabis is known to increase cerebral dopamine an excess of which is found in mania and schizophrenia. This association is more complex and certainly not dose-related. Other personal variables other than social and genetic are storage. release, tolerance and reverse tolerance.

In the mild use of cannabis (once or twice a week) THC will accumulate in the body and will slowly be released, affecting overall functioning to some degree resulting in a pleasant feeling of well-being (27). In more frequent users, there is the development of reverse tolerance, in which there is over time more sensitiveness or responses to identical doses. This effect can occur only after one month of cannabis use (28. 29). This reverse tolerance is one of the mechanisms that may explain the increased and potential effect of cannabis use over a longer period of time. These findings are supportive of our own unpublished results that show no relationship between clinical presentations of cannabis users and percentage concentration of cannabinoids isolated in the blood and urine.

The world wide pattern of cannabis use and abuse among adolescents has changed over the decades with an increase use at a lower age and among girls (14). The social pattern of use in the 1950's and 60's at large public gatherings such as concerts and festivals has given way to an almost ritualistic, solitary style of consumption at higher doses. This is not only applicable to developed countries, but to developing countries in the Caribbean region where the rates of cannabis use among secondary school students have changed over a decade from $8 \%$ in Trinidad and Tobago in 1993 to $20 \%$ in $2005(19,20)$. Substance use has been directly related to crime (30) and suicidal behaviour (31). There is a sudden 
increase in crime rates (32) in Trinidad and Tobago which is drug-felated resulting in a high availability of drugs like marijuana at low prices. This causes a higher rate of adolescent cannabis use, which affects their emotional and behavioural states.

The pattern of cannabis use among adolescents is a very complex problem with multi factorial etiologies and presentations. In this study emphasis were not placed on the important confounding variables of environmental factors and genetic predispositions. These are indeed important factors and only passing references [figure 1] is indeed a limitation. This study investigates patterns of clinical presentation of cannabis users among the adolescent age group in a developing country with an emphasis on personal factors such as the age of first use, trequency of use, dose of use, duration of use, comorbidity with other drugs and constant use. Genetic influence $o r$ vulnerability was determined as far as possible from family bistory. A family history of schizophrenia may induce a risk factor of developing psychosis when using cannabis, but the phenotype may not express itself in the most extreme form such as schizophrenia, but may also express itself as a single phenotype symptom in the form of psychotic experiences (3). Psychotic experiences are not necessarily a diseased state.

This study has many strengths. It addresses patterns of elinical presentation of adolescents in a developing country. Most studies are from developed countries where the consumption of cannabis is from imported stock. Commercial cannabis is compressed, soaked in balming oil and spices for removal of the scent in order to facilitate smuggling. These 'preservatives' in themselves may have adverse effects. In this study locally grown and dried marijuana without compression and treatment was used. There was no uncertainty of variations in strength or preparation since all the marijuana joints were made by the consumer himself and used in a standard manner. Only male adolescents were included in the case histories to eliminate gender differences.

Our findings suggest that affective symptomatology and mood disorders are common findings in cannabis users in Trinidad and Tobago. These findings may differ from findings in developed countries because of the mode and local preparation of the cannabis used. Clinical presentations are determined by social, genetic and local factors. Further research is needed. The findings of this study are important to all developing countries; the future provision of health services, the planning and implementation of treatment strategies. The creation and enactment of new legislation concerning marijuana possession and use must take into consideration the effect of cannabis on the young age group and its effect on school children.

\section{REFERENCES}

1. American Psychiatric Association. Cannabis related disorders. Desk reference to the diagnostic criteria from DSM-IV-TR. Washington DC: APA 2000:127-9.

2. Henquet C, Krabbendam L, Spauwen J, Kaplan C, Lieb R, Wittchen H, van Os J. Prospective cohort study of cannabis use, predisposition for psychosis, and psychotic symptoms in young people. BMJ 2005; 330:11-3.

3. Van Os J, Bak M, Hanssen M, Van Bijl R, De Graaf R, Verdoux H. Cannabis Use and psychosis: a longitudinal population-based study. Am J Epidemiol 2002;156(4):319-27.

4. Lynskey MT, Glowinski AL, Todorov AA, Bucholz KK, Madden PA, Nelson EC, Statham DJ, Martin NG, Heath AC. Major depressive disorder, 
suicidal ideation, and suicide attempt in twins discordant for cannabis. dependence and earlyonset cannabis use. Arch Gen Psychiatry 2004;61 (10): 1026-32.

5. Chen CY, Wagner FA, Anthony JC. Marijuana use and the risk of Major Depressive Episode. Epidemiological evidence from the United States National Comorbidity Survey. Soc Psychiatry Psychiatr Epidemiol 2002; 37(5):199-206

6. Degenhardt L, Hall W, Lynskey M. The relationship between cannabis use, depression and anxiety among Australian adults: findings from the National Survey of Mental Health and Well Being. Soc Psychiatry Psychiatr Epidemiol 2001; 36(5):219-27.

7. Bovasso GB. Cannabis Abuse as a Risk Factor for Depressive Symptoms. Am J Psychiatry 2001;158(12):20337.

8. Miller FT, Busch F, Tanenbaum JH. Drug abuse in schizophrenia and bipolar disorder. Am J Drug Alcohol Abuse 1989;15(3):291-5.

9. Knight F. Role of cannabis in psychiatric disturbance. Ann N Y Acad Sci 1976;282:64-71.

10. Besubrun MH, Knight F. Psychiatric assessment of 30 chronic users of cannabis and 30 matched controls. Am J Psychiatry 1973;130(3):309-11.

11. Kohn L, Kittel F, Piette D. Peer, family integretion and other determinants of cannabis use among teenagers. Int J Adolese Med Health 2004: 16(4) $=359-70$.

12. Rottanburg $\mathrm{D}$, Robins $\mathrm{AH}$, BenArie O, Teggin A, Elk R. Cannabis associated psychosis with hypomanic features. Lancet 1982;18(8312): 13646.

13. Grinspoon L, Bakalar JB. The use of cannabis as a mood stabilizer in bipolar disorder: anecdotal evidence and the need for clinical research. J Psychoactive Drugs 1998;30(2):171-7.

14. Rossow I, Groholt, Wichstrom L. Intoxicants and suicidal behaviour among adolescents: changes in levels and associations from 1992 to 2002 . Addiction 2005;100(1):79-88.

15. Perkonigg A, Lieb $\mathrm{R}$, Hofler $\mathrm{M}$, Schuster P, Sonntag H, Wittchen HU. Patterns of cannabis use, abuse and dependence over time: incidence, progression and stability in a sample of 1228 adolescents. Addiction 1999,94 (11): $1663-78$.

16. Von Sydow $\mathrm{K}$, Lieb R, Pfister $\mathrm{H}$, Hofler M, Sonntag H, Wittchen HU. The natural course of cannabis use, abuse and dependence over four years: a longitudinal community study of adolescents and young adults. Drug Alcohol Depend 2001;64(3):347-61.

17. Nyari TA, Heredi $K$, Parker L. Addictive behaviour of adolescents in secondary schools in Hungary. Eur Addict Res 2005; 11 (1):38-43.

18. Coffey C, Carlin JB, Degenhardt L, Lynskey M, Sanci L, Patton GC. Cannabis dependence in young adults: an Australian population study. Addiction 2002;97(2):187-94.

19. Singh $H$, Maharajh HD, Shipp $M$. Pattern of substance abuse among secondary school students in Trinidad and Tobago. Public Health 1991;105: 435-41.

20. Maharajh HD. Cannabis-head cause of psychosis. Trinidad Guardian, 21 February 2005.

21. Strakowski SM, DelBello MP, Fleck DE, Amdt $\mathrm{S}$. The impact of substance abuse on the course of bipolar disorder. Biol Psychiatry 2000; 48(6); 477-85,

22. Sherwood Brown E, Suppes T, Adinoff B, Rajan Thomas N. Drug 
abuse and bipolar disorder: comorbidity or misdiagnosis? I Affect Disord 2001;65(2):105-15.

23. Kirk JM, Doty P, De Wit, H. Effects of expectancies on subjective responses to oral delta9-tetrahydrocannabinol. Pharmacol Biochem Behav. 1998;59(2):287-93.

24. Van Os J, Hanssen M, van Bijl R, Vollebergh W. Prevalence of Psychotic Disorder and Community Level of Psychotic Symptoms. Arch Gen Psychiatry 2001;58:663-8.

25. Johns LC, van Os J. The continuity of psychotic experiences in the general population. Clin Psychol Rev 2001;21 (8):1125-41.

26. Krabbendam L, Myin-Germeys I, De Graaf R, Vollebergh W, Nolen WA, ledema J, Van Os. J. Dimensions of depression, mania and psychosis in the general population. Psychol Med $2004 ; 34(7): 1177-86$

27. McKim WA. Cannabis. In: McKim WA. Drugs and behavior. An introduction to behavioral pharmacology, $4^{\text {th }}$ ed. Upper Saddle River, NJ: Prentice-Hall, 2000:298-321.

28. Breivogel CS, Scates SM, Beletskaya IO, Lowery OB, Aceto MD, Martin BR. The effects of delta9-tetrahydrocannabinol physical dependence on brain cannabinoid receptors. Eur J Pharmacol 2003; 459 (2-3): $139-50$.

29. Wikler A. Aspects of tolerance to and dependence on cannabis. Ann NY Acad Sci 1976;282:126-47.

30. Maharajh HD, Akleema A. Crime in Trinidad and Tobago : the effect of alcohol use and unemployment. Rev Pan Am J Public Health 2004; 15(6) :417-23.

31. Akleema A, Maharajh HD. Social predictors of suicidal behavior in adolescents in Trinidad and Tobago. Soc Psychiatry Psychiatr Epidemiol 2005;40:186-91.

32. Balroop P. Killers on the loose! Frightening senario for murder toll in 2004. Sunday Guardian 2005 Jan 02. 



\section{CHAPTER IV}

\section{Validity and reliability of the CAPE: a self-}

report instrument for the measurement of psychotic experiences in the general population

Konings M, Bak M, Hanssen M, van Os J, Krabbendam L.

Acta Psychiatr Scand 2006: 114: 55-61 



\section{Validity and reliability of the CAPE: a self-report instrument for the measurement of psychotic experiences in the general population}

Konings M, Bak M, Hanssen M, van Os J, Krabbendam L. Validity and reliability of the CAPE: a self-report instrument for the measurement of psychotic experiences in the general population.

Objective: General population longitudinal cohort studies have demonstrated the prognostic validity of self-reported psychotic experiences, but data on reliability and cross-validation with interviewbased measures of these experiences are sparse. This study tested the reliability and validity of the Community Assessment of Psychic Experiences (CAPE42).

Method: At baseline, the CAPE42 was used to measure the subclinical psychosis phenotype in a general population sample $(n=765)$. At follow-up (mean interval: 7.7 months), the Structured Interview for Schizotypy, Revised (SIS-R), the Brief Psychiatric Rating Scale (BPRS), and the CAPE42 were administered $(n=510)$.

Results: Baseline self-reported dimensions of psychosis were specifically and independently associated with their equivalent interview-based dimension at follow-up (standardized effect sizes of $0.4-0.5$ ) and with their equivalent self-reported measure (standardized effect sizes of $0.6-0.8$ ).

Conclusion: The results indicate that self-reported dimensions of psychotic experiences in general population samples appear to be stable, reliable and valid.

\section{Konings ${ }^{1}$, M. Bak', \\ M. Hanssen ${ }^{1}$, J. van $0 s^{1,2}$ L. Krabbendam ${ }^{1}$}

${ }^{1}$ Department of Psychiatry and Neuropsychology, South Limburg Mental Health Research and Teaching Network, EURON, Maastricht University, Maastricht, the Netherlands and ${ }^{2}$ Division of Psychological Medicine, Institute of Psychiatry, London, UK

Key words: psychotic disorders; population; reliability and validity; questionnaires

Lydia Krabbendam, Department of Psychiatry and Neuropsychology, Maastricht University, P0 Box 616 (KAP2), 6200 MD Maastricht, the Netherlands.

E-mail: I.krabbendam@sp.unimaas.nl

Accepted for publication December 8, 2005

\section{Significant outcomes}

- The CAPE has good reliability and validity.

- As the application of self-report measures is cost-effective, this research method may be more economical for the purpose of conducting research in the general population.

- Not only the positive psychotic experiences but also attenuated negative symptoms can be captured with self-report.

\section{Limitations}

- The low response rate in the first sampling phase may introduce selection possibly affecting generalizability.

- For psychometric reasons, the CAPE does not include a disorganization dimension.

- The finding that the CAPE has adequate reliability and validity does not mean that it can be used as a screening tool for psychotic disorders, because the prevalence of self-reported experiences is much higher than the prevalence of clinical disorder. 


\section{Konings et al.}

\section{Introduction}

Many studies have shown that subclinical experiences of psychosis occur as part of a continuous, albeit skewed, distribution that shows only partial overlap with clinical psychotic disorder (1-5). These milder forms of expression of psychosis seem to be quantitatively, rather than qualitatively, different from the clinical disorder. Phenomenological continuity is suggested by studies showing that the dimensions of the subclinical psychosis phenotype closely resemble those that have been identified in the clinical disorder. There is consistent evidence for the existence of a positive and a negative dimension, both in the clinical and the subclinical domain, whereas evidence for a third dimension of disorganization is more equivocal (6-10). In addition to psychopathological resemblance, several studies have shown that the clinical and non-clinical phenotypes share risk factors and epidemiological patterns of variation (11-17), providing further evidence that the clinical and subclinical expressions of psychosis form part of the same continuum.

Although the majority of individuals experiencing these lesser psychotic 'symptoms' are not in need for care, they may nevertheless have an increased risk of developing a clinical disorder (1820). Given that transitions over the continuum occur, assessment of subthreshold psychotic symptoms in the general population is crucially important (21). Most studies investigating psychotic or psychosis-like experiences in the general population use self-report instruments, for example, the Perceptual Aberration Scale (PAS) (22), the Schizotypal Personality Questionnaire (SPQ) (23), the Schizotypal Personality Scale (STA) (24) and the Rust Inventory of Schizoid Cognitions (RISC) (25). However, information about the reliability of these instruments and cross-validation with interview-based measures is sparse.

\section{Aims of the study}

The aims of the current study were i) to examine the reliability and stability of a recently developed self-report scale, the Community Assessment of Psychic Experiences (CAPE; http://www.cape42. homestead.com), and ii) cross-validate the CAPE using interview-based measures.

\section{Material and methods}

Procedure and sample

The Continuum of Mental Disorders Study (COMED study) (26) is a longitudinal family study in the general population in the city of Sittard, the Netherlands. The COMED study included two measurement points: T1 and T2. So as to recruit a general population sample at $\mathrm{T} 1$, subjects of the municipality of Sittard aged 3665 years were randomly selected from the municipal register and sent a letter in which they were asked to participate. The mailing frame comprised 2287 females and 2302 males. The subjects were randomly selected from the gender strata 'female' and 'male' combined with the age strata ' $36-45$ ', '46-55' and ' $56-65$ ' years of age. The response rate was $8-10 \%$ in the different strata. In the next sampling phase, a snowball sampling procedure was used: the participants (i.e. index subjects who had responded to the mail survey) were asked to invite their family members (i.e. mother/father, sister/brother, spouse, children, spouse's family, etc.) to take part in the study.

At T1, all participants filled in several self-report questionnaires, including the CAPEs (see Instruments) and a demographic questionnaire (see Instruments). The CAPE assesses psychotic experiences and has been shown to assess variation of positive and negative dimensions of the subclinical psychosis phenotype in the general population (27). The subjects with a mean (i.e. between 40th and 60th percentile) or a high (i.e. above 75th percentile) score on the CAPE positive psychosis dimension and their relatives were asked to participate in the second measurement. This strategy was aimed at oversampling of individuals with higher levels of psychosis, thus increasing statistical power, while at the same time ensuring that the sample included sufficient individuals with 'average' levels of the subclinical psychosis phenotype so as to have sufficient variation along a hypothesized continuum of psychosis. At T2, trained psychologists administered a 2-hour interview at the home of the subject, including the Structured Interview for Schizotypy, Revised (SIS-R; see Instruments), the CAPE and the Brief Psychiatric Rating Scale (BPRS). The mean period between T1 and T2 was 7.7 months (SD 4.8 months; range 1-26 months). The total general population sample at T1 comprised 768 subjects pertaining to 116 families, aged 17-77 years, 765 of whom filled in the CAPE at T1. Taking into consideration every possible family relationship between subjects, $61.0 \%$ of the sample were first-degree relatives, $18.2 \%$ second-degree, $6.6 \%$ third-degree, and $0.4 \%$ were fourth-degree relatives; $13.8 \%$ of the participating subjects were married to each other or were partners. At T2, 510 subjects completed the CAPE, 497 subjects were interviewed with the SIS-R and 495 subjects were interviewed with the BPRS. 


\section{Instruments}

The CAPE was developed so as to rate self-reports of lifetime psychotic experiences in the affective and non-affective domains. Items are modelled on patient experiences as contained in the PSE-9 (28) and the schedules assessing negative symptoms such as the SANS (29) and the SENS (30). The CAPE measures, on a dimensional scale, frequency of as well as distress associated with these experiences. The frequency score is measured on a fourpoint scale from 'never (1)', 'sometimes (2)', 'often (3)' to 'nearly always (4)'. The degree of distress associated with the experience is also measured on a four-point scale with labels ranging from 'not distressed (1)', 'a bit distressed (2)', 'quite distressed (3)' to 'very distressed (4)'. The CAPE includes dimensions of positive psychotic experiences, negative psychotic experiences and depressive experiences. Measures of hypomania and disorganization were not included in the CAPE, given the fact that these may not be reliably measured by self-report in the general population.

Previous research with the CAPE has shown i) a three-factor structure of positive, negative and depressive dimensions in a large and representative sample of young men (27) and in a large sample of undergraduate female students (31), and ii) discriminative validity across groups of individuals with schizophrenia, affective and anxiety disorders and individuals from the general population (32). The final version 42-item instrument is mainly based on the 21-item Peters et al. Delusions Inventory (PDI-21) (1). Furthermore, two items on auditory hallucinations, 14 negative and eight depressive symptom items were added. For a detailed description of the development of the CAPE, we refer to previous work $(27,32)$. The CAPE positive, negative and depressive dimensions encompass 20, 14 and 8 items respectively.

The CAPE provides a total score per dimension by adding up the scores on the frequency question. So as to account for partial non-response, CAPE scores were weighted for the number of valid answers per dimension (weighted scores), and weighted CAPE scores expressed as units standard deviation (standardized scores) conform with previous publications $(27,32)$.

The SIS was originally developed by Kendler et al. (33). Vollema and Ormel (34) translated the SIS into Dutch and revised the SIS by improving and standardizing the rating procedures, thus creating the SIS-Revised (SIS-R). The instrument is designed to measure the symptoms and signs comprising the three dimensions of the subclinical psychosis phenotype. Items can be scored on a four-point scale from absent (score 0) to severe (score 3). Positive schizotypy (PS) covers the symptoms referential thinking, magical ideation, illusions and suspiciousness (six items in total). Negative schizotypy (NS) contains the symptoms social isolation, social anxiety, introversion, restricted affect, referential thinking and suspiciousness (eight items in total).

The BPRS (35) was used to also allow a comparison with a clinical, symptom-based measure. The BPRS time frame used in the COMED study was the past four weeks. BPRS ratings of 2-3 indicate non-pathological experiences and ratings of 4-7 parallel pathological experiences (35). The BPRS positive score was composed of the following four items: suspiciousness, unusual thought content, delusions and hallucinations (score range 4-28). The BPRS negative score comprised the items flattened affect and self-neglect (score range 2-14).

\section{Analyses}

All analyses were carried out with STATA VERSION 8 (36). First, so as to examine reliability and stability of the CAPE dimensions, linear regression analyses were performed in which the associations between the corresponding CAPE dimensions of T1 and T2 were expressed as the standardized regression coefficients. Robust estimates of variance were used, which allows for observations that are not independent across groups (i.e. families). Also, intra-class correlation coefficients were calculated between the corresponding CAPE dimensions of T1 and T2 using the STATA LONEWAY command. Second, so as to examine associations between dimensions of the CAPE at T1 on the one hand and the SIS-R and BPRS at T2 on the other, linear regression analyses were performed in which the associations between the positive and the negative dimensions of the CAPE at T1 and the positive and the negative dimensions of the SIS-R and BPRS at $\mathrm{T} 2$ were expressed as the standardized regression coefficients. The T1 rather than the T2 measurement of the CAPE was used for this analysis, so as to avoid spuriously high associations that may be induced by administering the different scales immediately after each other (correlation by measurement occasion). Again, robust estimates of variance were used. So as to test whether the coefficients of these associations differed from each other, multivariate multiple regression analysis was carried out (stATA MVREG procedure). Multivariate multiple regression differs from ordinary multiple regression in that several dependent variables (in this case SIS-R positive and negative dimension 


\section{Konings et al.}

scores and BPRS positive and negative scores) are jointly regressed on the same independent variables (in this case CAPE positive and negative dimension scores). The advantage of using multivariate multiple regression analysis is that the between-equation covariances are estimated, so that coefficients across equations can be tested with the Wald test. For example, this procedure allowed us to directly test the hypothesis that the coefficient of the regression of the SIS-R negative dimension on the CAPE negative dimension was significantly greater than the coefficient of the regression of the SIS-R negative dimension on the CAPE positive dimension.

So as to examine dose-response relationships between the CAPE dimensions at T1 and T2, and between the CAPE dimensions at $\mathrm{T} 1$ and the SIS-R and BPRS dimensions at T2, the sample was divided into three groups according to their tertile group level on the continuous CAPE positive and negative dimension scores at $\mathrm{T} 1$.

\section{Results}

Sample characteristics at T2

The sample of 510 individuals at $\mathrm{T} 2$ comprised more women than men: $59.4 \%$ and $40.6 \%$ respectively. The mean age was 47.3 years (SD 12.0), ranging $18-77$ years. Most subjects $(71.3 \%)$ were married; $14 \%$ had an educational level of primary and lower technical/vocational education, $42 \%$ had a medium level of education and $43 \%$ had a high level of education. Three percent admitted to current use of drugs (range: 0-6 drugs used). Psychological complaints were reported lifetime by $44.8 \%$ of the sample, conform recent epidemiological investigations in the Netherlands, which reported a $40 \%$ lifetime prevalence of psychiatric disorders (37). Depressed mood, nervous exhaustion and anxiety were the most commonly reported psychological complaints. The means of the weighted positive (PSY), negative (NEG) and depressive (DEP) dimensions of the CAPE, before standardization, were, at $\mathrm{T} 11.4(\mathrm{SD}=0.25), 1.6(\mathrm{SD}=$ $0.38)$ and $1.7(\mathrm{SD}=0.42)$ respectively, and at $\mathrm{T} 2$, $1.2(\mathrm{SD}=0.18), 1.6(\mathrm{SD}=0.34)$ and $1.6(\mathrm{SD}=$ 0.35 ) respectively. Participants scored a mean of, respectively, $2.2(\mathrm{SD}=2.2$, range of $0-14$ for six items) and $2.9(\mathrm{SD}=2.8$, range of $0-17$ for eight items) on the positive (PS) and negative (NS) dimensions of the SIS-R. The sample mean BPRS score were $4.4(\mathrm{SD}=1.1$, score range $4-16$ for four items) and $2.1(\mathrm{SD}=0.40$, score range $2-6$ for two items) for the positive and negative dimension respectively. The BPRS scores were markedly
Table 1. Associations between the CAPE dimensions at T1 and the corresponding CAPE dimensions at T2

\begin{tabular}{lcrc}
\hline & $\beta$ & \multicolumn{1}{c}{$t$} & $P$ \\
\hline CAPE positive dimension & 0.71 & 8.08 & 0.000 \\
CAPE negative dimension & 0.78 & 19.43 & 0.000 \\
CAPE depressive dimension & 0.76 & 15.36 & 0.000 \\
\hline
\end{tabular}

CAPE, Community Assessment of Psychic Experiences.

skewed: $19.9 \%$ of the sample had a score higher than 1 on one or more of the BPRS positive items and $5.7 \%$ on one or more of the negative items.

\section{Reliability of CAPE dimensions}

The positive dimension of the CAPE at T1 was strongly associated with the positive dimension of the CAPE at T2 (see Table 1). Similarly, the negative dimension at $\mathrm{T} 1$ was strongly associated with the negative dimension at T2, and the depressive dimension of the CAPE at T1 was strongly associated with its corresponding dimension at $\mathrm{T} 2$. The intraclass-correlation coefficient for the CAPE positive dimension at $\mathrm{T} 1$ and $\mathrm{T} 2$ was 0.63 (95\% CI 0.43, 0.83). For the CAPE negative dimension the intra-class correlation coefficient was $0.64(95 \%$ CI $0.47,0.81)$. For the CAPE depressive dimension the intra-class correlation coefficient was $0.62(95 \%$ CI $0.40,0.85)$.

\section{Cross-validation of CAPE dimensions}

There was a significant and moderately strong association between the positive dimension of the CAPE at T1 and the positive dimension of the SIS$\mathrm{R}$ at $\mathrm{T} 2(\beta=0.52, t=8.48, P=0.000)$. The strength of the association increased with increasing levels of CAPE positive dimension scores as indicated by the summary coefficient over three tertile levels of the CAPE positive dimension (linear trend, $\beta=0.40, t=7.93, P=0.000$ ). The association was only slightly reduced when the CAPE positive and negative dimensions were entered simultaneously in the equation (Table 2). The association between the negative dimension of the CAPE and the positive dimension of the SIS-R was much weaker and not statistically significant (Table 2). The association between the positive dimension of the SIS-R and its corresponding dimension of the CAPE was significantly stronger than its association with the CAPE negative dimension $(F(1,488)=35.0, P=0.000)$.

There was a significant and moderately strong association between the negative dimension of the CAPE at $\mathrm{T} 1$ and the negative dimension of the SIS-R at T2 $(\beta=0.50, t=9.19, P=0.000)$. 
Table 2. Associations between the CAPE dimensions at T1 and the corresponding SIS-R and BPRS dimensions at T2 with the effect sizes for both CAPE dimensions adjusted for each other

\begin{tabular}{lrrr}
\hline & $\beta$ & $t$ & $P$ \\
\hline $\begin{array}{l}\text { SIS-R positive dimension } \\
\text { CAPE positive dimension }\end{array}$ & 0.49 & 7.83 & 0.000 \\
$\quad$ CAPE negative dimension & 0.07 & 1.46 & 0.145 \\
SIS-R negative dimension & & & \\
$\quad$ CAPE positive dimension & 0.18 & 7.89 & 0.003 \\
$\quad$ CAPE negative dimension & 0.42 & 3.03 & 0.000 \\
BPRS positive dimension & & & \\
$\quad$ CAPE positive dimension & 0.21 & 2.59 & 0.010 \\
$\quad$ CAPE negative dimension & 0.14 & 1.95 & 0.051 \\
BPRS negative dimension & & & \\
$\quad$ CAPE positive dimension & -0.04 & -0.63 & 0.529 \\
CAPE negative dimension & 0.21 & 2.56 & 0.011 \\
\hline
\end{tabular}

CAPE, Community Assessment of Psychic Experiences; SIS-R, Structured Interview for Schizotypy, Revised; BPRS, Brief Psychiatric Rating Scale.

The strength of the association increased with increasing levels of CAPE negative dimension scores (linear trend, $\beta=0.32, \quad t=3.45, \quad P=$ $0.000)$. In the model with both the positive and the negative dimension of the CAPE, the association with the negative dimension of the CAPE was only slightly reduced and there was a much less strong association with the positive dimension of the CAPE (Table 2). The association between the negative dimension of the SIS-R and its corresponding dimension of the CAPE was significantly stronger than its association with the CAPE positive dimension $(F(1,488)=8.67, P=0.003)$.

The CAPE positive dimension at T1 was significantly associated with the BPRS positive dimension at T2 $(\beta=0.27, t=3.54, P=0.000)$. The strength of the association increased with increasing levels of CAPE positive dimension scores (linear trend, $\beta=0.19, t=3.45, P=0.000$ ). The joint regression analysis of the positive dimension of the BPRS on the positive and negative dimension of the CAPE yielded a significant association with the positive dimension of the CAPE, which was stronger than the association with the negative dimension of the CAPE (Table 2), although not significantly so $(F(1,487)=2.1, P=0.15)$.

The CAPE negative dimension at T1 was significantly associated with the BPRS negative dimension at T2 $(\beta=0.19, t=2.76, P=0.006)$. The strength of the association increased with increasing levels of CAPE negative dimension scores (linear trend, $\beta=0.15, \quad t=2.74, \quad P=0.006$ ). When both dimensions of the CAPE were entered simultaneously in the model, the negative dimension of the BPRS remained significantly associated with the negative dimension of the CAPE and this coefficient was significantly greater than the coefficient of the positive dimension of the CAPE (Table 2) $(F(1,487)=7.36, P=0.007)$.

\section{Discussion}

Baseline self-reported positive and negative dimensions of psychosis were specifically and in a doseresponse fashion associated with the interviewbased positive and negative dimensions at followup. The standardized effect sizes were between 0.4 and 0.5 for the associations with the SIS-R dimensions and slightly lower (around 0.2) but still statistically precise for the associations with the BPRS dimensions. The effect sizes for the internal stability were high (0.6-0.8), indicating that self-reported dimensions of subthreshold psychotic experiences at baseline were strongly associated with the same dimensions at follow-up. This implicates good validity and reliability of the CAPE. As the application of self-report measures is cost-effective, this research method may be more economical for the purpose of conducting research in the general population.

The effect sizes of the associations between the CAPE and the SIS-R were equally large for the positive and the negative dimensions. Although the SIS-R negative dimension showed some overlap with the CAPE positive dimension, possibly partly because of the fact that the SIS-R negative dimension contains some positive experiences, the association with the CAPE negative dimension was much stronger. Similarly, the association between the CAPE positive dimension and the corresponding dimension of the SIS-R was much stronger than the association of the latter with the negative dimension of the CAPE. This confirms previous findings with the CAPE (27) and suggests adequate discriminative validity of the CAPE dimensions in relation to established measures of the psychosis phenotype. In addition, these findings suggest that not only the positive psychotic experiences but also attenuated negative symptoms can be captured with self-report.

Associations with the CAPE dimensions were lower for the instrument assessing clinical symptoms than for the instrument assessing schizotypy. A likely explanation for this finding is that the BPRS interview captures experiences and symptoms at the higher end of the psychosis continuum, whereas both CAPE and SIS-R are sensitive to variation across the whole range of expression of psychosis.

Although both CAPE and SIS-R measure the subclinical expression of psychosis, the instruments differ in their approach to the measurement of the distribution of psychosis. Schizotypy instruments, 


\section{Konings et al.}

such as the SIS-R, are based on the assumption that in the subdisorder range along the continuum, the expression of the trait is attenuated and takes on the form of 'schizotypal' signs and symptoms. In this tradition, several schizotypy instruments have been developed of which some, such as the PAS (22), include items that are close to the 'pathological' experiences seen in clinical psychosis, whereas others include items that are closer to 'normal' experiences, for example, the STA (24) and the RISC (25), and yet others, such as the SPQ (23), have based their items on the DSM criteria for schizotypy. However, schizotypy instruments do not always cover the type and range of experiences seen in clinical patients (1). In addition, the choice of instruments greatly influences the resulting distribution of psychotic and psychosislike experiences. For example, the distribution of scores on a scale with a more clinical approach to schizotypy, such as the PAS, will be half normal, whereas the distribution on a scale that is more normalized in its approach to schizotypy, such as the SPQ, will be closer to normal (11). The approach adopted in the CAPE is to measure in the general population the same symptoms that are seen in patients with clinical psychotic disorders, rather than the variably defined attenuated experiences. The implicit assumption of this approach is that experiencing symptoms of psychosis, such as delusions and hallucinations, is not inevitably associated with the presence of disorder. The latter is dependent on symptom factors, such as intrusiveness and frequency and comorbidity of symptoms on the one hand, and personal and cultural factors, such as coping, illness behaviour, societal tolerance and functional impairments on the other (11).

The finding that the CAPE has adequate reliability and validity does not mean that self-reported psychotic experiences form a useful screening tool for psychotic disorders. This is because the prevalence of these self-reported experiences is much higher than the prevalence of clinical disorder according to DSM-IV and ICD-10, which opens the risk for a large number of false-positive diagnoses. In a previous study, we have shown that the predictive value of the presence of selfreported psychotic experiences in a non-selected general population sample was too low to be an accurate indicator of clinician-assessed disorder, both cross-sectionally and longitudinally $(38,39)$. For example, in a cross-sectional comparison, out of 100 subjects with at least one self-reported psychotic symptom associated with distress, onequarter had a psychotic disorder and three-quarter did not have a psychotic disorder (39). In a prospective study, only around $5-15 \%$ of individuals with incident self-reported psychotic experiences had developed an outcome defined in terms of functional impairment associated with need for care 2 years later (38).

\section{Methodological issues}

Arguably, a disadvantage of the CAPE is the fact that it does not, for psychometric reasons, attempt to measure a disorganization dimension. Therefore, the self-report and interview measures in the present study could not be compared regarding disorganization.

The low response rate in the first sampling phase (i.e. 8-10\%, see Material and methods) did introduce selection possibly affecting generalizability. However, the results showed a level of self-reported lifetime psychological complaints in the general population sample $(44.8 \%)$ that corresponded with other large-scale general population studies in the Netherlands such as the NEMESIS survey, which reported a $41.2 \%$ lifetime prevalence of at least one DSM-III-R disorder (37). In this and previous general population studies, depressed mood, nervous exhaustion and anxiety were the most prevalent problems. Moreover, the mean of the BPRS positive dimension in our general population sample (total score of 4.4 for four items pertaining to the positive psychosis dimension) does not fall into the pathological range of the psychiatric rating scale and the $20 \%$ rate of BPRS psychotic experiences corresponds to the rate reported in previous Dutch, New Zealand and German general population samples $(20,40,41)$. Therefore, the prevalence of self-reported lifetime psychological complaints and the prevalence of subclinical positive psychotic experiences measured with a psychiatric rating scale argues against poor generalizability of the results obtained in the present sample.

\section{Acknowledgements}

This work was made possible in part through the 2002 Research Prize of the Association of European Psychiatrists, sponsored by Sanofi-Synthélabo Group.

\section{References}

1. Peters ER, Joseph SA, Garety PA. Measurement of delusional ideation in the normal population: introducing the PDI (Peters et al. Delusions Inventory). Schizophr Bull 1999;25:553-576

2. Verdoux H, Maurice-Tison S, Gay B, Van Os J, Salomon R, Bourgeors ML. A survey of delusional ideation in primarycare patients. Psychol Med 1998;28:127-134. 
3. Eaton WW, Romanoski A, Anthony JC, Nestadt G. Screening for psychosis in the general population with a selfreport interview. J Nerv Ment Dis 1991;179:689-693.

4. TIEN AY. Distributions of hallucinations in the population. Soc Psychiatry Psychiatr Epidemiol 1991;26:287-292.

5. Johns LC, Nazroo JY, Bebington P, Kuipers E. Occurrence of hallucinatory experiences in a community sample and ethnic variations. Br J Psychiatry 2002;180:174-178.

6. Mata I, Gilvarry CM, Jones PB, Lewis SW, Murray RM, SнAм PC. Schizotypal personality traits in nonpsychotic relatives are associated with positive symptoms in psychotic probands. Schizophr Bull 2003;29:273-283.

7. Vollema MG, Hoistink H. The multidimensionality of selfreport schizotypy in a psychiatric population: an analysis using multidimensional Rasch models. Schizophr Bull 2000;26:565-575.

8. Kitamura T, Okazaki Y, Fujinawa A, Yoshino M, Kasahara Y. Symptoms of psychoses. A factor-analytic study. Br J Psychiatry 1995;166:236-240.

9. Gruzelier JH. The factorial structure of schizotypy. Part I. Affinities with syndromes of schizophrenia. Schizophr Bull 1996;22:611-620.

10. van Os J, Verdoux H. Diagnosis and classification of schizophrenia: categories vs dimensions, distributions vs disease. In: Murray RM, Jones PB, Susser E, van Os J, Cannon M, eds. The epidemiology of schizophrenia. Cambridge: Cambridge University Press, 2002:364-410.

11. Johns LC, van Os J. The continuity of psychotic experiences in the general population. Clin Psychol Rev 2001;21:11251141.

12. Sharpley MS, Peters ER. Ethnicity, class and schizotypy. Soc Psychiatry Psychiatr Epidemiol 1999;34:507-512.

13. Spaumen J, Krabbendam L, Lieb R, Wittchen HU, Os J. Early maternal stress and health behaviours and offspring expression of psychosis in adolescence. Acta Psychiatr Scand 2004;110:356-364.

14. Spauwen J, Krabbendam L, Lieb R, Wittchen hU, Van Os J. Does urbanicity shift the population expression of psychosis? J Psychiatr Res 2004;38:613-618.

15. Van Os J, Hanssen M, Bisl RV, Vollebergh W. Prevalence of psychotic disorder and community level of psychotic symptoms: an urban-rural comparison. Arch Gen Psychiatry 2001;58:663-668.

16. Johns LC, Cannon M, Singleton N et al. Prevalence and correlates of self-reported psychotic symptoms in the British population. Br J Psychiatry 2004;185:298-305.

17. Janssen I, Krabbendam L, BaK M, Hanssen M, Vollebergh W, GraAF R, et al. Childhood abuse as a risk factor for psychotic experiences. Acta Psychiatr Scand 2004;109:38-45.

18. Chapman LJ, Chapman JP, Kwapil TR, Eckblad M, Zinser MC. Putatively psychosis-prone subjects 10 years later. J Abnorm Psychol 1994;103:171-183.

19. Miller PM, Lawrie SM, Byrne M, Cosway R, Johnstone EC. Self-rated schizotypal cognitions, psychotic symptoms and the onset of schizophrenia in young people at high risk of schizophrenia. Acta Psychiatr Scand 2002;105:341-345.

20. Poulton R, Caspi A, Moffitt te, Cannon M, Murray R, HARRINGTON H. Children's self-reported psychotic symptoms and adult schizophreniform disorder: a 15-year longitudinal study. Arch Gen Psychiatry 2000;57:1053-1058.

21. Verdoux H. Have the times come for early intervention in psychosis? Acta Psychiatr Scand 2001;103:321-322.

22. Chapman LJ, Chapman JP, Raulin ML. Body-image aberration in Schizophrenia. J Abnorm Psychol 1978;87:399-407.
23. RAINE A. The SPQ: a scale for the assessment of schizotypal personality based on DSM-III-R criteria. Schizophr Bull 1991;17:555-564.

24. Claridge G, Broks P. Schizotypy and hemisphere function. I. Theoretical considerations and the measurement of schizotypy. Pers Individ Diff 1984;5:633-648.

25. Rust J. The Rust Inventory of Schizoid Cognitions (RISC): a psychometric measure of psychoticism in the normal population. Br J Clin Psychol 1987;26:151-152.

26. Hanssen M, Krabbendam L, Vollema M, Delespaul P, van Os J. Evidence for instrument and family-specific variation of subclinical psychosis dimensions in the general population. J Abnorm Psychol 2006; in press.

27. Stefanis NC, Hanssen M, Smirnis NK et al. Evidence that three dimensions of psychosis have a distribution in the general population. Psychol Med 2002;32:347-358.

28. Wing JK, Cooper JE, Sartorius N. The measurement and classification of psychiatric symptoms. London: Cambridge University Press, 1974.

29. Andreasen NC. Negative symptoms in schizophrenia. Definition and reliability. Arch Gen Psychiatry 1982;39:784-788.

30. Selten JP, Sijben Ne, van den Bosch RJ, Omloo Visser J, WARMERDAM $\mathrm{H}$. The subjective experience of negative symptoms: a self-rating scale. Compr Psychiatry 1993;34:192-197.

31. Verdoux H, Sorbara F, Gindre C, Swendsen JD, van Os J. Cannabis use and dimensions of psychosis in a nonclinical population of female subjects. Schizophr Res 2003;59:7784.

32. Hanssen M, Peeters F, Krabbendam L, Radstake S, Verdoux H, VAN Os J. How psychotic are individuals with nonpsychotic disorders? Soc Psychiatry Psychiatr Epidemiol 2003;38:149-154.

33. Kendler KS, Lieberman JA, Walsh D. The Structured Interview for Schizotypy (SIS): a preliminary report. Schizophr Bull 1989;15:559-571.

34. Vollema MG, Ormel J. The reliability of the structured interview for schizotypy-revised. Schizophr Bull 2000;26:619-629.

35. Lukoff D, Nuechterlein KH, Ventura J. Manual for the Expanded Brief Psychiatric Rating Scale. Schizophr Bull 1986;12:594-602.

36. StataCorp. STATA Statistical Software: Release 8.0. College Station, Texas: StataCorp, 2002.

37. Bill RV, Ravelli A, van Zessen G. Prevalence of psychiatric disorder in the general population: results of The Netherlands Mental Health Survey and Incidence Study (NEMESIS). Soc Psychiatry Psychiatr Epidemiol 1998;33: 587-595.

38. Hanssen M, Bak M, Bijl RV, Vollebergh W, van Os J. The incidence and outcome of subclinical psychotic experiences in the general population. Br J Clin Psychol 2005;44:181191 .

39. Hanssen M, Bijl RV, Vollebergh W, van Os J. Self-reported psychotic experiences in the general population: a valid screening tool for DSM-III-R psychotic disorders? Acta Psychiatr Scand 2003;107:369-377.

40. Spaumen J, Krabbendam L, Lieb R, Wittchen HU, van Os J. Sex differences in psychosis: normal or pathological? Schizophr Res 2003;62:45-49.

41. Van Os J, Hanssen M, BiJl RV, Ravelli A. Strauss (1969) revisited: a psychosis continuum in the general population? Schizophr Res 2000;45:11-20. 



\section{CHAPTER V}

\section{Early exposure to cannabis and risk for psychosis in young adolescents in Trinidad}

Konings M, Henquet C, Maharajh HD, Hutchinson G, Van Os JKonings M, Bak M, Hanssen M, van Os J, Krabbendam L.

Acta Psychiatr Scand 2008: 1-5 



\section{Early exposure to cannabis and risk for psychosis in young adolescents in Trinidad}

\begin{abstract}
Konings M, Henquet C, Maharajh HD, Hutchinson G, Van Os J. Early exposure to cannabis and risk for psychosis in young adolescents in Trinidad.

Objective: Cannabis use increases the risk for psychosis, but psychotogenic effects of cannabis may be restricted to exposure during early adolescence.

Method: Four hundred and seventy-two participants (aged 1223 years), randomly selected from the general population in Trinidad, completed questionnaires on past and current cannabis use and psychotic symptoms (using the Community Assessment of Psychic Experiences).

Results: Cannabis use increased the risk of experiencing psychotic symptoms and this effect was conditional on early exposure, defined around the mean age of onset of cannabis use. Thus, exposure before but not after the age of 14 years predicted psychotic symptoms (respectively $\beta$ : $0.71,95 \%$ CI $0.22 ; 1.19, P=0.004$ and $\beta:-0.11,95 \%$ CI $-0.57 ; 0.36, P=0.66$ ). The developmental effect of cannabis use was independent of use of other drugs or current use of cannabis.

Conclusion: Early adolescence may be a critical period with regard to the psychotogenic effect of cannabis across geographical settings and ethnic groups.
\end{abstract}

\author{
M. Konings ${ }^{1,2}, C$. Henquet ${ }^{2,3}$, \\ H. D. Maharajh ${ }^{4}$, G. Hutchinson ${ }^{4}$, \\ J. Van $0 \mathrm{~s}^{2,5}$ \\ ${ }^{1}$ Department of Psychiatry, GGZ Eindhoven, Eindhoven, \\ ${ }^{2}$ Department of Psychiatry and Neuropsychology, \\ EURON, Maastricht University Medical Centre, South \\ Limburg Mental Health Research and Teaching \\ Network, Maastricht, the Netherlands, ${ }^{3}$ Division \\ Addiction Care, Mondriaan Zorggroep, South Limburg, \\ The Netherlands, ${ }^{4}$ Psychiatry Unit, Department of \\ Clinical Medicine, University of West-Indies, Trinidad, \\ West Indies and ${ }^{5}$ Division of Psychological Medicine, \\ Institute of Psychiatry, London, UK \\ Key words: cannabis; adolescence; psychotic \\ disorders; age of onset
}

Cécile Henquet, Department of Psychiatry and Neuropsychology, Maastricht University Medical Centre, P0 B0X 616 (location Vijverdal), 6200 MD Maastricht, The Netherlands.

E-mail: cecile.henquet@sp.unimaas.nl

Accepted for publication April 4, 2008

\section{Significant outcomes}

- Early onset of cannabis use is associated with a greater risk of developing psychotic symptoms.

- Findings regarding this association are not restricted to geographical settings and ethnic groups.

\section{Limitations}

- The study was cross-sectional.

- Self-report questionnaires were used to assess the psychosis outcome.

\section{Introduction}

Cannabis is the most widely used illicit substance in the world, particularly among young people. In the Netherlands, it was found that the proportion of cannabis users starting at age 13 years or younger increased from $21 \%$ to $41 \%$ between 1992 and 1998 (1). In several other European countries and in the USA, increasing drug use among young people has also been reported $(2,3)$. A growing body of evidence suggests that cannabis is associated with increased levels of positive symptoms (4) and constitutes a risk factor for psychotic outcomes including psychotic illness (5-8). In addi- tion, it has been suggested that the psychotogenic effects of cannabis may be most profound after exposure during early adolescence, indicating the existence of a developmentally specific window of exposure in relation to psychosis $(9,10)$. Until now, however, the psychosis-enhancing effects of cannabis have only been shown in western populations, where reporting bias may be an issue (11).

\section{Aims of the study}

The aims of this study, therefore, were to i) cross sectionally investigate the association between cannabis use and positive psychotic experiences in 


\section{Konings et al.}

young people living in a non-western society and ii) investigate whether this association was moderated by age of onset. This is the first study in a nonwestern country investigating the association between cannabis and psychotic experiences in a multi-ethnic community.

\section{Material and methods}

Procedure and sample

Four hundred and seventy-two pupils (aged 1223 years, mean age 16 years) were randomly selected from different schools in Trinidad (Republic of Trinidad and Tobago), an island located at the southern most position of the Caribbean islands, $11 \mathrm{~km}$ from the Venezuelan coast, and were asked to participate in the study. To obtain a representative sample of Trinidadian adolescents, participants were recruited through randomly selected (based on the geographical position of the school) vocational and governmental schools. Vocational and governmental schools are the main schools in Trinidad, and are attended by approximately $70 \%$ of all adolescents (12). Every school agreed to participate, and during a 1-day school visit, every student present at that time was invited to participate in the study and none of them refused. Questionnaires on cannabis use and psychotic symptoms were completed in the classroom under the supervision of a teacher. Of all collected questionnaires, 41 were incomplete. The study sample therefore consisted of 431 subjects.

\section{Instruments}

Use of cannabis and use of other drugs, including age of first use, were assessed using a self-report questionnaire. The questionnaire consisted of dichotomous items assessing life time (phrased as 'at least once') and current use of cannabis and life time and current use of other drugs. Age of first cannabis use was assessed as well. The Community Assessment of Psychic Experiences (CAPE), a self-report instrument, was used to assess positive psychotic experiences (10, 11 and 13). The CAPE has shown to be reliable and valid $(13,14)$. For the current analyses, the total score on the positive dimension was used as the psychosis outcome. To account for partial nonresponse, CAPE scores were weighted for the number of valid answers per dimension. These weighted CAPE scores were expressed as standardised scores.

\section{Analyses}

Multiple linear regression was used to examine the association between lifetime cannabis use (exposure variable) and psychotic symptoms (response variable). To investigate cannabis effects in association with the age of onset of cannabis use, the sample was divided a priori (on the basis of the group's mean age of onset of cannabis use of 13 years) in three groups as follows: i) no cannabis use; ii) cannabis use before 14 years and iii) cannabis use at or after the age of 14 years.

All analyses were a priori adjusted for age, school type $(0=$ average school; $1=$ vocational school $)$ ethnicity $(0=$ other; $1=$ Indian; 2 = African), sex and in addition current use of cannabis and use of other drugs. Sensitivity analyses were conducted using the HOTDECK command in STATA (version 9.0) to examine whether missing data on the cannabis question in the questionnaire could have biased the findings.

\section{Results}

The final sample consisted of 431 adolescents and young adults. Mean age of the sample at the time of interview was 16.0 years (range 12-21), 239 $(55 \%)$ were females and $27 \%$ of the individuals were attending vocational schools. Twenty-seven per cent was from Indian and 39\% from African origin. The rate of lifetime cannabis use was $21 \%$ $(n=90)$ and of these, 34 had started their use before the age of 14 years $38 \%$ of the cannabis users) and 40 at or after the age of 14 years (answers on age of onset were missing for 16 subjects). The mean age of onset of cannabis use was 13.3 (range 7-19, SD 2.3). Current cannabis use was reported by $49 \%(n=44)$ of the pupils with lifetime cannabis use. Lifetime use of other drugs was reported in $6 \%$ of the sample.

Overall, cannabis use was not associated with increased levels of psychotic symptoms $(\beta=0.14$, 95\% CI: $-0.10 ; 0.37, P=0.25)$. However, there was a significant interaction between cannabis use and the age of first use, indicating that the effect of cannabis on the psychosis outcome was significantly stronger with early use of cannabis $(F(1$, $371)=3.91, P=0.05)$. Thus, the use of cannabis before the age of 14 years was significantly associated with higher levels of psychotic symptoms ( $\beta=0.39$, 95\% CI: $0.04 ; 0.74, P=0.029)$. This association remained both large and statistically significant after adjustment for age, school type, ethnicity, sex, current use of cannabis and use of other drugs (Table 1). No such association was 
Table 1. Effect of age of first cannabis use on positive psychotic symptoms (CAPE scores)

\begin{tabular}{|c|c|c|c|c|}
\hline Adjustment & $\begin{array}{c}\text { Age of } \\
\text { first use* }\end{array}$ & $\begin{array}{c}\text { CAPE } \\
\text { scores } \\
(\beta \dagger)\end{array}$ & $95 \% \mathrm{Cl} ; P$ & $\begin{array}{l}\text { Comparison } \\
\text { early vs. } \\
\text { old-age of } \\
\text { onset }\end{array}$ \\
\hline Not adjusted & $\begin{array}{l}\text { Never used } \$ \\
\geq 14 \text { years } \\
<14 \text { years }\end{array}$ & $\begin{array}{l}0 \\
0.01 \\
0.39\end{array}$ & $\begin{array}{c}- \\
-0.32 ; 0.34 ; P=0.95 \\
0.04 ; 0.74 ; P=0.029\end{array}$ & \\
\hline Adjusted§ & $\begin{array}{l}\text { Never used } \\
\geq 14 \text { years } \\
<14 \text { years }\end{array}$ & $\begin{array}{l}0 \\
-0.11 \\
0.71\end{array}$ & $\begin{array}{c}- \\
-0.57 ; 0.36 ; P=0.66 \\
0.22 ; 1.19 ; P=0.004\end{array}$ & $\begin{array}{c}F(1,371)=3.91 \\
P=0.05\end{array}$ \\
\hline
\end{tabular}

CAPE, Community Assessment of Psychic Experiences.

*The effect of age of first cannabis use, expressed dichotomously as before the age of 14 years or after the age of 14 years.

†Regression coefficient indicates change in CAPE positive symptom scores associated with different categories of age of first use.

\$Reference category.

§Adjusted for age, school type, ethnicity, sex, current use of cannabis and use of other drugs.

- Statistical comparison between the effect sizes of the categories $\geq 14$ years and $<14$ years by Wald test indicates that the cannabis effect size in the younger age group $(<14$ years) is significantly greater than in the older age group ( $\geq 14$ years)

observed for the individuals who started their use of cannabis after the age of 14 years (Table 1).

\section{Discussion}

Sub-clinical psychotic symptoms as measured by the CAPE are of interest as they show longitudinal continuity with more severe states of psychotic illness (15). Furthermore, a recent study showed that cannabis may not only play a role in the onset of sub-clinical expression of psychosis, but also causes abnormal persistence of sub-clinical symptoms and eventually, as a consequence, need for psychiatric care (16). The results of this study confirm findings from two earlier epidemiological studies $(9,10)$ that early onset of cannabis use is associated with a greater risk to develop psychotic symptoms than later onset of use. The association between early exposure to cannabis and psychotic symptoms remained significant after adjustment for current use of cannabis and other drug use. In addition, this is the first study, to our knowledge, to show psychotogenic effects of early cannabis exposure in a non-western society, where cannabis use has a long, non-stigmatised history for medical and recreational use (17).

Based on the current findings, it may be argued that cannabis early exposure effects are developmental in nature and that they do not simply reflect effects of long-term exposure associated with earlier onset of use. In other words, a 10-year history of cannabis use may impact differentially on risk of psychosis depending on whether the current age of the subject is 22 or 32 years. Similar evidence comes from animal studies in which only $\Delta$-9-tetrahydrocannabinol (THC, the principal component of cannabis) exposure during puberty, but not in adult rats, induced behavioural and cognitive changes (18). In addition, studies investigating the long-term effects of THC on cognition found similar developmental effects of cannabis exposure $(19,20)$. The fact that the endocannabinoid and the dopamine system are closely related (21) may partly explain why early adolescence in particular may be such a vulnerable period with respect to the adverse effects of THC. In rodents, THC facilitates dopamine transmission in different brain areas $(22,23)$. Chronic exposure to THC on the other hand, may result in a reduction of dopamine metabolism in the PFC (24). In addition, the Val allele (of the COMT Val158Met polymorphism), which is associated with higher levels of mesolimbic dopamine signalling and lower dopaminergic activity in the prefrontal cortex (PFC) (25), is also associated with increased sensitivity to the psychotic and cognitive effects of THC $(26,27)$. Schizophrenia has a postadolescent age of onset and is related to PFC dysfunction. As changes in synaptic dopamine activity in the PFC occur until adulthood, the PFC in particular may be sensitive to adverse environmental influences during puberty (28). A recent study by Tunbridge showed that COMT enzyme activity increases across the lifespan, and that COMT may play a functional role in the changes occurring in the PFC during adolescence (29). Therefore, in individuals with genetic vulnerability (e.g. carriers of the COMT Val158Met Val allele), early cannabis exposure may cause later psychosis by enhancing pre-existing dysregulation of the prefrontal and mesolimbic dopamine system (30). In addition, there is evidence that the effect of different environmental risk factors for psychosis may be additive (16) as was recently shown for early cannabis exposure and childhood trauma (31-33).

A methodological limitation of this study is that as symptoms and cannabis use were investigated cross sectionally, reverse causality cannot be excluded. However, previous studies have shown that although self-medication effects may in part contribute to the cannabis-psychosis relationship (34), they cannot explain the association entirely and cannabis is more likely to predict psychosis than vice versa (35). A second limitation is that cannabis use was assessed using self-report questionnaires under the supervision of a teacher, which may have yielded false negatives. Any false negative however, would have caused an underrather than an over-representation of the actual effect size. In addition, cannabis use has a long 
history for medical and recreational use in the Caribbean, which makes under-reporting unlikely.

\section{Acknowledgements}

Dr C. Henquet was supported by the Dutch Medical Research Council (VENI grant).

\section{Declaration of interest}

Jim van Os is a speaker or grant holder with Lilly, BMS, Lundbeck, Organon, Janssen-Cilag, GSK, Otsuka and AstraZeneca.

\section{References}

1. Monshoumer K, Smit F, de Graaf R, van Os J, Vollebergh W. First cannabis use: does onset shift to younger ages? Findings from 1988 to 2003 from the Dutch National School Survey on Substance Use. Addiction 2005;100:963-970

2. Chinet L, Plancherel B, Bolognini M, Holzer L, Halfon O. Adolescent substance use assesment: methodological issue in the use of the Adolescent Drug Abuse Diagnosis (ADAD). Subst Use Misuse 2007;42:1505-1525.

3. WIESSING L. European drugs agency highlights trends in drug use and problems affecting drug users. Euro Surveill 2005;10:EO51215.3.

4. Addington J, Addington D. Patterns, predictors and impacts of substance use in early psychosis: a longitundinal study. Acta Psychiatr Scand 2007;115:304-309.

5. Andréasson S, Allebeck P, Rydberg U. Schizophrenia in users and nonusers of cannabis. A longitudinal study in Stockholm County. Acta Psychiatr Scand 1989;79:505510 .

6. Arseneault L, Cannon M, Witton J, Murray RM. Causal association between cannabis and psychosis: examination of the evidence. Br J Psychiatry 2004;184:110-117.

7. Henquet C, Krabbendam L, Spaumen J et al. Prospective cohort study of cannabis use, predisposition for psychosis, and psychotic symptoms in young people. BMJ 2005;330: $11-15$.

8. Moore TH, Zammit S, Lingford-Hughes A et al. Cannabis use and risk of psychotic or affective mental health outcomes: a systematic review. Lancet 2007;370:319-328.

9. Arseneault L, Cannon M, Poulton R, Murray R, Caspi A, MofFitT TE. Cannabis use in adolescence and risk for adult psychosis: longitudinal prospective study. BMJ 2002;325:1212-1213.

10. Stefanis NC, Delespaul P, Henquet C, Bakoula C, Stefanis $\mathrm{CN}, \mathrm{V}_{\mathrm{AN}}$ Os J. Early adolescent cannabis exposure and positive and negative dimensions of psychosis. Addiction 2004;99:1333-1341.

11. Hanssen M, Peeters F, Krabbendam L, Radstake S, Verdoux $\mathrm{H}$, van Os J. How psychotic are individuals with non-psychotic disorders? Soc Psychiatry Psychiatr Epidemiol 2003;38:149-154.

12. UNICEF [HOMEPAGE ON THE INTERNET]. At a glace: Trinidad and Tobago 2000-2005 [data source : UNESCO, including the education for All 2000 assessment; last update 2005, cited 2 March 2008]. Available at: http://www.unicef.org/ infobycountry/trinidad_tobago_statistics.html.

13. Konings M, Bak M, Hanssen M, van Os J, Krabbendam L. Validity and reliability of the CAPE: a self-report instrument for the measurement of psychotic experiences in the general population. Acta Psychiatr Scand 2006;114:55-61.
14. Brenner K, Schmitz N, Pawliuk N et al. Validation of the English and French versions of the Community Assessment of Psychic Experiences (CAPE) with a Montreal community sample. Schizophr Res 2007;95:86-95.

15. Poulton R, Caspi A, Moffitt TE, Cannon M, Murray R, HaRRINGTon H. Children's self-reported psychotic symptoms and adult schizophreniform disorder: a 15-year longitudinal study. Arch Gen Psychiatry 2000;57:1053-1058.

16. Cougnard A, Marcelis M, Myin-Germeys I et al. Does normal developmental expression of psychosis combine with environmental risk to cause persistence of psychosis? A psychosis proneness-persistence model. Psychol Med 2007; 37:513-527.

17. Rubin V, Comitas L. Ganja in Jamaica. A medical antropological study of chronic marihuana use. The Hague: Mouton, 1975.

18. SChNeider M, Косh M. Chronic pubertal, but not adult chronic cannabinoid treatment impairs sensorimotor gating, recognition memory, and the performance in a progressive ratio task in adult rats. Neuropsychopharmacology 2003;28:1760-1769.

19. Pope HG, Gruber AJ, Hudson Ji, Cohane G, Huestis Ma, YuRgelun-Todd D. Early-onset cannabis use and cognitive deficits: what is the nature of the association? Drug Alcohol Depend 2003;69:303-310.

20. Ehrenreich H, Rinn T, Kunert HJ et al. Specific attentional dysfunction in adults following early start of cannabis use. Psychopharmacology (Berl) 1999;142:295-301.

21. LeWeKe FM, Giufrerida A, Koethe D et al. Anandamide levels in cerebrospinal fluid of first-episode schizophrenic patients: impact of cannabis use. Schizophr Res 2007;94:2936.

22. Chen J, Paredes W, Lowinson JH, Gardner EL. Delta 9-tetrahydrocannabinol enhances presynaptic dopamine efflux in medial prefrontal cortex. Eur J Pharmacol 1990;190: 259-262.

23. Tanda G, Pontieri Fe, Di Chiara G. Cannabinoid and heroin activation of mesolimbic dopamine transmission by a common mul opioid receptor mechanism. Science 1997;276:2048-2050.

24. Jentsch JD, Verrico CD, Le D, Roth RH. Repeated exposure to delta 9-tetrahydrocannabinol reduces prefrontal cortical dopamine metabolism in the rat. Neurosci Lett 1998;246:169-172.

25. Bllder RM, Volavka J, Lachman HM, Grace aA. The catechol-O-methyltransferase polymorphism: relations to the tonic-phasic dopamine hypothesis and neuropsychiatric phenotypes. Neuropsychopharmacology 2004;29:19431961.

26. Caspi A, Moffitt TE, CAnnon M et al. Moderation of the effect of adolescent-onset cannabis use on adult psychosis by a functional polymorphism in the catechol-O-methyltransferase gene: longitudinal evidence of a gene $\mathrm{X}$ environment interaction. Biol Psychiatry 2005;57:1117-1127.

27. Henquet C, Rosa A, Krabbendam L et al. An experimental study of catechol-o-methyltransferase val(158)met moderation of delta-9-tetrahydrocannabinol-induced effects on psychosis and cognition. Neuropsychopharmacology 2006; 31:2748-2757.

28. LewIS DA. Development of the prefrontal cortex during adolescence: insights into vulnerable neural circuits in schizophrenia. Neuropsychopharmacology 1997;16:385398.

29. Tunbridge EM, Weickert CS, Kleinman JE et al. Catechol-omethyltransferase enzyme activity and protein expression in human prefrontal cortex across the postnatal lifespan. Cereb Cortex 2007;17:1206-1212. 
30. Di Forti M, Lappin JM, Murray RM. Risk factors for schizophrenia - all roads lead to dopamine. Eur Neuropsychopharmacol 2007;17(suppl. 2):S101-S107.

31. Gracie A, Freeman D, Green $S$ et al. The association between traumatic experience, paranoia and hallucinations: a test of the predictions of psychological models. Acta Psychiatr Scand 2007;116:280-289.

32. Houston JE, Murphy J, Adamson G, Stringer M, Shevlin M. Childhood sexual abuse, early cannabis use, and psychosis: testing an interaction model based on the National Comorbidity Study. Schizophr Bull 2008;34:580-585.
33. Janssen I, Krabbendam L, Hanssen M et al. Are apparent associations between parental representations and psychosis risk mediated by early trauma? Acta Psychiatr Scand 2005;112:372-375.

34. Ferdinand RF, Sondeijker F, van der Ende J, Selten JP, Huizink A, Verhulst FC. Cannabis use predicts future psychotic symptoms, and vice versa. Addiction 2005;100: 612-618.

35. Henquet C, Murray R, Linszen D, van Os J. The environment and schizophrenia: the role of cannabis use. Schizophr Bull 2005;31:608-612. 



\section{CHAPTER VI}

Replication in two independent populationbased samples that childhood maltreatment and cannabis use synergistically impact on psychosis risk

M. Konings, N. Stefanis, R. Kuepper, R. de Graaf, M. ten Have, J. van Os, C. Bakoula and $\mathrm{C}$. Henquet

Psychol Med $2011 ;$ Jun $16: 1$-11 



\title{
Replication in two independent population-based samples that childhood maltreatment and cannabis use synergistically impact on psychosis risk
}

\author{
M. Konings ${ }^{1,2}$, N. Stefanis ${ }^{3}$, R. Kuepper ${ }^{2}$, R. de Graaf ${ }^{4}$, M. ten Have ${ }^{4}$, J. van Os ${ }^{2,5}$, \\ C. Bakoula ${ }^{6}$ and C. Henquet ${ }^{2,7 *}$ \\ ${ }^{1}$ Department of Psychiatry and Neuropsychology, South Limburg Mental Health Research and Teaching Network, EURON, Maastricht \\ University Medical Centre, The Netherlands \\ ${ }^{2}$ Department of Psychiatry, GGZ Eindhoven, The Netherlands \\ ${ }^{3}$ University of Mental Health Research Institute (UMHRI) and Department of Psychiatry, National and Kapodistrian University of Athens, \\ Greece \\ ${ }^{4}$ Netherlands Institute of Mental Health and Addiction, Utrecht, The Netherlands \\ ${ }^{5}$ Department of Psychosis Studies, Institute of Psychiatry, King's College London, King's Health Partners, London, UK \\ ${ }^{6}$ First Department of Pediatrics, Athens University Medical School, 'Aghia Sophia' Children's Hospital, Athens, Greece \\ ${ }^{7}$ PsyQ Heerlen, Mondriaan, Zuid-Limburg, The Netherlands
}

Background. There may be biological plausibility to the notion that cannabis use and childhood trauma or maltreatment synergistically increase the risk for later development of psychotic symptoms. To replicate and further investigate this issue, prospective data from two independent population-based studies, the Greek National Perinatal Study $(n=1636)$ and The Netherlands Mental Health Survey and Incidence Study (NEMESIS) $(n=4842)$, were analyzed.

Method. Two different data sets on cannabis use and childhood maltreatment were used. In a large Greek population-based cohort study, data on cannabis use at age 19 years and childhood maltreatment at 7 years were assessed. In addition, psychotic symptoms were assessed using the Community Assessment of Psychic Experiences (CAPE). In NEMESIS, the Composite International Diagnostic Interview (CIDI) was used to assess psychotic symptoms at three different time points along with childhood maltreatment and lifetime cannabis use.

Results. A significant adjusted interaction between childhood maltreatment and later cannabis use was evident in both samples, indicating that the psychosis-inducing effects of cannabis were stronger in individuals exposed to earlier sexual or physical mistreatment [Greek National Perinatal Study: test for interaction $F(2,1627)=4.18, p=0.02$; NEMESIS: test for interaction $\left.\chi^{2}(3)=8.08, p=0.04\right]$.

Conclusions. Cross-sensitivity between childhood maltreatment and cannabis use may exist in pathways that shape the risk for expression of positive psychotic symptoms.

Received 16 September 2010; Revised 13 May 2011; Accepted 17 May 2011

Key words: Cannabis, childhood trauma, interaction, psychosis, schizophrenia.

\section{Introduction}

Cannabis use increases the risk for psychotic outcomes in a dose-response manner (Henquet et al. 2005; Semple et al. 2005; Moore et al. 2007). Only a minority of cannabis users develops psychosis, suggesting that cannabis may act as a component cause, impacting on psychosis risk in co-dependence with other factors. Gene-environment or environment-environment interactions may underlie this association (Henquet $e t$ al. 2008), where, for example, individuals at increased genetic risk (a patient or a first-degree relative of a

* Address for correspondence: Dr C. Henquet, Department of Psychiatry and Neuropsychology, Maastricht University Medical Centre, PO Box 616 (Vijverdal), 6200 MD Maastricht, The Netherlands. (Email : cecile.henquet@sp.unimaas.nl) patient) or psychometric risk (the existence of subthreshold psychotic experiences) show increased sensitivity to the psychosis-inducing effects of cannabis (van Os et al. 2002; Verdoux et al. 2003b; D'Souza et al. 2005; Henquet et al. 2005; GROUP, 2011). Similarly, methodologically strong studies, including prospective studies, have demonstrated associations between childhood trauma, childhood maltreatment and childhood adversity on the one hand and psychotic symptoms/psychotic disorder on the other (Whitfield et al. 2005; Wicks et al. 2005; Lataster et al. 2006; Spauwen et al. 2006; Scott et al. 2007; Shevlin et al. 2007; Kelleher et al. 2008; Shevlin et al. 2008; Freeman \& Fowler, 2009; Read et al. 2009; Schreier et al. 2009; Elklit \& Shevlin, 2010; Fisher et al. 2010; Mackie et al. 2010; Arseneault et al. 2011). The pathway through 
which trauma causes psychosis is the subject of increasing investigation (Read et al. 2009). In a prospective study, Cougnard et al. (2007) suggested that trauma, urbanicity and cannabis do not reflect the same environmental risk in bringing about abnormal persistence of developmental subclinical expression of psychosis because of the synergistic action of these factors. More recent evidence also indicates that joint exposure to cannabis and childhood trauma occasions more-than-additive effects; Houston et al. (2008) showed that early sexual trauma increased the risk for psychosis only in individuals who had been exposed to cannabis before the age of 16 years. In a recent study with adolescents, the same evidence for interaction between childhood trauma and cannabis use and psychotic symptoms was found (Harley et al. 2010).

There is some biological evidence to support this association. Both stressful experiences and delta-9tetrahydrocannabinol (THC, the main psycho-active constituent of cannabis) have been found to increase dopaminergic signaling in the mesolimbic system (Voruganti et al. 2001; Soliman et al. 2008; Bossong et al. 2009) and prefrontal cortex (Stokes et al. 2010). Hyperdopaminergia may be associated with psychosis (Kapur, 2003) and the interaction between early life adversity and cannabis may increase risk for psychosis by bringing about enduring sensitization to dopamine agonists (Kuepper et al. 2010). Indications for this biological mechanism come from animal and human research showing that early life stress may result in an altered behavioral response to dopamine agonists in adulthood (Engert et al. 2009; Rodrigues et al. 2011). The aim of the current study was to further investigate the interaction between different kinds of childhood adversities and later cannabis use, assessed at different time points, ensuring independent exposure assessment, and to establish whether early experience of maltreatment moderates the association between later cannabis use and psychotic outcomes in a dose-response fashion, using two longitudinal population-based studies. In addition, correlation between childhood maltreatment and later cannabis use was investigated to establish whether interaction may point to underlying moderation (one factor influencing the effect of the other) or mediation (one factor influencing the occurrence of the other).

\section{Method}

\section{Samples}

\section{The Greek National Perinatal Study}

The Greek National Perinatal Survey is a prospective cohort study of all individuals who were born in Greece between 1 and 30 April $1983(n=11048)$
(Tzoumaka-Bakoula, 1987; Stefanis et al. 2004). Data were collected at three different time points. After birth (T0), data on the children's health and on socioeconomic factors of the parents were collected by the obstetrician and/or the midwife who was responsible for or present at the delivery. In 1990, at age 7 years (T1), questionnaires were sent to the primary school teachers who then invited the parents to complete further questionnaires (parental questionnaire). A total of 6594 questionnaires were completed by parents or caregivers (60\% response rate). In 2001, when subjects were 19 years old (T2), 4675 questionnaires were sent to the parents and to the subjects (parental and subject self-report questionnaires), which yielded completed questionnaires on 3500 subjects (75\% response rate). The Greek study sought and received approval, as required, from both the National Hellenic Research Foundation (NHRF) Institute of Biological Research and Biotechnology (IBRB) and the National Privacy Principles Board. Written parental informed consent was obtained at T0; at T2, subjects also provided written informed consent (Stefanis et al. 2004).

\section{The Netherlands Mental Health Survey and Incidence Study (NEMESIS)}

NEMESIS is a prospective study on the incidence, course and consequences of psychiatric disorders in the Dutch general population (aged 18-64 years) (Bijl et al. 1998a,b; Cougnard et al. 2007). Subjects were interviewed at home at three different time points: baseline (T0, 1996), T1 (1997, assessing the period between T0 and T1) and T2 (1999, assessing the period between T1 and T2). NEMESIS is based on a multistage, stratified, random sampling procedure in 90 municipalities. First, a sample of 90 Dutch municipalities was drawn. Second, a sample of private households within each municipality was selected and members with the most recent birthday within each household who were sufficiently fluent in Dutch were selected (Bijl et al. 1998a,b). A total of 7076 individuals provided written informed consent and were interviewed at T0 (response rate of $70 \%$ ); 5618 subjects (79\% of baseline sample) participated at T1; and 4848 subjects (69\% of baseline sample) were assessed at T2. Attrition was largely non-selective (de Graaf et al. 2000). Ethical approval was obtained from the ethics committee of the Netherlands Institute of Mental Health and Addiction.

\section{Measures}

\section{The Greek National Perinatal Study}

Childhood maltreatment at T1. At T1 (at age 7 years), childhood maltreatment was defined using a question 
from the parental questionnaire where parents could indicate the frequency of physical punishment in the form of spanking. The question was phrased as follows: 'Quite frequently, parents will resort to "spanking" as a way of "punishing" the child. How often has this happened with this particular child before the child went to school?' Categories were 'never', 'occasionally' or 'often'.

Cannabis use at T2. At T2 (at age 19 years), frequency of lifetime cannabis use was assessed (never, once, 2-4 times, $\geqslant 5$ times and regular use). Guided by a previous study using this sample and this measure (Stefanis et al. 2004), cannabis use was dichotomized as 'never' versus 'at least once'. Lifetime use of other drugs was similarly dichotomized as 'never' versus 'at least once'.

Psychosis outcome at T2. At T2, subjects completed the Community Assessment of Psychic Experiences (CAPE), a self-report questionnaire developed to measure lifetime psychotic experiences in the positive, negative and depressive symptom dimensions of psychosis in the general population (Konings et al. 2006), based on the Peters et al. Delusions Inventory (PDI; Peters et al. 1996). The CAPE measures frequency and also distress of experiences on a four-point scale from 'never' (1), 'sometimes' (2), 'often' (3) to 'nearly always' (4). The CAPE has been shown to be reliable (Verdoux et al. 2003a; Konings et al. 2006; Brenner et al. 2007) and displays discriminative validity across diagnostic groups and individuals from the general population (Hanssen et al. 2003), in addition to concurrent validity with clinical interview measures of psychosis proneness (Konings et al. 2006; Konings \& Maharajh, 2006). For the current analyses, the total score of the frequency items of positive psychotic experiences was used, expressed in units standard deviation (hereafter: psychosis, a continuous variable).

\section{NEMESIS}

Subjects were interviewed using the Composite International Diagnostic Interview (CIDI version 1.1, computerized version). The CIDI is a fully standardized, structured interview developed by the World Health Organization (WHO) to be used by trained health professionals for the assessment of mental disorders according to the definition and diagnostic criteria of the DSM-IV and ICD-10 (Smeets, 1993). It is intended for use in epidemiological studies and clinical trials. CIDI assessment at T0 yielded lifetime ratings; assessments at follow-up were interval ratings referring to the period between $\mathrm{T} 0$ and $\mathrm{T} 1$ and between $\mathrm{T} 1$ and $\mathrm{T} 2$ respectively.

Childhood maltreatment at T0. At T0, childhood maltreatment was assessed. Subjects were asked, using a semi-structured self-constructed interview, whether they had experienced any kind of emotional, physical, psychological or sexual abuse before the age of 16 years. This semi-structured interview with four questions was also used in the study by Janssen et al. (2004). Subjects were also asked to indicate the frequency of the abuse on a scale from 1 to 6 , with $1=$ never, $2=$ once, $3=$ sometimes, $4=$ regular, $5=$ often and $6=$ very often. Consistent with a previous study analyzing the association between maltreatment and psychosis in this sample (Janssen et al. 2004), the sum of answers of the four items (scale 1-6) was coded ' 0 ' when the score was $4, ' 1$ ' when the total score was 5-9 (defined as ' mild'), ' 2 ' when the total score was 10-14 (defined as 'moderate') and ' 3 ' when the total score was 15-24 (defined as 'severe'). A composite score as opposed to more specific forms of trauma was used to increase statistical power required to calculate interaction between trauma and cannabis, and because no specific hypothesis regarding interaction between cannabis and a specific kind of trauma was apparent.

Cannabis use at T0 and follow-up. At T0, lifetime cannabis use was assessed using the CIDI-L section on substance use. Consistent with a previous study using NEMESIS data (van Os et al. 2002), T0 lifetime cannabis use was dichotomized as 'never' versus 'at least once'. T0 lifetime use of other drugs was similarly categorized as 'never' versus 'at least once'. Cannabis use over the follow-up period was combined into a single variable, defined as 'no use' versus 'use at least once at $\mathrm{T} 1$ or $\mathrm{T} 2$ ', consistent with previous analyses (Henquet et al. 2006) and hereafter referred to as 'T1/T2 cannabis use'.

Psychosis outcome over the follow-up period (T1 and T2). At T1 and T2, data on the psychosis outcome were collected using the psychosis section (G) of the CIDI. This section consists of 17 items concerning delusions (13 items) and hallucinations (four items), which correspond to classic psychotic symptoms such as persecution, thought interference, auditory hallucinations and passivity phenomena. Each item was scored on a scale from 1 to 6 with $1=$ no symptom, $2=$ psychotic symptom present but not clinically relevant, $3=$ psychotic symptom is the result of drug use, $4=$ psychotic symptom is the result of a somatic disease, $5=$ true psychotic symptom, and $6=$ interviewer is in doubt because there is a plausible explanation for 
what seems to be a psychotic symptom. Conforming with previous work, individuals with at least one positive rating on any of the CIDI psychosis items (a score of $>1$ on at least one item) at either T1 or T2, irrespective of the type of rating (2-6), were considered as having psychotic symptoms at follow-up (hereafter: T1/T2 psychosis) (Henquet et al. 2006). The psychosis outcome at T0 was used to assess a possible association between $\mathrm{T} 0$ psychotic symptoms and later $\mathrm{T} 1 / \mathrm{T} 2$ cannabis use.

\section{Analyses}

Analyses were carried out using Stata version 10.0 (Stata Corporation, USA). The dependent variable in the analyses of both the Greek study and NEMESIS was psychosis (Greek study: continuous T2 CAPE psychosis outcome; NEMESIS: dichotomous CIDI $\mathrm{T} 1 / \mathrm{T} 2$ psychosis). Independent variables for main and interactive effects were early childhood maltreatment and later cannabis use (Greek study: three-level continuous childhood maltreatment variable at $\mathrm{T} 1$ and dichotomous cannabis use at T2; NEMESIS: four-level continuous childhood maltreatment at T0 and dichotomous T1/T2 cannabis use). Associations were tested using regression [Greek data: multiple regression yielding $B$ effect size of continuous standardized psychosis outcome variable; NEMESIS: logistic regression of dichotomous psychosis outcome yielding odds ratios (ORs)]. To test whether the association between cannabis use and the psychosis outcome would differ as a function of childhood maltreatment, maltreatment $\times$ cannabis interaction terms were fitted. In case of significant interaction, cannabis effect sizes for the different maltreatment levels (Greek data: three levels; NEMESIS: four levels) were calculated by making the appropriate linear combinations derived from the model containing the interaction, using the Stata LINCOM routine. Statistical significance was assessed by the Wald test. In both studies, all analyses were a priori adjusted for sex, urbanicity and other drug use. In line with previous studies using NEMESIS data, NEMESIS analyses were additionally adjusted for age (10-year groups), ethnic group ( 0 , subject and both parents born in The Netherlands; 1 , other), dichotomous single marital status, experience with discrimination (four levels of severity) and dichotomous unemployment (van Os et al. 2002). In addition, for both studies, analyses were carried out investigating whether individuals with a history of childhood maltreatment were more likely to start using cannabis compared to individuals with no childhood maltreatment, using logistic regression analysis of dichotomous cannabis use as the dependent variable. To assess self-medication effects (psychosis causing cannabis use), the association between psychotic symptoms at T0 and cannabis use at follow-up was calculated in NEMESIS only (as no prospective data for this association were available in the Greek study).

Synergism refers to the situation where the combined effect of two or more factors is greater than the sum (additive model) or the product (multiplicative model) of their solitary effects. It has been shown that the true degree to which two factors co-participate in producing an outcome can be estimated from the additive statistical interaction that comes closer to, but is not the same as, biological synergism or the proportion of those exposed to the two factors that have the outcome because of the specific combined action of the two factors (Darroch, 1997; van Os \& Sham, 2003). This method is commonly used in psychiatric research, showing synergy between proxy measures of genetic risk on the one hand and traumatic head injury (Corcoran \& Malaspina, 2001), cannabis use (van Os et al. 2002), prenatal maternal infection (Clarke et al. 2009) and urbanicity (van Os \& Sham, 2003; van Os et al. 2004; Spauwen et al. 2006) on the other, and also as between trauma and cannabis use (Harley et al. 2010). In line with these previous publications, the additive interaction was calculated between early maltreatment and later cannabis use, in models of psychotic symptoms.

\section{Results}

\section{The Greek National Perinatal Study}

The final sample consisted of subjects whose parents had completed questionnaires on childhood maltreatment at $\mathrm{T} 1$ and who had completed the self-report CAPE questionnaire and questions on cannabis use at T2. This yielded a risk set of 1636 subjects ( $45 \%$ male). At T1, maltreatment was reported to occur 'sometimes' in 940 subjects (58\%) and 'often' in 196 (12\%) of children. At T2, at age 19 years, 96 of the adolescents $(6 \%)$ reported cannabis use.

\section{Main effects of childhood maltreatment and cannabis use on psychosis outcome}

Exposure to T1 childhood maltreatment, after adjustment, was positively associated with $\mathrm{T} 2$ psychosis outcome [adjusted $B$ linear trend over three levels $=0.11,95 \%$ confidence interval (CI) $0.03-0.18$, $p=0.006]$, with evidence of dose-response ( $B$ 'sometimes': $0.08,95 \%$ CI -0.3 to $0.18, p=0.151 ; B$ 'often': $B=0.23,95 \%$ CI $0.07-0.39, p=0.005)$. The association between childhood maltreatment and psychosis outcome remained statistically significant after further 
Table 1. Mean T2 positive symptom scores (CAPE) by T1 childhood maltreatment and T2 cannabis use in the Greek National Perinatal Study

\begin{tabular}{|c|c|c|c|c|c|c|c|}
\hline \multirow[b]{2}{*}{$\mathrm{T} 1$ maltreatment } & \multirow{2}{*}{$\begin{array}{l}\text { T2 CAPE score } \\
\text { Mean (s.D.) }\end{array}$} & \multicolumn{3}{|c|}{ Unadjusted T2 cannabis effect size } & \multicolumn{3}{|c|}{ Adjusted T2 cannabis effect size ${ }^{a}$} \\
\hline & & $\beta$ & $95 \% \mathrm{CI}$ & $p$ & $\beta$ & $95 \% \mathrm{CI}$ & $p$ \\
\hline \multicolumn{8}{|l|}{ Never } \\
\hline T2 Cannabis $-(n=481)$ & $-0.08(0.93)$ & 0.48 & $0.05-0.93$ & 0.032 & 0.55 & $0.11-0.99$ & 0.015 \\
\hline T2 Cannabis $+(n=19)$ & $0.41(0.85)$ & & & & & & \\
\hline \multicolumn{8}{|l|}{ Occasionally } \\
\hline T2 Cannabis $-(n=874)$ & $-0.04(0.99)$ & 0.51 & $0.27-0.75$ & $<0.001$ & 0.55 & $0.30-0.81$ & $<0.001$ \\
\hline T2 Cannabis $+(n=66)$ & $0.47(0.89)$ & & & & & & \\
\hline \multicolumn{8}{|l|}{ Often } \\
\hline T2 Cannabis $-(n=185)$ & $0.06(1.00)$ & 1.34 & $0.75-1.93$ & $<0.001$ & 1.46 & $0.87-2.06$ & $<0.001$ \\
\hline T2 Cannabis $+(n=11)$ & $1.40(1.05)$ & & & & & & \\
\hline
\end{tabular}

CAPE, Community Assessment of Psychic Experiences; CI, confidence interval; s.D., standard deviation.

a Adjusted effects sizes, a priori adjusted for sex, urbanicity and other drug use.

adjustment for cannabis use ( $B$ linear trend $=0.10,95 \%$ CI $0.01-0.02, p=0.01$ ).

T2 cannabis use was associated with T2 psychosis outcome after adjustment $(B=0.65,95 \%$ CI $0.44-0.86$, $p=0.000$ ). The association between cannabis and psychosis outcome remained significant after further adjustment for childhood maltreatment $(B=0.65,95 \% \mathrm{CI}$ $0.44-0.86, p=0.000)$.

\section{Cannabis use $\times$ childhood maltreatment interaction}

There was a significant adjusted interaction between T1 three-level continuous childhood maltreatment and T2 dichotomous cannabis use in the model of T2 psychosis [test for interaction: $F(2,1627)=4.18$, $p=0.016]$. An extra-linear relationship was observed, the psychosis-inducing effects of cannabis being elevated only in those with the highest level of physical punishment ('often') in childhood (Table 1). For these individuals, the adjusted effect of cannabis on psychosis outcome was much stronger $(B=1.46,95 \% \mathrm{CI}$ $0.87-2.06, p<0.001)$, compared to those with physical punishment rated 'occasionally' $(B=0.55,95 \% \mathrm{CI}$ $0.30-0.81, p<0.001)$ or 'never' $(B=0.55,95 \%$ CI $0.11-0.99, p=0.015)$. There was no evidence that $\mathrm{T} 1$ childhood maltreatment was associated with increased risk of T2 cannabis use (OR 1.21, 95\% CI 0.85$1.74, p=0.29)$.

\section{NEMESIS}

The final sample consisted of subjects who (i) completed the CIDI at T1 and (ii) at T2 and (iii) completed the questions on childhood maltreatment at T0. This yielded a risk set of 4842 subjects ( $47 \%$ male). The mean age at $\mathrm{T} 0$ was 41.2 years (S.D. $=11.9$ ). Moderate to severe maltreatment was reported by $8.5 \%$ of the sample and $9.5 \%$ reported $\mathrm{T} 1 / \mathrm{T} 2$ cannabis use.

\section{Main effects of childhood maltreatment and cannabis use on psychosis}

Exposure to T0 childhood maltreatment, after adjustment, was positively associated with $\mathrm{T} 1 / \mathrm{T} 2$ psychosis outcome (OR linear trend over four levels 1.96, 95\% CI 1.73-2.20, $p=0.000$ ), and this association remained statistically significant after further adjustment for cannabis use (OR 1.93, 95\% CI 1.71-2.18, $p=0.000$ ). T0 cannabis use was associated, after adjustment, with $\mathrm{T} 1 / \mathrm{T} 2$ psychosis (OR 1.73, 95\% CI 1.24-2.42 $p=0.001$ ), and this association remained significant after further adjustment for T0 childhood maltreatment (OR 1.45, 95\% CI 1.03-2.03, $p=0.034$ ). T0 childhood maltreatment was associated with a significantly increased risk of $\mathrm{T} 1 / \mathrm{T} 2$ cannabis use (OR 1.57, 95\% CI 1.33-1.86, $p<0.001)$. There was no large or significant association between T0 psychotic symptoms and later cannabis use (T1: OR 1.22, 95\% CI 0.84-1.78, $p=0.31$; T2: OR $1.27,95 \%$ CI $0.84-1.93, p=0.25)$.

\section{Cannabis $\times$ maltreatment interaction}

There was a significant interaction between childhood maltreatment and T1/T2 cannabis use in the model of $\mathrm{T} 1 / \mathrm{T} 2$ psychosis $\left[\chi^{2}(3)=8.08, p=0.04\right]$. Again, an extra-linear relationship was observed (Table 2). Thus, the effect of cannabis in the group with severe maltreatment exposure was much higher [adjusted risk difference (RD) $30.5 \%, 95 \%$ CI 9.4-51.7, $p=0.005$ ] than those with moderate (adjusted RD 4.6\%, 95\% CI -8.9 to $18.1, p=0.50$ ) or mild maltreatment exposure (adjusted RD 4.8\%, 95\% CI -0.7 to $10.3, p=0.09$ ). 
Table 2. T1/T2 psychosis outcome by T0 childhood maltreatment and T1/T2 cannabis use in NEMESIS

\begin{tabular}{|c|c|c|c|c|c|}
\hline T0 maltreatment & $\begin{array}{l}\text { No. without } \\
\text { T1/T2 } \\
\text { psychosis }\end{array}$ & $\begin{array}{l}\text { No. with } \\
\text { T1/T2 } \\
\text { psychosis }\end{array}$ & $\begin{array}{l}\% \mathrm{~T} 1 / \mathrm{T} 2 \\
\text { psychosis }\end{array}$ & $\begin{array}{l}\% \text { Unadjusted risk } \\
\text { difference }(95 \% \mathrm{CI})\end{array}$ & $\begin{array}{l}\% \text { Adjusted risk } \\
\text { difference }(95 \% \mathrm{CI})^{\mathrm{a}}\end{array}$ \\
\hline \multicolumn{6}{|l|}{ Never } \\
\hline T1/T2 Cannabis $-(n=3017)$ & 2873 & 144 & 4.8 & $4.4(0.5$ to 8.4$)$ & $1.2(-2.3$ to 4.6$)$ \\
\hline $\mathrm{T} 1 / \mathrm{T} 2$ Cannabis $+(n=217)$ & 197 & 20 & 9.2 & & \\
\hline \multicolumn{6}{|l|}{ Mild } \\
\hline T1/T2 Cannabis $-(n=1026)$ & 945 & 81 & 7.9 & $7.9(2.2$ to 13.6$)$ & $4.8(-0.7$ to 10.3$)$ \\
\hline $\mathrm{T} 1 / \mathrm{T} 2$ Cannabis $+(n=171)$ & 144 & 27 & 15.8 & & \\
\hline \multicolumn{6}{|l|}{ Moderate } \\
\hline $\mathrm{T} 1 / \mathrm{T} 2$ Cannabis $-(n=239)$ & 189 & 50 & 20.9 & $9.1(-4.6$ to 22.8$)$ & $4.6(-8.9$ to 18.1$)$ \\
\hline $\mathrm{T} 1 / \mathrm{T} 2$ Cannabis $+(n=50)$ & 35 & 15 & 30.0 & & \\
\hline \multicolumn{6}{|l|}{ Severe } \\
\hline T1/T2 Cannabis $-(n=98)$ & 72 & 26 & 26.5 & $36.0(14.7-57.2)$ & $30.5(9.4-51.7)$ \\
\hline $\mathrm{T} 1 / \mathrm{T} 2$ Cannabis $+(n=24)$ & 9 & 15 & 62.5 & & \\
\hline
\end{tabular}

NEMESIS, The Netherlands Mental Health Survey and Incidence Study; CI, confidence interval.

a Adjusted difference in risk, a priori adjusted for sex, urbanicity, other drug use, age, ethnicity, urbanicity, single marital status, discrimination and unemployment.

\section{Discussion}

This study, using two independent population-based samples, has shown that experience of childhood maltreatment moderates the association between cannabis and psychosis. Even maltreatment sometimes considered less severe, such as spanking, displayed main effects if it was 'often', and interacted with cannabis use. These findings are in accordance with two earlier studies (Houston et al. 2008; Harley et al. 2010). The current study adds strength to these results because of its longitudinal design and because it has shown that maltreatment moderates the effects of cannabis in a dose-dependent, extra-linear fashion, more severe maltreatment being associated with the greatest effect of cannabis in later expression of psychosis. Furthermore, the findings indicate that selfmedication (people using cannabis to self-medicate their psychotic symptoms or the traumatizing effects of early adversities) (Shevlin et al. 2009) is unlikely to account for the interaction between childhood maltreatment and cannabis exposure because only in NEMESIS was an association between childhood maltreatment and later cannabis use present, and also in NEMESIS, psychosis at baseline did not predict future cannabis use.

\section{Interaction between environmental factors}

There is accumulating evidence that cannabis use and maltreatment in childhood or early adolescence play a role in the pathway to psychotic symptoms. The current results add credence to the suggestion that these environmental factors may act synergistically on the same final common pathway, as evidenced by the more-than-additive interaction. Interpretation of interaction of risk factors is difficult because correlation needs to be taken into account as well, as simulations show that environment-environment interaction (one environmental factor controlling sensitivity to the other) may be confounded by environment-environment correlation (one environmental factor controlling exposure to the other). The current results are inconsistent with respect to correlation between maltreatment and cannabis because only in NEMESIS, and not in the Greek survey, do early maltreatment predisposed individuals start using cannabis later in life. Because this association was only present in NEMESIS and was absent in the Greek survey, it suggests that there may be a small amount of gene-environment correlation in addition to gene-environment interaction. In the earlier study by Harley et al. (2010), the possible correlation between early cannabis use and childhood maltreatment was also calculated, showing that subjects who had experienced childhood maltreatment were five times more likely to use cannabis, confirming the hypothesis that environment-environment correlation cannot be ruled out. The occurrence of both interaction and correlation for the same risk factor at the same time was shown before in depression: the genetic liability for depression acts in part by increasing the sensitivity to stressful life events (Kendler et al. 1995) but the same genes also influence the probability that individuals will experience stressful life events in the 
first place (Kendler \& Karkowski-Shuman, 1997). The same may hold for perinatal adversity and risk for schizophrenia: the genes predisposing for schizophrenia may not only render an individual more sensitive to the risk-increasing effect of perinatal adversity but also increase the risk for perinatal adversity itself (Marcelis et al. 1998).

\section{Cross-sensitization between maltreatment and cannabis}

Exposure to cannabis increases risk for psychosis outcomes in a dose-response fashion (Henquet et al. 2005; Zammit et al. 2007), suggesting an underlying process of sensitization. Evidence for this hypothesis comes from animal studies: rats that were pretreated with increasing doses of THC showed a greater behavioral response to a THC challenge after a 14-day washout period than did THC-naïve rats (Cadoni et al. 2001, 2008). The current finding suggests that the psychosis-inducing effects of cannabis are moderated by early experience of maltreatment, suggesting cross-sensitization between stress and cannabis in shaping risk of psychotic outcomes. Sensitization involving dopaminergic signaling has been proposed as a possible mechanism by which environmental factors such as stress or cannabis use impact on psychosis risk (Collip et al. 2008). Animal studies have shown fairly consistently that both stress and THC lead to increased release of dopamine, particularly striatal regions (Abercrombie et al. 1989; Tidey \& Miczek 1996; French et al. 1997; Tanda et al. 1997; Cheer et al. 2004), although evidence for this in humans is less clear (Bossong et al. 2009; Stokes et al. 2009; Kuepper et al. 2010). Few studies have examined possible cross-sensitization between THC and stress. Rats living under normal conditions (i.e. access to water and food), that were exposed to THC, showed only minor behavioral changes and no change in dopaminergic neurotransmission (MacLean \& Littleton, 1977). By contrast, under stressful housing conditions (i.e. isolation and food deprivation), THC administration had marked behavioral consequences. Furthermore, it also resulted in significantly increased dopamine uptake (MacLean \& Littleton, 1977). Similarly, Mokler et al. (1987) showed that, in rat pups, pretreatment with THC altered the stressinduced dopamine response in the hypothalamus and frontal cortex. Exposure to traumatic experiences during childhood similarly may occasion enduring neurobiological effects with over-reactivity of the hypothalamus and the hypothalamic-pituitaryadrenal (HPA) axis, abnormalities in neurotransmitter systems and structural brain changes (Read et al. 2001).

\section{Limitations}

Childhood maltreatment, cannabis use and psychosis outcome measures were assessed using different instruments across NEMESIS and the Greek study. Childhood maltreatment in NEMESIS was specified as any kind of emotional, physical, psychological or sexual abuse whereas in the Greek study, childhood maltreatment was limited to physical punishment. The question that arises is what degree of spanking may be considered a traumatic experience. Nevertheless, it has been shown that repeated slapping or spanking is associated with increased lifetime rates of psychiatric disorder (MacMillan et al. 1999). Similarly, a longitudinal birth cohort study in New Zealand showed that those exposed to 'harsh or abusive' treatment during childhood were at greater risk of later mental health problems (Fergusson \& Lynskey, 1997). In addition, several studies have shown that the same biological mechanism that is thought to underlie the association between trauma and psychosis may also be relevant for moderate levels of stress, as studies suggest that even small stressors occasion increases in dopamine levels in the brain (Davis et al. 1991; Glenthoj, 1995; Laruelle, 2000; Myin-Germeys et al. 2005). The current study is the first to demonstrate that even non-severe physical mistreatment can interact with cannabis on psychosis risk. No data on continuation of childhood maltreatment were available in the Greek study. However, there is little doubt that these smaller stressors occur more frequently during childhood than major traumatic experiences, and as such could impact on the aforementioned process of sensitization in a cumulative way.

Another limitation is that, in the Greek National Perinatal Study, the measure of childhood maltreatment relied on parental information, which may have resulted in under-reporting and underestimation of effect sizes. Nevertheless, the results were consistent across studies, and the Greek data are unique in that maltreatment was assessed prospectively. The measurement of childhood maltreatment relied on self-report. This type of assessment is acceptable, is associated with a high response rate and yields rates that are comparable to face-to-face interviews (Dill et al. 1991; Wurr \& Partridge, 1996; Read et al. 1997; Janssen et al. 2004).

In both studies, psychotic symptoms rather than psychotic illness were assessed in non-clinical samples. Psychotic symptoms are more prevalent in the general population than psychotic illness yet are associated with the same environmental risk factors as psychotic illness (van Os \& Kapur 2009; Polanczyk et al. 2010) and predict psychotic disorder over time 
(Poulton et al. 2000; Hanssen et al. 2005). The current results confirm earlier findings that both cannabis and adversity not only affect psychotic illness but also impact on the broader extended psychosis phenotype in the general population, which represents behavioral expression of liability to psychotic disorder. The results do not, however, provide information about to what degree the interaction between cannabis and maltreatment contributes to the onset of new psychotic symptoms or to the persistence of existing symptoms (Dominguez et al. 2010). A further limitation of the current study is that self-reported cannabis use was not confirmed by urinalysis. Lifetime prevalence of cannabis use in the Greek National Perinatal Study was low $(6 \%)$ compared to other that in European countries (20-31\%) (Wone et al. 2004; Kokkevi et al. 2006). However, in other Greek studies, comparable prevalence rates of $4-8.6 \%$ have been reported (Kokkevi et al. 2007; Menti et al. 2007). NEMESIS was conducted in The Netherlands, where cannabis is sold and consumed legally in coffee shops, which makes under-reporting unlikely. In addition, false negatives would probably have contributed to a more, rather than a less, conservative result. Cannabis use in the current study was dichotomously defined; however, frequency and duration of use, and also the potency of cannabis consumed, were not specified. Given recent findings that different types of cannabis affect mental health differentially (Di Forti et al. 2009; Morgan et al. 2010), future research should take into account differences in potency of cannabis in addition to duration of exposure (Henquet et al. 2010). The samples included in this study were not sufficiently genetically sensitive to allow examination of underlying gene-environment interaction or geneenvironment correlation. It is unlikely, however, that the reported interactions between cannabis and childhood adversities are reducible to gene-environment interplay. If genes predisposing to schizophrenia also contribute to exposure to both adversity and cannabis use, an interaction between these two factors would not be expected.

\section{Appendix}

\section{NEMESIS trauma questionnaire}

The following questions are about forms of childhood trauma to which you may have been exposed before the age of 16 years.

(1) Do you think that there was any kind of emotional neglect?

(This means, for example, that people at home didn't listen to you, that your problems were ignored, that you had the feeling of not receiving attention, care or support by the people in your house)
(2) Do you think there was any kind of psychological abuse? (This means, for example, being sworn at, brothers or sisters who were being favored, unjust punishment, blackmail)

(3) Do you think there was any kind of physical abuse?

(That is, were you ever beaten, kicked, punched or did you experience any other kind of physical abuse?)

(4) Were you ever approached sexually against your will?

(This means: had you ever been touched sexually by anyone against your will or forced to touch anybody; were you ever pressurized into sexual contact against your will?)

\section{Acknowledgements}

C. Henquet received support from the Dutch Medical Research Council (VENI grant). The research leading to these results has received funding from the European Community's Seventh Framework Program under grant agreement HEALTH-F2-2009-241909 (Project EU-GEI).

\section{Declaration of Interest}

J. van Os is a speaker or grant holder with Lilly, BMS, Lundbeck, Organon, Janssen-Cilag, GSK, Otsuka and Astra-Zeneca.

\section{References}

Abercrombie ED, Keefe KA, DiFrischia DS, Zigmond MJ (1989). Differential effect of stress on in vivo dopamine release in striatum, nucleus accumbens, and medial frontal cortex. Journal of Neurochemistry 52, 1655-1658.

Arseneault L, Cannon M, Fisher HL, Polanczyk G, Moffitt TE, Caspi A (2011). Childhood trauma and children's emerging psychotic symptoms: a genetically sensitive longitudinal cohort study. American Journal of Psychiatry $168,65-72$.

Bijl RV, Ravelli A, van Zessen G (1998a). Prevalence of psychiatric disorder in the general population: results of The Netherlands Mental Health Survey and Incidence Study (NEMESIS). Social Psychiatry and Psychiatric Epidemiology 33, 587-595.

Bijl RV, van Zessen G, Ravelli A, de Rijk C, Langendoen Y (1998b). The Netherlands Mental Health Survey and Incidence Study (NEMESIS): objectives and design. Social Psychiatry and Psychiatric Epidemiology 33, 581-586.

Bossong MG, van Berckel BN, Boellaard R, Zuurman L, Schuit RC, Windhorst AD, van Gerven JM, Ramsey NF, Lammertsma AA, Kahn RS (2009). Delta 9-tetrahydrocannabinol induces dopamine release in the human striatum. Neuropsychopharmacology 34, 759-766.

Brenner K, Schmitz N, Pawliuk N, Fathalli F, Joober R, Ciampi A, King S (2007). Validation of the English and French versions of the Community Assessment of Psychic Experiences (CAPE) with a Montreal community sample. Schizophrenia Research 95, 86-95. 
Cadoni C, Pisanu A, Solinas M, Acquas E, Di Chiara G (2001). Behavioural sensitization after repeated exposure to Delta 9-tetrahydrocannabinol and cross-sensitization with morphine. Psychopharmacology (Berlin) 158, 259-266.

Cadoni C, Valentini V, Di Chiara G (2008). Behavioral sensitization to delta 9-tetrahydrocannabinol and cross-sensitization with morphine: differential changes in accumbal shell and core dopamine transmission. Journal of Neurochemistry 106, 1586-1593.

Cheer JF, Wassum KM, Heien ML, Phillips PE, Wightman RM (2004). Cannabinoids enhance subsecond dopamine release in the nucleus accumbens of awake rats. Journal of Neuroscience 24, 4393-4400.

Clarke MC, Tanskanen A, Huttunen M, Whittaker JC, Cannon M (2009). Evidence for an interaction between familial liability and prenatal exposure to infection in the causation of schizophrenia. American Journal of Psychiatry 166, 1025-1030.

Collip D, Myin-Germeys I, van Os J (2008). Does the concept of 'sensitization' provide a plausible mechanism for the putative link between the environment and schizophrenia? Schizophrenia Bulletin 34, 220-225.

Corcoran C, Malaspina D (2001). Traumatic brain injury and schizophrenia. International Journal of Mental Health 30, 17-33.

Cougnard A, Marcelis M, Myin-Germeys I, De Graaf R, Vollebergh W, Krabbendam L, Lieb R, Wittchen HU, Henquet C, Spauwen J, van Os J (2007). Does normal developmental expression of psychosis combine with environmental risk to cause persistence of psychosis? A psychosis proneness-persistence model. Psychological Medicine 37, 513-527.

Darroch J (1997). Biologic synergism and parallelism. American Journal of Epidemiology 145, 661-668.

Davis KL, Kahn RS, Ko G, Davidson M (1991). Dopamine in schizophrenia: a review and reconceptualization. American Journal of Psychiatry 148, 1474-1486.

de Graaf R, Bijl RV, Smit F, Ravelli A, Vollebergh WA (2000). Psychiatric and sociodemographic predictors of attrition in a longitudinal study: The Netherlands Mental Health Survey and Incidence Study (NEMESIS). American Journal of Epidemiology 152, 1039-1047.

Di Forti M, Morgan C, Dazzan P, Pariante C, Mondelli V, Marques TR, Handley R, Luzi S, Russo M, Paparelli A, Butt A, Stilo SA, Wiffen B, Powell J, Murray RM (2009). High-potency cannabis and the risk of psychosis. British Journal of Psychiatry 195, 488-491.

Dill DL, Chu JA, Grob MC, Eisen SV (1991). The reliability of abuse history reports: a comparison of two inquiry formats. Comprehensive Psychiatry 32, 166-169.

Dominguez MD, Wichers M, Lieb R, Wittchen HU, van Os J (2010). Evidence that onset of clinical psychosis is an outcome of progressively more persistent subclinical psychotic experiences: an 8-year cohort study. Schizophrenia Bulletin 37, 84-93.

D'Souza DC, Abi-Saab WM, Madonick S, Forselius-Bielen K, Doersch A, Braley G, Gueorguieva R, Cooper TB, Krystal JH (2005).
Delta-9-tetrahydrocannabinol effects in schizophrenia: implications for cognition, psychosis, and addiction. Biological Psychiatry 57, 594-608.

Elklit A, Shevlin M (2010). Female sexual victimization predicts psychosis: a case-control study based on the Danish Registry System. Schizophrenia Bulletin. Published online: 20 May 2010. doi:10.1093/schbul/sbq048.

Engert V, Joober R, Meaney MJ, Hellhammer DH, Pruessner JC (2009). Behavioral response to methylphenidate challenge: influence of early life parental care. Developmental Psychobiology 51, 408-416.

Fergusson DM, Lynskey MT (1997). Physical punishment/maltreatment during childhood and adjustment in young adulthood. Child Abuse and Neglect 21, 617-630.

Fisher HL, Jones PB, Fearon P, Craig TK, Dazzan P, Morgan K, Hutchinson G, Doody GA, McGuffin P, LeffJ, Murray RM, Morgan C (2010). The varying impact of type, timing and frequency of exposure to childhood adversity on its association with adult psychotic disorder. Psychological Medicine 40, 1967-1978.

Freeman D, Fowler D (2009). Routes to psychotic symptoms: trauma, anxiety and psychosis-like experiences. Psychiatry Research 169, 107-112.

French ED, Dillon K, Wu X (1997). Cannabinoids excite dopamine neurons in the ventral tegmentum and substantia nigra. Neuroreport 8, 649-652.

Glenthoj BY (1995). The brain dopaminergic system. Pharmacological, behavioural and electrophysiological studies. Danish Medical Bulletin 42, 1-21.

GROUP (2011). Evidence that familial liability for psychosis is expressed as differential sensitivity to cannabis: an analysis of patient-sibling and sibling-control pairs. Archives of General Psychiatry 68, 138-147.

Hanssen M, Bak M, Bijl R, Vollebergh W, van Os J (2005). The incidence and outcome of subclinical psychotic experiences in the general population. British Journal of Clinical Psychology 44, 181-191.

Hanssen M, Peeters F, Krabbendam L, Radstake S, Verdoux H, van Os J (2003). How psychotic are individuals with non-psychotic disorders? Social Psychiatry and Psychiatric Epidemiology 38, 149-154

Harley M, Kelleher I, Clarke M, Lynch F, Arseneault L, Connor D, Fitzpatrick C, Cannon M (2010). Cannabis use and childhood trauma interact additively to increase the risk of psychotic symptoms in adolescence. Psychological Medicine 40, 1627-1634.

Henquet C, Krabbendam L, de Graaf R, ten Have M, van Os J (2006). Cannabis use and expression of mania in the general population. Journal of Affective Disorders 95, 103-110

Henquet C, Krabbendam L, Spauwen J, Kaplan C, Lieb R, Wittchen HU, van Os J (2005). Prospective cohort study of cannabis use, predisposition for psychosis, and psychotic symptoms in young people. British Medical Journal 330, 11.

Henquet C, Di Forti M, Morrison P, Kuepper R, Murray RM (2008). Gene-environment interplay between cannabis and psychosis. Schizophrenia Bulletin 34, 1111-1121.

Henquet C, van Os J, Kueper R, Delespaul P, Smits M, Campo JA, Myin-Germeys I (2010). Psychosis reactivity to 
cannabis use in daily life: an experience sampling study. British Journal Psychiatry 196, 447-453.

Houston JE, Murphy J, Adamson G, Stringer M, Shevlin M (2008). Childhood sexual abuse, early cannabis use, and psychosis: testing an interaction model based on the National Comorbidity Survey. Schizophrenia Bulletin 34, 580-585.

Janssen I, Krabbendam L, Bak M, Hanssen M, Vollebergh W, de Graaf R, van Os J (2004). Childhood abuse as a risk factor for psychotic experiences. Acta Psychiatrica Scandinavica 109, 38-45.

Kapur S (2003). Psychosis as a state of aberrant salience: a framework linking biology, phenomenology, and pharmacology in schizophrenia. American Journal of Psychiatry 160, 13-23.

Kelleher I, Harley M, Lynch F, Arseneault L, Fitzpatrick C, Cannon M (2008). Associations between childhood trauma, bullying and psychotic symptoms among a school-based adolescent sample. British Journal of Psychiatry 193, 378-382.

Kendler KS, Karkowski-Shuman L (1997). Stressful life events and genetic liability to major depression: genetic control of exposure to the environment? Psychological Medicine 27, 539-547.

Kendler KS, Kessler RC, Walters EE, MacLean C, Neale MC, Heath AC, Eaves LJ (1995). Stressful life events, genetic liability, and onset of an episode of major depression in women. American Journal of Psychiatry 152, 833-842.

Kokkevi A, Fotiou A, Richardson C (2007). Drug use in the general population of Greece over the last 20 years: results from nationwide household surveys. European Addiction Research 13, 167-176.

Kokkevi A, Nic Gabhainn S, Spyropoulou M (2006). Early initiation of cannabis use: a cross-national European perspective. Journal of Adolescent Health 39, 712-719.

Konings M, Bak M, Hanssen M, van Os J, Krabbendam L (2006). Validity and reliability of the CAPE: a self-report instrument for the measurement of psychotic experiences in the general population. Acta Psychiatrica Scandinavica 114, 55-61.

Konings M, Maharajh HD (2006). Cannabis use and mood disorders: patterns of clinical presentations among adolescents in a developing country. International Journal of Adolescent Medicine and Health 18, 221-233.

Kuepper R, Morrison PD, van Os J, Murray RM, Kenis G, Henquet C (2010). Does dopamine mediate the psychosis-inducing effects of cannabis? A review and integration of findings across disciplines. Schizophrenia Research 121, 107-117.

Laruelle M (2000). The role of endogenous sensitization in the pathophysiology of schizophrenia: implications from recent brain imaging studies. Brain Research Reviews 31, 371-384.

Lataster T, van Os J, Drukker M, Henquet C, Feron F, Gunther N, Myin-Germeys I (2006). Childhood victimisation and developmental expression of non-clinical delusional ideation and hallucinatory experiences: victimisation and non-clinical psychotic experiences. Social Psychiatry and Psychiatric Epidemiology 41, 423-428.
Mackie CJ, Castellanos-Ryan N, Conrod PJ (2010).

Developmental trajectories of psychotic-like experiences across adolescence: impact of victimization and substance use. Psychological Medicine 29, 1-12.

MacLean KI, Littleton JM (1977). Environmental stress as a factor in the response of rat brain catecholamine metabolism to delta8-tetrahydrocannabinol. European Journal of Pharmacology 41, 171-182.

MacMillan HL, Boyle MH, Wong MY, Duku EK, Fleming JE, Walsh CA (1999). Slapping and spanking in childhood and its association with lifetime prevalence of psychiatric disorders in a general population sample. Canadian Medical Association Journal 161, 805-809.

Marcelis M, van Os J, Sham P, Jones P, Gilvarry C, Cannon M, McKenzie K, Murray R (1998). Obstetric complications and familial morbid risk of psychiatric disorders. American Journal of Medical Genetics 81, 29-36.

Menti E, Lekka NP, Assimakopoulos K, Varvarigou A, Beratis NG, Beratis S (2007). Smoking, psychosocial factors, psychopathologic behavior, and other related conditions in hospitalized youth suicide attempters. Comprehensive Psychiatry 48, 522-528.

Mokler DJ, Robinson SE, Johnson JH, Hong JS, Rosecrans JA (1987). Neonatal administration of delta-9-tetrahydrocannabinol (THC) alters the neurochemical response to stress in the adult Fischer-344 rat. Neurotoxicology and Teratology 9, 321-327.

Moore TH, Zammit S, Lingford-Hughes A, Barnes TR, Jones PB, Burke M, Lewis G (2007). Cannabis use and risk of psychotic or affective mental health outcomes: a systematic review. Lancet 370, 319-328.

Morgan CJ, Schafer G, Freeman TP, Curran HV (2010). Impact of cannabidiol on the acute memory and psychotomimetic effects of smoked cannabis : naturalistic study: naturalistic study [corrected]. British Journal of Psychiatry 197, 285-290.

Myin-Germeys I, Delespaul P, van Os J (2005). Behavioural sensitization to daily life stress in psychosis. Psychological Medicine 35, 733-741.

Peters ER, Day S, Garety PA (1996). The Peters et al. Delusions Inventory (PDI) : new forms for the 21-item version. Schizophrenia Research 18, 118.

Polanczyk G, Moffitt TE, Arseneault L, Cannon M, Ambler A, Keefe RS, Houts R, Odgers CL, Caspi A (2010). Etiological and clinical features of childhood psychotic symptoms: results from a birth cohort. Archives of General Psychiatry 67, 328-338.

Poulton R, Caspi A, Moffitt TE, Cannon M, Murray R, Harrington H (2000). Children's self-reported psychotic symptoms and adult schizophreniform disorder: a 15-year longitudinal study. Archives of General Psychiatry 57, 1053-1058.

Read J, Bentall RP, Fosse R (2009). Time to abandon the bio-bio-bio model of psychosis: exploring the epigenetic and psychological mechanisms by which adverse life events lead to psychotic symptoms. Epidemiologia e Psichiatria Sociale 18, 299-310.

Read J, Perry BD, Moskowitz A, Connolly J (2001). The contribution of early traumatic events to schizophrenia in 
some patients: a traumagenic neurodevelopmental model. Psychiatry 64, 319-345.

Read JP, Stern AL, Wolfe J, Ouimette PC (1997). Use of a screening instrument in women's health care: detecting relationships among victimization history, psychological distress, and medical complaints. Women and Health $\mathbf{2 5}$, $1-17$.

Rodrigues AJ, Leao P, Carvalho M, Almeida OF, Sousa N (2011). Potential programming of dopaminergic circuits by early life stress. Psychopharmacology (Berlin) 214, 107-120.

Schreier A, Wolke D, Thomas K, Horwood J, Hollis C, Gunnell D, Lewis G, Thompson A, Zammit S, Duffy L, Salvi G, Harrison G (2009). Prospective study of peer victimization in childhood and psychotic symptoms in a nonclinical population at age 12 years. Archives of General Psychiatry 66, 527-536.

Scott J, Chant D, Andrews G, Martin G, McGrath J (2007). Association between trauma exposure and delusional experiences in a large community-based sample. British Journal of Psychiatry 190, 339-343.

Semple DM, McIntosh AM, Lawrie SM (2005). Cannabis as a risk factor for psychosis: systematic review. Journal of Psychopharmacology 19, 187-194.

Shevlin M, Dorahy MJ, Adamson G (2007). Trauma and psychosis: an analysis of the National Comorbidity Survey. American Journal of Psychiatry 164, 166-169.

Shevlin M, Houston JE, Dorahy MJ, Adamson G (2008). Cumulative traumas and psychosis: an analysis of the National Comorbidity Survey and the British Psychiatric Morbidity Survey. Schizophrenia Bulletin 34, 193-199.

Shevlin M, Murphy J, Houston JE, Adamson G (2009). Childhood sexual abuse, early cannabis use, and psychosis: testing the effects of different temporal orderings based on the National Comorbidity Survey. Psychosis: Psychological, Social and Integrative Approaches 1, 19-28.

Smeets R (1993). Composite International Diagnostic Interview (CIDI), version 1.1. World Health Organization: Geneva.

Soliman A, O'Driscoll GA, Pruessner J, Holahan AL, Boileau I, Gagnon D, Dagher A (2008). Stress-induced dopamine release in humans at risk of psychosis: a $\left[{ }^{11} \mathrm{C}\right]$ raclopride PET study. Neuropsychopharmacology 33, 2033-2041.

Spauwen J, Krabbendam L, Lieb R, Wittchen HU, van Os J (2006). Impact of psychological trauma on the development of psychotic symptoms: relationship with psychosis proneness. British Journal of Psychiatry 188, 527-533.

Stefanis NC, Delespaul P, Henquet C, Bakoula C, Stefanis CN, van Os J (2004). Early adolescent cannabis exposure and positive and negative dimensions of psychosis. Addiction 99, 1333-1341.

Stokes PR, Egerton A, Watson B, Reid A, Breen G, Lingford-Hughes A, Nutt DJ, Mehta MA (2010). Significant decreases in frontal and temporal [11C]-raclopride binding after THC challenge. NeuroImage 52, 1521-1527.
Stokes PR, Mehta MA, Curran HV, Breen G, Grasby PM (2009). Can recreational doses of THC produce significant dopamine release in the human striatum? Neurolmage 48, 186-190.

Tanda G, Pontieri FE, Di Chiara G (1997). Cannabinoid and heroin activation of mesolimbic dopamine transmission by a common mu1 opioid receptor mechanism. Science 276, 2048-2050.

Tidey JW, Miczek KA (1996). Social defeat stress selectively alters mesocorticolimbic dopamine release: an in vivo microdialysis study. Brain Research 721, 140-149.

Tzoumaka-Bakoula C (1987). The Greek National Perinatal Survey. I: Design, methodology, case ascertainment. Paediatric and Perinatal Epidemiology 1, 43-55.

van Os J, Bak M, Hanssen M, Bijl RV, de Graaf R, Verdoux H (2002). Cannabis use and psychosis: a longitudinal population-based study. American Journal of Epidemiology 156, 319-327.

van Os J, Kapur S (2009). Schizophrenia. Lancet 374, 635-645. van Os J, Pedersen CB, Mortensen PB (2004). Confirmation of synergy between urbanicity and familial liability in the causation of psychosis. American Journal of Psychiatry 161, 2312-2314.

van Os J, Sham P (2003). Gene-environment interactions. In The Epidemiology of Schizophrenia (ed. R. M. Murray, P. B. Jones, E. Susser, J. van Os and M. Cannon), pp. 235-254. Cambridge University Press: Cambridge.

Verdoux H, Gindre C, Sorbara F, Tournier M, Swendsen JD (2003a). Effects of cannabis and psychosis vulnerability in daily life: an experience sampling test study. Psychological Medicine 33, 23-32.

Verdoux H, Sorbara F, Gindre C, Swendsen JD, van Os J $(2003 b)$. Cannabis use and dimensions of psychosis in a nonclinical population of female subjects. Schizophrenia Research 59, 77-84.

Voruganti LN, Slomka P, Zabel P, Mattar A, Awad AG (2001). Cannabis induced dopamine release: an in-vivo SPECT study. Psychiatry Research 107, 173-177.

Whitfield CL, Dube SR, Felitti VJ, Anda RF (2005). Adverse childhood experiences and hallucinations. Child Abuse and Neglect 29, 797-810.

Wicks S, Hjern A, Gunnell D, Lewis G, Dalman C (2005). Social adversity in childhood and the risk of developing psychosis: a national cohort study. American Journal of Psychiatry 162, 1652-1657.

Wone I, Dia AT, Ndiaye P, Fall IS, Sarr YF (2004). Prevalence of cannabis use among students in Dakar [in French]. Santé 14, 49-53.

Wurr CJ, Partridge IM (1996). The prevalence of a history of childhood sexual abuse in an acute adult inpatient population. Child Abuse and Neglect 20, 867-872.

Zammit S, Spurlock G, Williams H, Norton N, Williams N, O'Donovan MC, Owen MJ (2007). Genotype effects of CHRNA7, CNR1 and COMT in schizophrenia: interactions with tobacco and cannabis use. British Journal of Psychiatry 191, 402-407. 

CHAPTER VII

\section{Discussion}


Both exposure to cannabis and childhood maltreatment have consistently been found to be associated with risk on psychotic symptoms. As mentioned in chapter I, the aim of this thesis was to investigate the association between cannabis and psychiatric diseases, with the focus on psychosis, and to test whether this association is also present in a non-western society. This thesis furthermore explored whether early traumatic experiences moderate the long-term psychosis inducing effects of cannabis use later in life in population based samples.

\section{Cannabis and the broader psychosis phenotype}

The traditional medical model of schizophrenia or psychosis assumes a categorical view with symptoms being present in an all-or-none phenomenon. Many studies, however, have now shown that schizophrenia is not a discrete illness entity, but that psychotic symptoms generally exist as a continuum of severity and differ in quantitative ways and are prevalent in the general population [1-4]. The majority of people with subclinical psychotic symptoms never develop psychosis, but experiencing these subclinical symptoms does increase the risk of developing clinical psychosis $[5,6]$. Poulton and colleagues showed in a prospective longitudinal study that self-reported symptoms in children at age 11 years were associated with an increased risk of developing a schizophreniform disorder at the age of 26 years (odds ratio 16.4) [7]. In another large population based study in which 7076 individuals were followed up for 2 years, these results were replicated. $8 \%$ of the individuals who showed psychotic experiences, developed a clinical psychotic disorder within 2 years, indicating a greater than 60-fold increase in risk compared to those without psychotic experiences [2] A more recent study in a Latin-American community also found evidence of the existence of a continuum of psychosis with $38,9 \%$ of the individuals (adults) showing at least one life time psychotic symptom and one third having clinically non-relevant symptoms [8]. Most studies investigating psychotic experiences in the general population use self-report instruments. Information about the reliability of these instruments and cross-validation with interview based measures, however, is limited. Therefore, in chapter IV, the reliability and stability of the self-report scale the Community Assessment of Psychic Experiences (CAPE ; Retrieved from http:// www.cape42.homestead.com) was examined. The CAPE was developed to assess positive, negative and depressive dimensions of psychotic experiences in the general population and can be an important scale in detecting psychotic experiences in the general population. In a general population sample the CAPE was administered at baseline and again at follow-up 8 months later. In addition, the Structured Interview for Schizotypy, Revised (SIS-R) and the Brief Psychiatric Rating Scale (BPRS) were administered. Given that the results indicated that selfreported dimensions of psychotic experiences in the general population were sta- 
ble, reliable and valid, the CAPE could then be used in subsequent studies to investigate the role of cannabis use in the development of subclinical psychosis.

\section{Cross cultural aspects: cannabis use in a non-western society}

As previously described, cannabis use among adolescents is prevalent and is of importance since the onset of psychotic disorders most commonly occurs in this life stage. Data on adolescent cannabis use is mainly collected in western societies however and data on trends in substance use from developing countries is limited. This data is nevertheless important since it may provide further information on the specific association between cannabis and psychosis. The few studies published that include non-western samples, showed similar patterns of cannabis use as in studies using western societies: with prevalence rates being highest among adolescents [9, 10]. To investigate the prevalence and patterns of substance abuse in a non western society among adolescents, patterns of lifetime and current substance use were estimated among schoolchildren in Trinidad (chapter II). The results of this study showed that lifetime use of cannabis was high in the different school systems in Trinidad, with one third of the schoolchildren having used cannabis at least once. Current cannabis use was different in the different school systems as more than $20 \%$ of the vocational school children (with learning and behavioural problems) reported present use of cannabis, whereas in government assisted schools only $5 \%$ of the children presently used cannabis. It was furthermore shown that schoolchildren in Trinidad start to use cannabis at an early age: in both school systems the mean age to start cannabis use was 13 years. These percentages are comparable with the rates in Western countries, where as the rates in the vocational schools tend to be high and in general, more children start to use cannabis as very early ages (13 years) compared to rates of European countries where only 5-9\% of the individuals started to use cannabis at 13 years [11].

As stated before, exposure to cannabis not only seems to play a role in the emergence of psychotic experiences, but may also increase the risk of affective symptoms (depressive and manic symptoms) [12-14], suicidal thoughts $[15,16]$ and cognitive impairment $[17,18]$. A large cohort study of schoolchildren, for example, revealed that frequent cannabis use in teenage girls was associated with later depression and anxiety with the highest frequency of use associated with the highest risk [19]. In a recently published review on cannabis use and mood symptoms, it was shown that indeed high rates of comorbidity were seen between use/ abuse/ dependency of cannabis and affective disorders in several both longitudinal population based studies and in clinical samples. It was also shown that more frequent use of cannabis was associated with elevated risk of developing affective disorders, 
whereas there was no evidence for reverse causality (i.e affective symptoms at baseline without use of cannabis did not result in an increased risk of using cannabis at follow-up) [12]. Since the prevalence of cannabis is high in non western societies, the association between use of cannabis and psychiatric symptoms, also other than psychotic symptoms, was again investigated in a non-western country. Patterns of clinical presentations among cannabis users were described using a psychiatric outpatient sample in Trinidad and international literature on this subject was used as comparison (chapter III). The results showed that affective symptoms, suicidal thoughts but also hypomania were common among Caribbean cannabis users. Moreover, psychotic symptoms were most prominent findings in the cannabis users. This study, furthermore, confirms that it is difficult to differentiate the nosological differences between schizophrenia and mania where affective symptomatology are common findings in cannabis users in Trinidad and it can be assumed that the phenomenological presentation is determined by factors as genes, environmental factors and local factors (potency of cannabis consumed where different kinds of cannabis may affect psychic symptoms differentially) [13, 20, 21]. There may be some cultural differences between western and non-western societies, as Afro-Caribbean patients may show more symptoms of a mixed affective nature than non Caribbean patients who show less affective symptoms [22]. Other studies also suggest these different presentations of psychiatric symptoms in different ethnicities where people with a darker skin are said to have more severe first rank symptoms compared to blank people [23].

Several studies have shown that genetic vulnerability to psychosis is equal in migrants and non migrants. There seems to exist an increased risk of developing psychotic disorders in migrants however (Moroccan migrants in the Netherlands, AfroCaribbean migrants in the United Kingdom) but this risk seems more likely to be due to environmental factors [24-26] rather than genetic factors. As mentioned in the introduction, Veling and colleagues showed that the increased risk of psychosis in ethnic minorities was not due to immigration in itself but is more likely associated with environmental factors such as belonging to an ethnic minority which perceives a high degree of discrimination [27]. Furthermore also differences in course and outcome of psychotic disorders between Western and developing countries have been reported, with a better outcome being more frequently found in developed and non-Western compared to Western societies [28]. Factors underlying a better outcome of psychotic disorders in developing countries are not known yet, but are likely to involve some socio-cultural factors [29-31] Kulhara for example, suggests that unidentified factors that vary within cultures may be responsible for the good outcome in developing countries: factors such as social acceptance by peer group, availability of a social network, cohesive family ties etc.[29]. Lin and Kleinman [32] 
suggested similar social (protective) factors and suggested that disabilities are generally more accepted in developing countries compared to western societies.

As stated before, there is only limited data and systematic research available from developing countries and there is not much information on the health consequences of cannabis use in developing countries. Therefore, the studies presented in this thesis that were conducted in Trinidad (chapter II, III, V) are of importance and show that cannabis is also frequently used among young people in this developed country and it also shows that, similar to findings in western-societies, cannabis before the age of 14 years may have a negative impact on mental health outcome $[33,34]$. Thus, this thesis confirms the importance of doing research in developing countries, and shows comparable findings that strengthen the earlier findings found in Western societies. This thesis confirms the converging evidence of the association between cannabis and psychosis, regardless of whether the studies are performed in western or non-western societies.

\section{On the pathway from cannabis to psychosis: biological mechanisms}

The biochemical mechanism by which cannabis exerts its psychotogenic effect is not fully understood yet. Delta-9-tetrahydrocannabinol is supposed to be its most psychotropic ingredient of cannabis. It binds to endogenous cannabinoid CB1 receptors which are most prevalent in specific brain regions such as striatum, cerebellum, and exist as a presynaptic receptor. Activation of this CB1 receptor inhibits neurotransmitter release such as gamma aminobutyric acid (GABA), glutamate, serotonin, dopamine and acetylcholine [35, 36]. Dopaminergic function is among other regulated by this GABAergic and glutamergic signalling [37, 38]. Most of the work on the neurobiology of psychosis focuses on alterations in the dopamine neurotransmitter system and this dopaminergic pathway is the most studied one [39]. The classic dopamine hypothesis assumes a hyperactivity in the dopaminergic system resulting in positive symptoms [40]. Nowadays it is also assumed that in prefrontal regions of the brain, not a hyperactivity but a reduced dopaminergic activity exists [41]. Exposure to THC has been found to acutely increase mesolimbic dopamine release [4246]. Bossong and colleagues investigated the acute effects of cannabis in healthy volunteers using Positron Emission Tomography and showed that inhalation of THC resulted in an immediate increase in dopamine in the ventral striatum [47]. Longer lasting exposure to cannabis has shown to be associated with increased density of cannabinoid receptors in the caudate-putamen [48,49]. Use of cannabis also shows alterations in the endocannabinoid signalling of the endogenous anadamide which is an important system that is involved in many physiological processes and which is also involved in the dopaminergic system [38]. So it seems that cannabis has a direct 
effect on the dopaminergic flow but also more indirectly by influencing the endocannabinoid signaling system.

Environmental risk factors for psychotic symptoms, such as cannabis, not only impact on dopaminergic systems, but it is nowadays more and more assumed that exposure to these risk factors results in alterations in myelination, synapse formation, immune systems and mitochondrial metabolism [37]. One study showed that patients using cannabis had, statistically significant, less frontal white matter volume compared to healthy controls [50]. Another study also showed that users of cannabis in a heavy way also had lower grey matter density in some hippocampal areas compared to non users [51].

The involvement of the dopaminergic system does not exist solely for exposure to cannabis, but exposure to traumatic experiences and stress also causes changes in the mesolimbic dopaminergic system. Several animal and human studies show that disturbances in the dopaminergic system are related to stress [52]. Studies using mice and rats show an increase in dopamine levels after exposure to acute stress [53-55] with chronic stress resulting in a reduction of the sensitivity in dopamine metabolism in these mice [53]. Several human studies also showed that exposure to chronic stress, such as childhood abuse, results in changes in the mesolimbic system but also in higher cortisol levels and hyperactivity in the hypothalamic-pituitaryadrenal axis [56-58] .

\section{On the pathway from cannabis to psychosis: adolescence}

Thus, the dopaminergic system seems to be involved in the aetiology of psychosis where the dopaminergic system shows changes after exposure to either cannabis or trauma. There seems to exist, however, developmentally sensitive periods meaning that exposure to risk factors during a certain period increases the risk of developing psychosis more strongly than is the case during other periods. The findings presented in chapter $V$ suggest that adolescence seems to be one of these sensitive periods. In this period the brain is still developing, in particular the region including the frontal cortex [59] where especially white matter connectivities are developing [60] and the endocannabinoid systems shows substantial changes [36]. Interestingly, animal studies have identified this period of adolescence as a sensitive period for cannabis exposure as well, as chronic exposure to THC in rodents was found to result in behavioural changes : there was a significant impairment in learning a maze. This effect on behaviour could not be found in rats which were exposed during adulthood. This indicates that the age of exposure may be of importance of psychic / behavioural outcome $[61,62]$. Another animal study showed the same 
results: chronic cannabis exposure in juvenile rats but not adult rats, resulted in less social play and social behaviour [63]. A very recent study showed that rats treated with THC at a younger age showed less performance in a complex operant task compared to the other groups who were exposed to THC at a later age [64].

In humans, literature on adolescent brain changes shows that the volume of grey matter increases during adolescence and starts to decrease in late puberty, in particular the frontal and parietal lobes $[65,66]$. A recent study in adolescents using diffusion tensor imaging, compared adolescents using cannabis and cannabis naïve adolescents in white matter structure. Adolescents using cannabis showed more white mater abnormalities, especially in the medial temporal and callosal pathways, compared to cannabis naïve adolescents. In addition, it was also found that younger ages of onset of cannabis use was associated with lower frontal white matter integrity, suggesting that earlier use may result in greater injury [67]. Another study with early cannabis users (before the age of 16 years) showed a significant impairment in reaction time compared to late onset cannabis users (after the age of 16 years) and controls [68]. Another study investigating adolescents, showed that exposure to cannabis during adolescence, resulted in impairments in learning and working memory $[69,70]$ and that these adolescents showed hypoactivity in the anterior cortex [71]. The endocannabinoid signalling system may be an important system since it plays an important role in regulating the neuroendocrine and behavioural effects of stress [72] and it also an important role during adolescent development, as it is involved in processes like neuronal migration, axonal guidance, fasciculation, positioning of cortical interneurons. Therefore alterations in this system caused by environmental factors can result in less efficient maturation and impaired functioning of the brain [36].

To summarize, evidence from both animal and human studies shows that exposure to cannabis can result in different effects where early adolescent cannabis use seems to be a critical period for cannabis exposure and may lead to enduring effects in the still developing brain during this period. More studies on the specific effects of cannabis on brain maturation during adolescence and its underlying biological mechanism are urgently needed given that cannabis use is very common especially among young people [73, 74].

\section{On the pathway from cannabis to psychosis: (cross)sensitization}

Previous studies show that genetic factors moderate the long-term effects of cannabis use on psychosis outcome $[75,76]$. The results presented in Chapter VI show that apart from genetic factors, interplay between environmental factors such as cannabis and trauma may determine an individual's sensitivity to cannabis as well. 
Recently, an interaction between two other environmental factors, urbanicity and cannabis exposure, was also shown in a longitudinal population based study, as in this study the effects of cannabis use were particularly detrimental to adolescents who were growing up in an urban environment [77] This data together with the findings from this thesis are suggestive of a process of cross-sensitization between cannabis and stress that my underlie the development of psychosis [78].

Sensitization is defined as a process in which early and repeated exposure to certain factors results in a progressively greater response over time, finally resulting in lasting changes in response amplitude $[79,80]$. This process of sensitization is a well known phenomenon from animal studies. In these studies, it is clear that intermittent administration of a drug like amphetamine causes long-lasting behavioural changes in response to a challenge dose of the drug [81, 82]. With respect to cannabis, there are only a few animal studies investigating sensitization processes following THC exposure. These studies are also summarized in chapter VI. In one study for example, rats pre-treated with THC were compared to THC-naïve rats in their response to THC. The pre-treated rats showed a significantly stronger behavioural response to THC compared to the THC-naïve rats [83]. In another study, rats were administered with THC or morphine and at 14-20 days following the last injection, the rats received either THC or morphine. Also here, rats pre-exposed to THC showed greater behavioural responses in response to the THC exposure than rats who were THC-naïve.

Indications for the sensitization process in animals were not only tested with drugs but also with exposure to stress. In one study, some rats were exposed to chronic stress and thereafter all animals were exposed to acute stress. Rats which were previously exposed to chronic stress and then exposed to acute stress, exhibited a greater increase in serotonin and noradrenalin in response to this acute stress, compared to rats which were not exposed to chronic stress [84]. An earlier study showed similar results : acutely stressed mice were re-exposed to even small stressors and these re-exposed rats showed higher amine levels compared to mice which were not pre-exposed to stress. So, the results of both studies suggest that repeated exposure to stress also may also lead, just like exposure to drugs, to a process of sensitization [85].

In humans, several studies have also shown that repeated exposure to a drug like amphetamine may result in sensitization : re-exposure to amphetamine resulted in increased behavioural and neuro-chemical responses (e.g. increased striatal dopamine release) $[86,87]$. A recent study showed that repeated administration of amphetamine resulted in hyperactivity of the prefrontal cortex, measured by functional magnetic resonance imaging. This change in the prefrontal cortex can also be 
found in patients with schizophrenia [88]. So, sensitization seems to be a common process in exposure to drugs.

With respect to stress, studies on humans have already shown that stress is an important factor in the aetiology of psychosis. It has been found that stress is associated with higher levels of symptomatology, in a dose response fashion, which is suggestive as well for a process of sensitization [89]. Not only major life events, but also smaller stressful events in daily life have been found to increase the risk for psychotic symptoms [89-91]. A prospective cohort study for example showed that even relatively mild traumatic experiences such as being bullied, can increase the risk of psychotic symptoms later in life [92]. In the study presented in Chapter VI of this thesis, a similar risk-enhancing effect of mild traumatic experiences was found as well. In addition, a dose-response association was found between "being spanked" in the Greek study and risk for psychotic symptoms since it was shown in this study that the more severe the childhood maltreatment, the more risk of developing psychosis ("often being spanked compared to "occasionally or never being spanked"), which is again suggestive for this process of sensitization [93-97].

A process of cross-sensitization between several kind of drugs has first been shown in animal studies, in which repeated exposure to one drug leads to sensitization to another drug. For example, rats which were previously exposed to methylphenidate (MPD) and than later exposed to amphetamine, showed more behavioural disturbances than those which were not pre-treated with MPD [98]. Another experiment with rats showed that pre-treatment with morphine affected the subsequent response to a systemic injection of amphetamine. The results were not only indicative of cross-sensitization between different types of drug, but, interestingly, also showed that the process of cross-sensitization was environment-specific. That is, cross sensitization to amphetamine was evident only in those animals that were tested in the environment where they had previously received morphine [99].

Other animal studies showed that repeated exposure to THC induced behavioural sensitization not only to cannabinoids but also to opiates, suggesting a similar process of cross-sensitization [100, 101].

Indication for cross sensitization has not only been shown between different drugs, but has also been shown in relation to stress. Rats which were placed in stressful situations, showed an increase in striatal dopamine uptake after administration of THC compared to the rats which were given THC in a non-stressful condition [102, 103].

In humans, studies on possible cross sensitization are rare. Therefore, cross sensitization between environmental risk factors were investigated in chapter VII, by ex- 
amining the psychotogenic effect of cannabis in persons with and without a history of (mild) traumatic experiences during childhood. In this study it was shown that being exposed to trauma during childhood moderated the long-term effect of cannabis on psychosis outcome in a dose-dependent, with more severe trauma being associated with the greatest effect of cannabis on psychosis later in life. This is one of the first studies in humans to show that a process of cross sensitization may underlie the development of psychosis.

In addition to the possible biological mechanisms, a process of psychological sensitization has also been suggested as playing a role in the emergence of psychotic symptoms. In psychological sensitization, it is thought that early exposure to environmental risk factors may shape specific negative beliefs about oneself and about others and such negative schemas may predispose an individual to attribute negative thoughts and believes to external rather than internal causes. It is shown in studies that subjects who have experienced traumatic events in early life indeed show more emotional reaction if exposed to stress [104] and they also show fewer strategies for coping with this stress which may result in non-clinical psychotic experiences [105].

To conclude, multiple factors (as well genetic as environmental) are involved in the development of psychotic symptoms. Figure 1 shows that in a very early stage genetic risk factors and pre and perinatal factors may increase an individual's vulnerability psychosis, whereas later risk factors (early childhood trauma) further impact on this liability. Subclinical psychotic experiences are not uncommon in adolescence (see this chapter) and are mostly transient. Repeated exposure to environmental risk factors can result in persistence of these subclinical psychotic symptoms and can also result in development of more severe psychotic symptoms and even clinical psychosis by the process of sensitization $[77,106]$. So, as in thesis was shown, exposure to cannabis in persons with early childhood maltreatment, show an increased risk in developing psychotic symptoms. A recent study by Kuepper and colleagues showed that growing up in an urban area also moderates the psychotogenic effect of cannabis : adolescents who grew up in a city were more likely to develop psychotic symptoms after use of cannabis compared to those who did not grow up in a city [77]. 


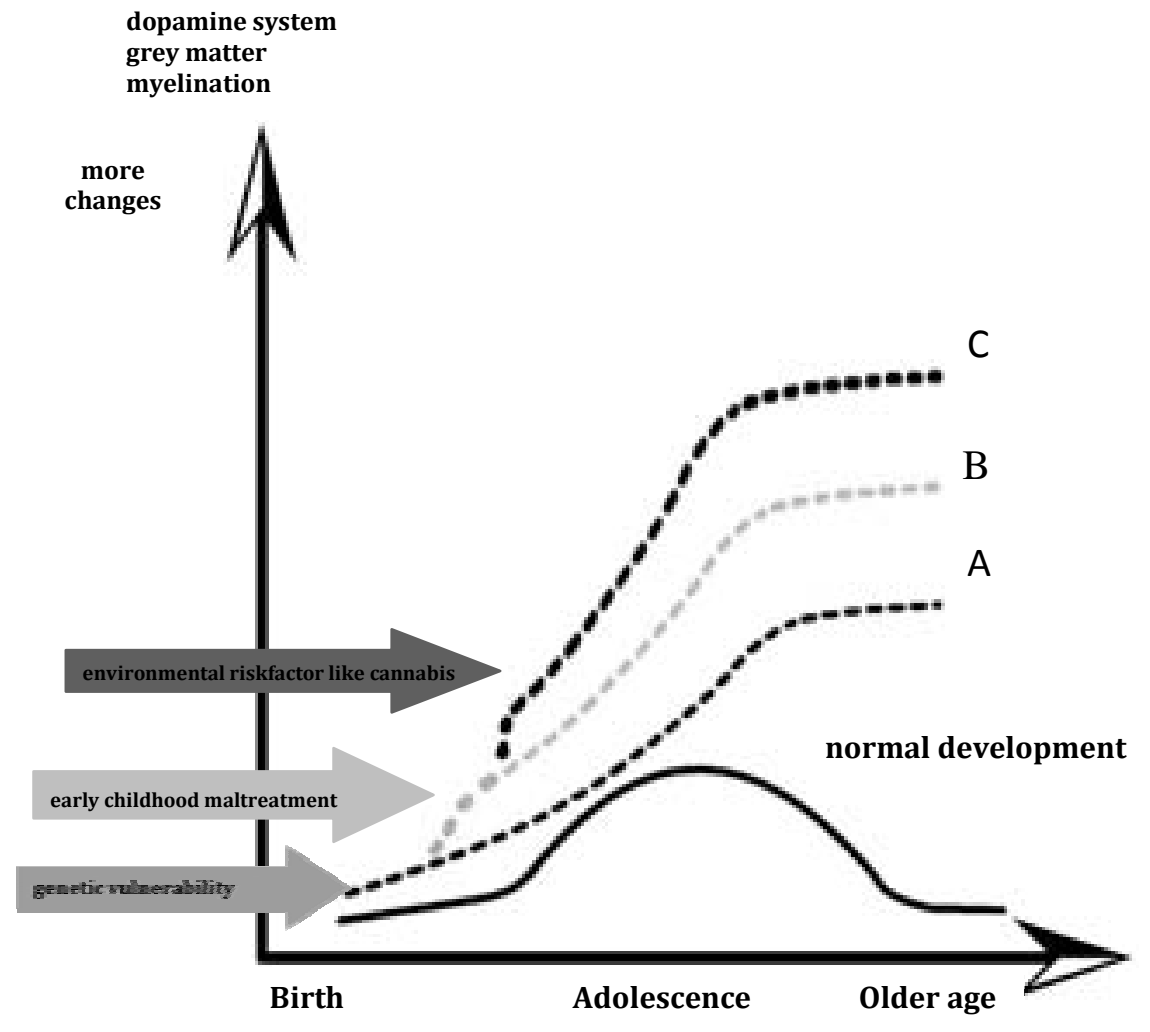

Figure 1: Schematic representations of the interaction between effect of exposure to several risk factors and increasing biological changes resulting in psychotic symptoms, partly adapted from Collip D. et al, Schizohr Bull 2008 34:220-225.
A : Elevated risk with only genetic vulnerability : more risk on persistence
B : Elevated risk after also early childhood trauma : even more risk on persistence
C : Elevated risk after exposure to also cannabis : highest risk on persistence of subclinical psychotic symptoms

\section{Clinical implications}

The present findings have several clinical implications. What is obvious is that cannabis is widely used among young people worldwide, both in developed countries and in more developing countries. Being exposed to cannabis increases the risk of psychosis, especially when individuals start to use it at an early age (before 14-15 years) (chapter $V)[33,34]$. Therefore, it is important to design specific prevention programmes aimed at young individuals specifically and to inform them about the possible risks involved in their cannabis use. Furthermore, special attention should 
be given to those young adolescents who experience subclinical psychotic symptoms while using cannabis.

Thus, special attention should be paid to young people within the general population who may be at increased risk for psychosis due to i) genetic factors (family history), ii) existence of subclinical psychotic experiences (is association or without cannabis use), iii) earlier experience of childhood trauma. Currently, world wide prevention and intervention programmes are available for young people using active methodologies such as interactive learning strategies. For example, in one prevention programme a combination of social resistance skills and general life skills was taught to junior high school children for at least 2 years. The results of this study showed that attendance to this programme resulted in a significant reduction of alcohol, tobacco and marihuana use [107]. Overall, meta-analysis evaluating such intervention programmes shows initial effectiveness in reducing the amount of users in cannabis $[108,109]$. Effect sizes however prove to be small, possibly due to methodological difficulties [110]. There is evidence that these prevention programmes also may be effective with respect to long-term effects after discontinuation of the programme, although evidence is less consistent [111].

As mentioned before, use of cannabis is specifically frequent in patients with a psychotic disorder. In addition, continued use of cannabis among patients has been found to be associated with a less favourable disease course [49], with more relapses, more positive symptoms and more continuity of the illness [112]. This stresses the importance for patients with psychosis to reduce their use of cannabis as early as possible, in order to limit the progression of the disease. For psychiatrists and other care workers, it is therefore important to inquire routinely about current and life time drug use. In training psychiatrists and therapists, more attention still needs to be given to assessment and treatments of the different substances. Studies on the effectiveness of treatment programs of comorbid substance use in psychotic patients are sparse. Several studies, however, have shown that programmes in which motivational interviewing, cognitive behavioural therapy and family intervention are integrated, are probably most effective [113, 114].

Research shows that only a small proportion of childhood traumas are identified by clinicians [115]. A large proportion of psychiatric patients (46\%) report a history of childhood sexual abuse while only a minority of this is revealed in case notes (14\%) [116]. It is therefore important to assess traumatic life events structurally, specifically in patients who use cannabis on a regular basis. This thesis shows that environmental factors enhancing the risk for psychosis by interacting with each other. Treatment should therefore aim at an integrated approach where attention is given to both diminishing cannabis use and treating trauma, while at the same time focussing on psychotic symptoms. A recent study in which this approach was used, 
showed that motivational interviewing for substances use in combination with individual and family cognitive behavioural therapy, was effective [117]. This thesis confirms the importance of combined treatment for people with a psychotic disorder since several environmental risk factors are intertwined in the disease and need to be treated concurrently with the psychotic symptoms.

\section{Directions for future research}

To conclude, the aim of this thesis is not to understand the full complexity of interaction between environmental factors in the risk of psychosis. This thesis confirms that cannabis is an important risk factor in psychosis world wide, whereby exposure to cannabis in combination with traumatic experiences during childhood trauma, increases this risk even more. For future research, it can be concluded that more research on the cross sensitization trauma - cannabis is needed. Our findings of interaction between early traumatic experiences and later cannabis use in two independent population-based samples (chapter $V I$ ) need to be further replicated in larger samples of adolescents, given the low incidences of childhood trauma. These studies should use a prospective design so possible retrospective bias can be avoided and the risk for environment - environment correlation is less. Therefore it would be interesting to conduct birth cohort studies where (early) traumatic experiences can be registered, age of initiation of cannabis use, dosage of use, frequency of use and the occurrence of psychotic symptoms are measured. In these studies, it can also be thought to use imaging techniques since it can be very useful to measure the degree of occupation of B1 receptors in an attempt to learn more of the effect of cannabis at different ages of initiation of use.

With these last findings, maybe more can be learned about whether the moderating effect of early exposure to cannabis is caused by longer duration of the exposure, or by exposure during a critical developmental phase (i.e. adolescence).

Another future study to test the interaction between stress and cannabis in the risk of developing psychosis can be to study several groups of healthy volunteers. Healthy volunteers are exposed to daily stress (tasks that enhance stress) and/ or use THC at the same time and compare them to volunteers who have not been exposed to THC and have been exposed to solely stress. Their reactions can be assessed at a behavioural level (symptoms) but also using imaging techniques is recommended, so more is learned again on biological processes.

It is also important that future research investigates the specific biological mechanisms of how cannabis and trauma interact in causing psychotic symptoms. The 
acute and long term effects of THC on dopaminergic neurotransmission needs to be further investigated, not only in animals but also in humans. These investigations should not only focus on THC, but also on the component cannabidiol (another constituent of cannabis), since recent research shows that this component can have an opposite effect and blocks the psychotogenic effect of THC [118] and reduces subjective anxiety [119].

The interaction between childhood trauma and cannabis use on psychosis risk need to be further explored, not only on the dopaminergic system but future research may wish to use more precise measurements to rate the specific type of trauma using biological markers of stress (e.g. diurnal cortisol levels) as well to further determine which specific type of trauma increases psychosis risk. In addition, other environmental factors need to be investigated, in order to determine whether they interact with cannabis as well to cause psychosis, for example urbanicity [120] or discrimination [121].

\section{Concluding word}

From this thesis, it can be concluded that cannabis is an independent risk factor in the development of psychosis. The fact that the psychotogenic effect of cannabis were also found in non western societies reinforces the strength of the cannabis psychosis association.

Cannabis use at a young age is especially associated with an elevated risk for psychosis. Cannabis use also increases the risk of experiencing subclinical psychotic symptoms. In addition, it was shown that for individuals who have been exposed to trauma earlier in life and then use cannabis later during adolescence, the risk of developing psychosis is much higher than in adolescent cannabis users who were not exposed to childhood trauma. A process of cross-sensitization has been proposed to underlie this finding, probably through mediation of a hypersensitive mesolimbic dopamine system. This implies that the aetiology of psychosis is characterized by a complex set of interactions between multiple genetic and environmental factors that may act from very early in development onwards. Exposure to environmental factors later in life (like use of cannabis) may then further enhance the psychosis vulnerability by promoting persistence of subclinical psychotic experiences, finally leading to the development of clinical psychosis. 


\section{References}

1. Johns, L.C. and J. van Os, The continuity of psychotic experiences in the general population. Clinical Psychology Review 2001. 21(8): p. 1125-41.

2. Hanssen, M., et al., The incidence and outcome of subclinical psychotic experiences in the general population. British Journal of Clinical Psychology 2005. 44(Pt 2): p. 181-91.

3. Peters, E.R., S.A. Joseph, and P.A. Garety, Measurement of delusional ideation in the normal population: introducing the PDI (Peters et al. Delusions Inventory). Schizophr Bull, 1999. 25(3): p. 553-76.

4. Rossler, W., et al., Psychotic experiences in the general population: a twenty-year prospective community study. Schizophrenia Research, 2007. 92(1-3): p. 1-14.

5. Miller, P.M., et al., Self-rated schizotypal cognitions, psychotic symptoms and the onset of schizophrenia in young people at high risk of schizophrenia. Acta Psychiatrica Scandinavica, 2002. 105(5): p. 341-5.

6. Chapman, L.J., et al., Putatively psychosis-prone subjects 10 years later. J Abnorm Psychol, 1994. 103(2): p. 171-83.

7. Poulton, R., et al., Children's self-reported psychotic symptoms and adult schizophreniform disorder: a 15-year longitudinal study. Archives of General Psychiatry, 2000. 57(11): p. 1053-8.

8. Loch, A.A., et al., The psychosis continuum in the general population: findings from the Sao Paulo Epidemiologic Catchment Area Study. Eur Arch Psychiatry Clin Neurosci, 2011.

9. van Heerden, M.S., et al., Patterns of substance use in South Africa: results from the South African Stress and Health study. S Afr Med J, 2009. 99(5 Pt 2): p. 358-66.

10. Dissabandara, L.O., et al., Patterns of substance use in male incarcerated drug users in Sri Lanka. Drug Alcohol Rev, 2009. 28(6): p. 600-7.

11. Addiction, E.M.C.f.D.a.D., Annual report 2010: the state of the drugs problem in Europe Cannabis. annual report, 2010: p. retrieved May 4, 2011 from http://www.emcdda.europe.eu/online/anualreport/2010/cannabis/3.

12. Sanches, R.F. and J.M. Marques, [Cannabis and mood]. Revista Brasileira de Psiquiatria, 2010. 32(2): p. $173-80$.

13. Henquet, C., et al., Cannabis use and expression of mania in the general population. Journal of Affective Disorders 2006. 95(1-3): p. 103-10.

14. Bovasso, G.B., Cannabis abuse as a risk factor for depressive symptoms. Am J Psychiatry, 2001. 158(12): p. 2033-7.

15. Rossow, I., K. Hawton, and M. Ystgaard, Cannabis use and deliberate self-harm in adolescence: a comparative analysis of associations in England and Norway. Archives of Suicide Research, 2009. 13(4): p. 340-8.

16. Pedersen, W., Does cannabis use lead to depression and suicidal behaviours? A population-based longitudinal study. Acta Psychiatrica Scandinavica, 2008. 118(5): p. 395-403.

17. Pope, H.G., Jr., et al., Early-onset cannabis use and cognitive deficits: what is the nature of the association? Drug Alcohol Depend, 2003. 69(3): p. 303-10.

18. Solowij, N., et al., Cognitive functioning of long-term heavy cannabis users seeking treatment. JAMA, 2002. 287(9): p. 1123-31.

19. Patton, G.C., et al., Cannabis use and mental health in young people: cohort study. BMJ, 2002. 325(7374): p. 1195-8.

20. Peralta, V. and M.J. Cuesta, Dimensional structure of psychotic symptoms: an item-level analysis of SAPS and SANS symptoms in psychotic disorders. Schizophr Res, 1999. 38(1): p. 13-26.

21. Morgan, C.J., et al., Impact of cannabidiol on the acute memory and psychotomimetic effects of smoked cannabis: naturalistic study: naturalistic study [corrected]. Br J Psychiatry, 2010. 197(4): p. 285-90.

22. Hutchinson, G., et al., Factor analysis of symptoms in schizophrenia: differences between White and Caribbean patients in Camberwell. Psychological Medicine, 1999. 29(3): p. 607-12. 
23. Arnold, L.M., et al., Ethnicity and first-rank symptoms in patients with psychosis. Schizophr Res, 2004. 67(2-3): p. 207-12.

24. Selten, J.P., et al., Psychosis risk for parents and siblings of Dutch and Moroccan-Dutch patients with non-affective psychotic disorder. Schizophrenia Research, 2008. 104(1-3): p. 274-8.

25. Sugarman, P.A. and D. Craufurd, Schizophrenia in the Afro-Caribbean community. Br J Psychiatry, 1994. 164(4): p. 474-80.

26. Hutchinson, G., et al., Morbid risk of schizophrenia in first-degree relatives of white and AfricanCaribbean patients with psychosis. British Journal of Psychiatry, 1996. 169(6): p. 776-80.

27. Veling, W., et al., Discrimination and the incidence of psychotic disorders among ethnic minorities in The Netherlands. Int J Epidemiol, 2007. 36(4): p. 761-8.

28. Jablensky, A., Epidemiology of schizophrenia: the global burden of disease and disability. European Archives of Psychiatry and Clinica Neuroscience, 2000. 250(6): p. 274-85.

29. Kulhara, P., Outcome of schizophrenia: some transcultural observations with particular reference to developing countries. European Archives of Psychiatry and Clinical Neuroscience 1994. 244(5): p. 227-35.

30. Patel, V., et al., Is the outcome of schizophrenia really better in developing countries? Rev Bras Psiquiatr, 2006. 28(2): p. 149-52.

31. Leff, J., et al., The International Pilot Study of Schizophrenia: five-year follow-up findings. Psychological Medicine, 1992. 22(1): p. 131-45.

32. Lin, K.M. and A.M. Kleinman, Psychopathology and clinical course of schizophrenia: a cross-cultural perspective. Schizophrenia Bulletin, 1988. 14(4): p. 555-67.

33. Stefanis, N.C., et al., Early adolescent cannabis exposure and positive and negative dimensions of psychosis. Addiction, 2004. 99(10): p. 1333-41.

34. Arseneault, L., et al., Cannabis use in adolescence and risk for adult psychosis: longitudinal prospective study. British Medical Journal, 2002. 325(7374): p. 1212-3.

35. Freund, T.F., I. Katona, and D. Piomelli, Role of endogenous cannabinoids in synaptic signaling. Physiol Rev, 2003. 83(3): p. 1017-66.

36. Malone, D.T., M.N. Hill, and T. Rubino, Adolescent cannabis use and psychosis: epidemiology and neurodevelopmental models. Br J Pharmacol, 2010. 160(3): p. 511-22.

37. van Os, J., G. Kenis, and B.P. Rutten, The environment and schizophrenia. Nature, 2010. 468(7321): p. 203-12.

38. Leweke, F.M., et al., Anandamide levels in cerebrospinal fluid of first-episode schizophrenic patients: impact of cannabis use. Schizophrenia Research, 2007. 94(1-3): p. 29-36.

39. Kuepper, R., et al., Does dopamine mediate the psychosis-inducing effects of cannabis? A review and integration of findings across disciplines. Schizophrenia Research, 2010. 121(1-3): p. 107-17.

40. Kapur, S., Psychosis as a state of aberrant salience: a framework linking biology, phenomenology, and pharmacology in schizophrenia. American Journal of Psychiatry, 2003. 160(1): p. 13-23.

41. Murray, R.M. and S.W. Lewis, Is schizophrenia a neurodevelopmental disorder? Br Med J (Clin Res Ed), 1987. 295(6600): p. 681-2.

42. Voruganti, L.N., et al., Cannabis induced dopamine release: an in-vivo SPECT study. Psychiatry Research, 2001. 107(3): p. 173-7.

43. Gessa, G.L., et al., Cannabinoids activate mesolimbic dopamine neurons by an action on cannabinoid CB1 receptors. Eur J Pharmacol, 1998. 341(1): p. 39-44.

44. Chen, J., et al., Delta 9-tetrahydrocannabinol enhances presynaptic dopamine efflux in medial prefrontal cortex. Eur J Pharmacol, 1990. 190(1-2): p. 259-62.

45. Tanda, G., F.E. Pontieri, and G. Di Chiara, Cannabinoid and heroin activation of mesolimbic dopamine transmission by a common mu1 opioid receptor mechanism. Science, 1997. 276(5321): p. 2048-50.

46. Bossong, M.G., et al., Delta9-Tetrahydrocannabinol Induces Dopamine Release in the Human Striatum. Neuropsychopharmacology, 2008.

47. Bossong, M.G., et al., Delta 9-tetrahydrocannabinol induces dopamine release in the human striatum. Neuropsychopharmacology, 2009. 34(3): p. 759-66. 
48. Dean, B., et al., Studies on [3H]CP-55940 binding in the human central nervous system: regional specific changes in density of cannabinoid-1 receptors associated with schizophrenia and cannabis use. Neuroscience, 2001. 103(1): p. 9-15.

49. van Os, J., et al., Cannabis use and psychosis: a longitudinal population-based study. American Journal of Epidemiology, 2002. 156(4): p. 319-27.

50. Schlaepfer, T.E., et al., Decreased frontal white-matter volume in chronic substance abuse. Int J Neuropsychopharmacol, 2006. 9(2): p. 147-53.

51. Matochik, J.A., et al., Altered brain tissue composition in heavy marijuana users. Drug Alcohol Depend, 2005. 77(1): p. 23-30.

52. Cabib, S. and S. Puglisi-Allegra, Stress, depression and the mesolimbic dopamine system. Psychopharmacology (Berl), 1996. 128(4): p. 331-42.

53. Cabib, S., et al., Different effects of acute and chronic stress on two dopamine-mediated behaviors in the mouse. Physiol Behav, 1988. 43(2): p. 223-7.

54. Finlay, J.M., M.J. Zigmond, and E.D. Abercrombie, Increased dopamine and norepinephrine release in medial prefrontal cortex induced by acute and chronic stress: effects of diazepam. Neuroscience, 1995. 64(3): p. 619-28.

55. Abercrombie, E.D., et al., Differential effect of stress on in vivo dopamine release in striatum, nucleus accumbens, and medial frontal cortex. Journal of Neurochemistry, 1989. 52(5): p. 1655-8.

56. Heim, C., et al., Pituitary-adrenal and autonomic responses to stress in women after sexual and physical abuse in childhood. JAMA, 2000. 284(5): p. 592-7.

57. Carpenter, L.L., et al., Decreased adrenocorticotropic hormone and cortisol responses to stress in healthy adults reporting significant childhood maltreatment. Biol Psychiatry, 2007. 62(10): p. 1080-7.

58. Walker, E., V. Mittal, and K. Tessner, Stress and the hypothalamic pituitary adrenal axis in the developmental course of schizophrenia. Annu Rev Clin Psychol, 2008. 4: p. 189-216.

59. Paus, T., et al., Structural maturation of neural pathways in children and adolescents: in vivo study. Science, 1999. 283(5409): p. 1908-11.

60. Lubman, D.I., M. Yucel, and W.D. Hall, Substance use and the adolescent brain: a toxic combination? J Psychopharmacol, 2007. 21(8): p. 792-4.

61. Stiglick, A. and H. Kalant, Residual effects of chronic cannabis treatment on behavior in mature rats. Psychopharmacology (Berl), 1985. 85(4): p. 436-9.

62. Stiglick, A. and H. Kalant, Learning impairment in the radial-arm maze following prolonged cannabis treatment in rats. Psychopharmacology (Berl), 1982. 77(2): p. 117-23.

63. Schneider, M. and M. Koch, Deficient social and play behavior in juvenile and adult rats after neonatal cortical lesion: effects of chronic pubertal cannabinoid treatment. Neuropsychopharmacology, 2005. 30(5): p. 944-57.

64. Wiley, J.L. and J.J. Burston, Chronic Delta9-tetrahydrocannabinol during adolescence increases sensitivity to subsequent cannabinoid effects in delayed nonmatch-to-position in rats. Pharmacology Biochemistry \& Behavior 94(4): p. 516-23.

65. Giedd, J.N., et al., Brain development during childhood and adolescence: a longitudinal MRI study. Nat Neurosci, 1999. 2(10): p. 861-3.

66. Paus, T., M. Keshavan, and J.N. Giedd, Why do many psychiatric disorders emerge during adolescence? Nat Rev Neurosci, 2008. 9(12): p. 947-57.

67. Yucel, M., et al., White-matter abnormalities in adolescents with long-term inhalant and cannabis use: a diffusion magnetic resonance imaging study. J Psychiatry Neurosci. 35(6): p. 409-12.

68. Ehrenreich, H., et al., Specific attentional dysfunction in adults following early start of cannabis use. Psychopharmacology (Berl), 1999. 142(3): p. 295-301.

69. Schweinsburg, A.D., S.A. Brown, and S.F. Tapert, The influence of marijuana use on neurocognitive functioning in adolescents. Curr Drug Abuse Rev, 2008. 1(1): p. 99-111.

70. Bartholomew, J., S. Holroyd, and T.M. Heffernan, Does cannabis use affect prospective memory in young adults? J Psychopharmacol. 24(2): p. 241-6. 
71. Hester, R., L. Nestor, and H. Garavan, Impaired error awareness and anterior cingulate cortex hypoactivity in chronic cannabis users. Neuropsychopharmacology, 2009. 34(11): p. 2450-8.

72. Hill, M.N. and B.S. McEwen, Involvement of the endocannabinoid system in the neurobehavioural effects of stress and glucocorticoids. Prog Neuropsychopharmacol Biol Psychiatry, 2010. 34(5): p. 791-7.

73. Beck, F. and S. Legleye, [Sociology and epidemiology of consumption of psychoactive substances in adolescents]. Encephale, 2009. 35 Suppl 6: p. S190-201.

74. Falkowski, C., Trends in drug abuse among Minnesota youths. Minn Med, 2010. 93(9): p. 47-50.

75. van Winkel, R., Family-based analysis of genetic variation underlying psychosis-inducing effects of cannabis: sibling analysis and proband follow-up. Arch Gen Psychiatry, 2011. 68(2): p. 148-57.

76. Henquet, C., et al., Gene-environment interplay between cannabis and psychosis. Schizophrenia Bulletin, 2008. 34(6): p. 1111-21.

77. Kuepper, R., et al., Do cannabis and urbanicity co-participate in causing psychosis? Evidence from a 10-year follow-up cohort study. Psychol Med, 2011: p. 1-9.

78. Henquet, C., et al., Gene-environment interplay between cannabis and psychosis. Schizophr Bull, 2008. 34(6): p. 1111-21.

79. Collip, D., I. Myin-Germeys, and J. Van Os, Does the concept of "sensitization" provide a plausible mechanism for the putative link between the environment and schizophrenia? Schizophrenia Bulletin, 2008. 34(2): p. 220-5.

80. van Os, J., et al., [A psychosis proneness-persistence-impairment model of psychotic disorders]. Tijdschr Psychiatr, 2008. 50 Spec no.: p. 77-83.

81. Akimoto, K., et al., Enhanced extracellular dopamine level may be the fundamental neuropharmacological basis of cross-behavioral sensitization between methamphetamine and cocaine--an in vivo dialysis study in freely moving rats. Brain Res, 1990. 507(2): p. 344-6.

82. Kilbey, M.M. and E.H. Ellinwood, Jr., Reverse tolerance to stimulant-induced abnormal behavior. Life Science, 1977. 20(6): p. 1063-75.

83. Rubino, T., et al., The psychoactive ingredient of marijuana induces behavioural sensitization. Eur J Neurosci, 2001. 14(5): p. 884-6.

84. Adell, A., et al., Chronic stress increases serotonin and noradrenaline in rat brain and sensitizes their responses to a further acute stress. Journal of Neurochemistry, 1988. 50(6): p. 1678-81.

85. Irwin, J., P. Ahluwalia, and H. Anisman, Sensitization of norepinephrine activity following acute and chronic footshock. Brain Research, 1986. 379(1): p. 98-103.

86. Featherstone, R.E., S. Kapur, and P.J. Fletcher, The amphetamine-induced sensitized state as a model of schizophrenia. Prog Neuropsychopharmacol Biol Psychiatry, 2007. 31(8): p. 1556-71.

87. Paulson, P.E. and T.E. Robinson, Amphetamine-induced time-dependent sensitization of dopamine neurotransmission in the dorsal and ventral striatum: a microdialysis study in behaving rats. Synapse, 1995. 19(1): p. 56-65.

88. O'Daly, O.G., et al., Functional magnetic resonance imaging investigation of the amphetamine sensitization model of schizophrenia in healthy male volunteers. Arch Gen Psychiatry, 2011. 68(6): p. 54554.

89. Janssen, I., et al., Childhood abuse as a risk factor for psychotic experiences. Acta Psychiatrica Scandinavica, 2004. 109(1): p. 38-45.

90. Monroe, S.M., Major and minor life events as predictors of psychological distress: further issues and findings. Journal of Behavioral Medicine 1983. 6(2): p. 189-205.

91. Kanner, A.D., et al., Comparison of two modes of stress measurement: daily hassles and uplifts versus major life events. International Journal of Behavioral Medicine 1981. 4(1): p. 1-39.

92. Schreier, A., et al., Prospective study of peer victimization in childhood and psychotic symptoms in a nonclinical population at age 12 years. Archives of General Psychiatry, 2009. 66(5): p. 527-36.

93. Carr, V., et al., A risk factor screening and assessment protocol for schizophrenia and related psychosis. Australian and New Zealand Journal of Psychiatry 2000. 34 Suppl: p. S170-80. 
94. Bebbington, P., et al., Life events and psychosis. Initial results from the Camberwell Collaborative Psychosis Study. British Journal of Psychiatry, 1993. 162: p. 72-9.

95. Shevlin, M., et al., Cumulative traumas and psychosis: an analysis of the national comorbidity survey and the British Psychiatric Morbidity Survey. Schizophrenia Bulletin, 2008. 34(1): p. 193-9.

96. Norman, R.M. and A.K. Malla, Stressful life events and schizophrenia. II: Conceptual and methodological issues. British Journal of Psychiatry, 1993. 162: p. 166-74.

97. Ventura, J., et al., Life events can trigger depressive exacerbation in the early course of schizophrenia. J Abnorm Psychol, 2000. 109(1): p. 139-44.

98. Yang, P.B., A.C. Swann, and N. Dafny, Chronic pretreatment with methylphenidate induces crosssensitization with amphetamine. Life Sci, 2003. 73(22): p. 2899-911.

99. Vezina, P., et al., Environment-specific cross-sensitization between the locomotor activating effects of morphine and amphetamine. Pharmacol Biochem Behav, 1989. 32(2): p. 581-4.

100.Cadoni, C., et al., Behavioural sensitization after repeated exposure to Delta 9-tetrahydrocannabinol and cross-sensitization with morphine. Psychopharmacology (Berl), 2001. 158(3): p. 259-66.

101.Cadoni, C., V. Valentini, and G. Di Chiara, Behavioral sensitization to delta 9-tetrahydrocannabinol and cross-sensitization with morphine: differential changes in accumbal shell and core dopamine transmission. Journal of Neurochemistry, 2008. 106(4): p. 1586-93.

102.Littleton, J.M., K.I. Maclean, and G. Brownlee, Proceedings: Alterations in dopamine uptake in rat corpus striatum induced by combinations of stress and delta8-tetrahydrocannabinol (delta8-THC). British Journal of Pharmacology 1976. 56(3): p. 370P.

103.MacLean, K.I. and J.M. Littleton, Environmental stress as a factor in the response of rat brain catecholamine metabolism to delta8-tetrahydrocannabinol. European Journal of Pharmacology 1977. 41(2): p. 171-82.

104.Glaser, J.P., et al., Childhood trauma and emotional reactivity to daily life stress in adult frequent attenders of general practitioners. Journal of Psychosomatic Research, 2006. 61(2): p. 229-36.

105.Bak, M., et al., Early trauma may increase the risk for psychotic experiences by impacting on emotional response and perception of control. Acta Psychiatr Scand, 2005. 112(5): p. 360-6.

106. Cougnard, A., et al., Does normal developmental expression of psychosis combine with environmental risk to cause persistence of psychosis? A psychosis proneness-persistence model. Psychological Medicine, 2007. 37(4): p. 513-27.

107. Botvin, G.J., et al., Long-term follow-up results of a randomized drug abuse prevention trial in a white middle-class population. JAMA, 1995. 273(14): p. 1106-12.

108.Chou, C.P., et al., Effects of a community-based prevention program on decreasing drug use in highrisk adolescents. Am J Public Health, 1998. 88(6): p. 944-8.

109.Palmer, R.F., et al., Applying multilevel analytic strategies in adolescent substance use prevention research. Prev Med, 1998. 27(3): p. 328-36.

110.Fernandez, S., M. Nebot, and M. Jane, [The evaluation of effectiveness of scholastic programs in the prevention of consumption of tobacco, alcohol and cannabis: what do meta-analyses tell us?]. Rev Esp Salud Publica, 2002. 76(3): p. 175-87.

111.Skara, S. and S. Sussman, A review of 25 long-term adolescent tobacco and other drug use prevention program evaluations. Prev Med, 2003. 37(5): p. 451-74.

112.Grech, A., et al., Cannabis use and outcome of recent onset psychosis. European Psychiatry, 2005. 20(4): p. 349-53.

113.Barrowclough C, H.G., Tarrier N, Lewis SW, Moring J, O’Brien R, Schofield N, McGovern J., Randomized controlled trial ofmotivational interviewing, cognitive behavior therapy, and familiy intervention fo patients with comorbis schizophrenia an substance use disorders. . Am J Psychiatry, 2001. 158(10): p. $1706-13$.

114. Hjorthoj C, F.A., Nordentoft M. , Treatment of cannabis use disorders in people with schizophrenia spectrum disorders - a systematic review. Addictive Behaviors., 2009. 34(6-7): p. 520 - 5.

115.Wurr, C.J. and I.M. Partridge, The prevalence of a history of childhood sexual abuse in an acute adult inpatient population. Child Abuse Negl, 1996. 20(9): p. 867-72. 
116. Wurr CJ, P.I., The prevalence of a history of childhood sexual abuse in an acute adult inpatient population. Child Abuse \& Neglect, 1996. 20: p. 867 - 872.

117.Barrowclough, C., et al., Evaluating integrated MI and CBT for people with psychosis and substance misuse: recruitment, retention and sample characteristics of the MIDAS trial. Addict Behav, 2009. 34(10): p. 859-66.

118. Bhattacharyya, S., et al., Opposite effects of delta-9-tetrahydrocannabinol and cannabidiol on human brain function and psychopathology. Neuropsychopharmacology, 2010. 35(3): p. 764-74.

119.Fusar-Poli, P., et al., Distinct effects of \{delta\}9-tetrahydrocannabinol and cannabidiol on neural activation during emotional processing. Arch Gen Psychiatry, 2009. 66(1): p. 95-105.

120.Marcelis, M., et al., Urbanization and psychosis: a study of 1942-1978 birth cohorts in The Netherlands. Psychologica Medicine, 1998. 28(4): p. 871-9.

121.Morgan, C., et al., Migration, Ethnicity, and Psychosis: Toward a Sociodevelopmental Model. Schizophrenia Bulletin, 2010. may 30. 
CHAPTER VIII

Summary 

Over the past two decades, research after and insight in the causal mechanisms underlying psychotic disorders has increased significantly. Multiple environmental and genetic factors have now been identified that are involved in the development of psychotic symptoms and illnesses. This thesis, cross-cultural studies on adolescent cannabis use and psychosis, investigates the association between adolescent cannabis use and risk on developing psychosis. Exposure to cannabis, especially its psychotogenic part $\Delta$-9-tetrahydrocannabinol (THC), has been shown to increase the risk for psychosis. This thesis confirms that cannabis is one of these environmental factors that increase psychosis risk, where this thesis investigates this association in a broader perspective by investigating this association in a developing country, Trinidad. More specifically, the results presented in this thesis confirm that cannabis is the most widely used illicit substance worldwide, especially among young adolescents, both in western and non-westerns societies.

Only a minority of cannabis users however, develop psychosis, which suggests that cannabis is neither a sufficient nor a necessary cause, but is maybe a component cause that impacts on the risk to develop psychotic symptoms in codependence with other factors. Another aim of this thesis therefore is to investigate the interaction of early childhood trauma with later cannabis use on the risk on psychosis. This thesis combines descriptive (chapter II, III), observational (chapter $V$ ) and epidemiological (chapter VI) studies.

Chapter I describes the etiology and phenomenology of psychosis. It describes the short and long term effects of cannabis and its psychoactive component $\Delta$-9tetrahydrocannabinol by summarizing and mentioning different studies who show this short and long term effect of cannabis on psychotic symptoms. Another environmental risk factor is thought to be early childhood trauma, and an overview of literature on childhood trauma as a risk factor for developing psychosis is presented.

In this thesis, studies are done in Trinidad and Tobago, a developing country and a non-western society. Cultural aspects of research on psychosis are described and examined. Its importance is emphasized since more information on the prevalence of psychosis, and possible differences in this, may give more information on the role of culture specific environmental factors that moderate the risk for psychosis. In this chapter, studies on adolescence and appearance of psychotic symptoms are further described since cannabis use is prevalent among young people. Adolescence and early adulthood appear to be critical periods for development of the brain where exposure to toxic substances like cannabis, may cause changes in, amongst other things, the frontal cortex of the brain. It is argued that the cannabinoid 1 (CB1) receptors, where endogenous cannabinoids bind, are involved. This cannabinoid system is involved in regulation of the dopamine system, and dysregu- 
lation of this dopaminergic system is supposed to be involved in the etiology of psychosis.

Chapter II investigates the lifetime and current use of cannabis and alcohol in two contrasting school systems in Trinidad. This is done in order to investigate possible differences in patterns of use in a developing country and a non-western society. Cannabis use is prominent in these different schools in Trinidad (including governmental schools and schools aimed at practicing with more children present with learning disabilities). The lifetime prevalence of cannabis is shown to be high in Trinidad, with no statistical differences in the two different school systems. It is shown that one at three children in Trinidad have used cannabis at least once in their life's. Current cannabis use is shown to be high in vocational schools (one at 4) where in governmental schools this is more low (one at 20). A possible explanation for this are the differences in the school systems and therefore the kind of adolescents who attend these schools. Children in Trinidad seem to start using cannabis at a young age: a mean age of first cannabis use is found to be around 13 years. So, this study provides insight into use of cannabis in young people in a non-western society within a broader range of school types. This study shows that use of cannabis is also very common in non-western societies and it shows that these rates are comparable with the more investigated, western-societies. Since cannabis is shown to be psychotogenic and since cannabis is also associated with other psychiatric symptoms, like mood symptoms and suicidal thoughts, these findings emphasizes the importance of decreasing the use of cannabis in young people, worldwide.

Chapter III investigates the hypothesis that cannabis is not only involved in psychotic symptoms, but that exposure to cannabis may also result in more affective symptoms like depressive and manic symptoms. In this descriptive study, data are collected from ambulatory psychiatric patients in Trinidad, and five cases with different patterns of cannabis use are described. The clinical, phenomenological, presentations of psychiatric symptoms appear to be determined by dosages, frequency, duration of cannabis use and also use of other drugs than cannabis. It is shown that exposure to cannabis during early and late adolescence can result in different kind of symptoms like anxiety-, mood- and psychotic symptoms and also suicidal ideation. This chapter shows the prevalence of different kind of psychiatric symptoms in users of cannabis in this developing country where not only psychotic but also affective symptoms and suicidal thoughts are common findings in cannabis users in Trinidad and Tobago. It supports the hypothesis of the existence of a continuum in psychosis. In this continuum model, psychiatric symptoms are not considered to be present as an all or none phenomenon but are instead present in the general population along a continuum, as so called subclinical experiences. These subclinical psychotic experiences seem to be milder forms of expression of psychosis and seem 
to share the same risk factors as clinical psychosis. It is thought that exposure to different (environmental) risk factors can result in an individual to move from subclinical symptoms to more clinical symptoms. For example, the expression of symptoms after exposure to cannabis seems in this study determined by the different patterns of cannabis use. So it seems that genetic and environmental (risk) factors may interfere and finally determine the kind of symptoms one individual develops after using cannabis.

Chapter IV further investigates the above-mentioned hypothesis of the continuum of psychosis. It is thought that subclinical psychotic experiences can be measured in the general population and mostly self-report instruments are used for this. The aim of this chapter is to investigate reliability and stability of the Community Assessment of Psychic Experiences (CAPE42), a scale to investigate psychotic experiences in the general population. For this study, data on a longitudinal family study in the general population in a city in the Netherlands are used. At different time points, different scales (CAPE, Structured Interview for Schizotypy Revised (SIS-R) and Brief Psychiatric Rating Scale (BPRS)) are used to measure psychotic symptoms (at T1: only CAPE is used, at T2: CAPE, SIS-R, BPRS). The reliability and stability of the CAPE dimensions is tested by applying linear regression analyses of the different CAPE dimensions at these two different time points. The effect sizes for this internal stability are shown to be high $(0.6-0.8)$. These high scores indicate that the self reported dimensions of the psychotic experiences at baseline (T1) are strongly associated with the same dimensions at follow-up (T2), implying a good reliability of the CAPE.

The validity of the CAPE is tested by examining the associations between dimension of the CAPE at T1 and dimensions of the two already validated interview based scales: SIS-R and BPRS at T2. It is shown that these baseline self-reported positive and negative dimensions of the CAPE are associated in a dose-response fashion with the two scales at follow up, indicating a good validity for the CAPE. So, it is concluded that the CAPE is well applicable as a self-report instrument to assess different dimensions of psychotic experiences in the general population and it appears to be a stable, valid and reliable instrument.

Chapter $\mathbf{V}$ describes a population based, cross-sectional study that was carried out in Trinidad as well. Here scholars (aged $12-23$ year) are asked to complete questionnaires on use of cannabis and age of onset and they also filled in the CAPE. It is found that individuals, who had started to use cannabis before the age of 14, had a, statistically significant, increased risk to develop psychotic symptoms. This statistically significant finding also remains after adjusting for possible confounding factors like age, school type, ethnicity, sex, current use of cannabis and use of other drugs. This increased risk is not observed for the individuals who start to use cannabis after 
the age of 14 years. The results of this study, in this non-western society, confirms two earlier epidemiological studies (in well-developed countries) that early onset of cannabis use is associated with a greater risk to develop psychotic symptoms than later onset of use. These studies all imply that the risk of exposure to cannabis may be of developmental nature where age of use of cannabis is important and early use of cannabis may impact differently on the brain, with more detrimental impact with earlier use.

It is described in this chapter that indications for this hypothesis of different detrimental impact on the brain can be found in animal studies, where exposure to THC induce behavioural and cognitive changes in rats in their puberty but not in adult rats. Again the endocannabinoid and dopamine system are mentioned as possible explanation for the existence of such a vulnerable period. Especially during puberty synaptic dopamine activity in the prefrontal cortex (which is an important area since it seems involved in the etiology of psychosis) changes and this area is vulnerable for toxic factors like cannabis.

Chapter VI describes an epidemiological study of two different data sets (the Greek National Perinatal Study and the Dutch NEMESIS study) to investigate that exposure to different environmental risk factors may enhance the risk to develop psychosis far more compared to exposure to one risk factor. For this, in these two different data sets, the elevated risk for psychosis is calculated for individuals who have experienced early childhood maltreatment combined with or without later exposure to cannabis. It was found that an interaction between childhood maltreatment and later cannabis use is evident and this also shows statistical significance. So individuals who have experienced early childhood trauma and who use cannabis later in their lives, show a greater risk for developing psychotic symptoms compared to those who are either exposed alone to cannabis and early trauma or who are exposed to neither. It is unlikely that processes like mediation (traumatized young people have a higher risk of starting to use cannabis) play a significant role because only in the Dutch NEMESIS study and not in the Greek study, there is a significant but small association between childhood trauma and later cannabis use. These findings are in accordance with two other studies where interaction between childhood trauma and early cannabis use is also reported. In this chapter, the model of cross-sensitization is presented and further explored as possible mechanism for these findings. In this model, people become increasingly sensitive to the toxic effects of e.g. cannabis after exposure to childhood trauma. Proof for the model of (cross)sensitization is found in different animal studies and studies on other drugs use and these studies are described in this chapter. Also studies on cannabis suggest this mechanism where longer exposure to cannabis increases the risk for psychosis in a dose-response fashion suggesting this role of sensitization. The current finding that the psychosis-inducing effects of cannabis are moderated by early experience 
of childhood maltreatment suggests that cross-sensitization between stress and cannabis is involved in shaping risk for psychotic symptoms.

In chapter VII, the results of this thesis, including the data from the mentioned studies, are discussed and further integrated. Emphasis is given to the adolescent period, but also on cross-cultural aspects and an attempt is made to describe a model to explain the pathway from cannabis use to psychosis. The chapter finishes with clinical implications as well as some directions for future research. 

CHAPTER IX

Samenvatting 

In de afgelopen twee decennia, is onderzoek naar en inzicht in de oorzakelijke mechanismen die aan psychotische belevingen ten grondslag liggen, beduidend gestegen. Er zijn verschillende omgevings- en genetische factoren geïdentificeerd die bij de ontwikkeling van psychotische symptomen en ziekten betrokken zijn. Dit proefschrift "cross cultural studies on adolescent cannabis use and psychosis" onderzoekt het verband tussen cannabis gebruik tijdens de adolescentie en risico op ontwikkelen van psychose. $\mathrm{Er}$ is aangetoond dat blootstelling aan cannabis, en dan met name zijn psychoactieve component $\Delta$-9-tetrahydrocannabinol (THC), het risico verhoogt op ontstaan van psychose. Dit proefschrift bevestigt dat cannabis inderdaad één van de omgevings-risicofactoren is die het risico op psychose verhoogt, waarbij dit proefschrift dit verband in een breder perspectief brengt door het te onderzoeken in een minder ontwikkeld land, Trinidad. Verder bevestigt dit proefschrift dat cannabis het meest gebruikte illegale drugs is wat wereldwijd wordt gebruikt, met name onder jonge mensen, zowel dus in Westerse als niet Westerse maatschappijen.

Slechts een minderheid van de mensen die cannabis gebruiken, ontwikkelen echter een psychose, wat betekent dat gebruik van cannabis niet voldoende is of noodzakelijk is om psychotische symptomen te ontwikkelen. Cannabis kan een deeloorzaak zijn in het risico voor psychotische symptomen waarbij het afhankelijk is van andere factoren. Een ander doel van dit proefschrift is dan ook om de interactie van vroeg kinderlijke traumatische belevingen en later cannabis gebruik en het risico op psychose verder te onderzoeken. Dit proefschrift combineert beschrijvende (hoofdstuk II en III), observationele (hoofdstuk V) en epidemiologische (hoofdstuk VI) studies.

Hoofdstuk I beschrijft de etiologie en fenomenologie van psychose. Het beschrijft de korte en lange termijn effecten van cannabis en zijn psychoactieve component $\Delta$ 9-tetrahydrocannabinol (THC) waarbij verschillende studies die deze korte en lange termijn effecten van cannabis op psychose laten zien, worden samengevat en besproken.

Traumatische ervaringen in de vroege kindertijd worden daarbij gezien als een andere omgevings- risicofactor bij psychose. Een samenvatting van de literatuur over traumatische ervaringen in de kindertijd als risicofactor voor psychose wordt dan ook in dit hoofdstuk beschreven. In dit proefschrift, worden studies besproken die uitgevoerd zijn in Trinidad en Tobago, een ontwikkelend land en een niet Westerse samenleving. Culturele aspecten van onderzoek naar psychose worden verder beschreven en onderzocht. Het belang hiervan wordt benadrukt aangezien meer informatie over de prevalentie van psychose en mogelijke verschillen hierin, meer informatie kunnen geven over de rol van cultuur specifieke omgevingsfactoren en hun risico op psychose. In dit hoofdstuk worden verder studies beschreven over adolescenten en het hebben van psychotische symptomen aangezien cannabis 
gebruik vaak voorkomt onder adolescenten. Deze adolescentie periode en jonge volwassenheid lijken cruciale periodes voor de ontwikkeling van de hersenen waar blootstelling aan giftige stoffen zoals cannabis, kan resulteren in veranderingen in met name de frontale cortex van de hersenen. Het lijkt erop dat in dit proces de cannabinoïd receptoren (CB1) , waar endogene cannabinoïden aan binden, betrokken zijn. Dit cannabinoïd systeem is betrokken in het regelen en dysreguleren van het dopamine systeem en daarmee betrokken bij de etiologie van psychose.

Hoofdstuk II onderzoekt het gebruik tijdens het leven van cannabis en alcohol en huidig gebruik van cannabis en alcohol in twee verschillende schoolsystemen in Trinidad. Dit is gedaan om zo eventuele verschillen in de patronen van gebruik in een niet westerse en westerse maatschappij verder te onderzoeken. Het bleek dat gebruik van cannabis in de verschillende schoolsystemen in Trinidad (met inbegrip van zowel openbare scholen als scholen die meer gericht zijn op de praktijk en waar bijvoorbeeld kinderen met leerproblemen aanwezig zijn) veel voorkomt. Cannabis gebruik tijdens het leven is hoog in Trinidad, waarbij er geen statistische verschillen werden gezien in deze prevalentie tussen beide schoolsystemen. In dit hoofdstuk wordt aangetoond dat één op de drie kinderen in Trinidad minimaal één keer in zijn/ haar leven cannabis heeft gebruikt. Het huidig gebruik van cannabis is hoog in de meer praktijd gerichte scholen (1 op 4) terwijl het huidig gebruik van cannabis veel lager is in de openbare scholen (1 op 20). Een mogelijke verklaring voor deze verschillen in de twee schoolsystemen is het type adolescenten wat de scholen bezoeken (kinderen met leerproblemen). Kinderen in Trinidad gebruiken cannabis op jonge leeftijd : de gemiddelde leeftijd van cannabis gebruik is ongeveer 13 jaar. Dus, deze studie geeft meer inzicht in het gebruik van cannabis bij jonge mensen in een niet Westerse samenleving, binnen de verschillende schoolsystemen. Deze studie laat zien dat gebruik van cannabis ook veel voorkomt in en niet Westerse samenleving en het laat zien dat de getallen van prevalentie vergelijkbaar zijn met de meer onderzochte, Westerse samenlevingen. Aangezien het aangetoond is dat cannabis gebruik kan leiden tot psychose en aangezien cannabis ook geassocieerd wordt met andere psychiatrische symptomen, zoals stemmingsproblemen en suïcidale gedachten, benadrukken onze bevindingen het belang van verminderen van cannabis gebruik door jongeren, over de hele wereld.

Hoofdstuk III onderzoekt de hypothese dat cannabis niet alleen betrokken is bij psychotische symptomen, maar ook dat blootstelling aan cannabis kan leiden tot meer affectieve symptomen zoals depressieve en manische symptomen. In deze beschrijvende studie, worden data van ambulante psychiatrische patiënten in Trinidad verzameld en er worden vijf casussen beschreven met verschillende patronen van cannabis gebruik. De klinische, fenomenologische, presentaties van psychiatrische symptomen lijken te worden bepaald door doses, frequentie en duur van ge- 
bruik van cannabis en ook door bv ander drugs gebruik. Het blijkt dat blootsteling aan cannabis gedurende vroeg en late adolescentie kan leiden tot verschillende symptomen zoals angst- stemmings- en psychotische klachten en ook suïcidale ideaties. Dit hoofdstuk laat de prevalentie van verschillende soorten psychiatrische symptomen zien onder cannabis gebruikers in dit ontwikkelend land waarbij niet alleen psychotische symptomen maar ook dus affectieve symptomen en suïcidale gedachten voorkomen bij gebruik van cannabis. Dit ondersteunt de hypothese van het bestaan van een continuüm bij psychose. In dit continuüm model gaat men ervan uit dat psychotische symptomen niet in een alles-of-niets fenomeen bestaan maar dat ze ook aanwezig zin in de normale bevolking in een continuüm van ernst, in zogenaamde subklinische ervaringen. Deze subklinische psychotische ervaringen zijn mildere vormen van de expressie van psychose en delen dezelfde risicofactoren als een klinische psychose. Men denkt dat blootstelling aan verschillende (omgevings-) risicofactoren ertoe kan leiden dat een individu van meer subklinische psychotische belevingen naar meer klinische symptomen kan gaan. Bijvoorbeeld de expressie van symptomen nadat iemand blootgesteld is aan cannabis lijkt in deze studie te worden bepaald door de verschillende patronen in cannabis gebruik. Dus het lijkt erop dat genetische en omgevingsrisicofactoren met elkaar interfereren en uiteindelijk bepalen welke symptomen een individu ontwikkelt nadat hij cannabis gebruikt.

Hoofdstuk IV onderzoekt de bovengenoemde hypothese van een continuüm bij psychose. Hierbij gaat men ervan uit dat subklinische psychotische ervaringen in de algemene bevolking gemeten kunnen worden en meestal worden hier zelfrapportages voor gebruikt. Het doel van dit hoofdstuk is om de betrouwbaarheid en stabiliteit van de Community Assessment of Psychic Experiences (CAPE42) te onderzoeken : een lijst om psychotische ervaringen binnen een normale bevolking te onderzoeken. Voor deze studie zijn data van een longitudinale familie studie in de algemene bevolking in een Nederlandse stad gebruikt. Op verschillende tijdstippen, worden verschillende lijsten (CAPE, Structured Interview for Schizotypy Revised (SIS-R) and Brief Psychiatric Rating Scale (BPRS)) gebruikt om psychotische symptomen te meten (op T1 : alleen de CAPE, op T2 : CAPE, SIS-R, BPRS). De betrouwbaarheid en stabiliteit van de CAPE dimensies wordt onderzocht door het toepassen van lineaire regressie analyse van de verschillende CAPE dimensies over de twee verschillende tijdsmomenten. Het blijkt dat de interne stabiliteit hoog is (0.6-0.8). Deze hoge scores betekenen dat de zelf gerapporteerde dimensies van psychotische ervaringen op de eerste meting (T1) sterk gerelateerd zijn met dezelfde dimensies bij de latere vervolg meting (T2), wat een goede stabiliteit van de CAPE impliceert.

De betrouwbaarheid van de CAPE wordt onderzocht door de associaties van de dimensies van de CAPE op T1 en de dimensies van de twee al betrouwbare, op interview gebaseerde, schalen, SIS-R en BPRS op T2 te vergelijken. Deze zelf gerappor- 
teerde positieve en negatieve dimensies van de CAPE laten een associatie zien, op een dosis-respons manier, met de twee schalen later wat een goede betrouwbaarheid voor de CAPE betekent.

Dus er kan geconcludeerd worden dat de CAPE een goed bruikbaar instrument is om verschillende dimensies van psychotische ervaringen in kaart te brengen in de algemene bevolking en het blijkt een stabiele, valide en betrouwbaar instrument te zijn.

Hoofdstuk $\mathbf{V}$ beschrijft een cross sectioneel onderzoek in de algemene bevolking dat ook in Trinidad werd uitgevoerd. Scholieren (12-23 jaar oud) werden gevraagd een vragenlijst in te vullen waarbij gevraagd werd naar gebruik van cannabis, leeftijd van starten met cannabis en ook vulden ze de CAPE in. Het bleek dat scholieren die voor hun $14^{\mathrm{e}}$ jaar waren begonnen met het gebruiken van cannabis, een statistisch significant verhoogd risico hadden op het ontwikkelen van psychotische symptomen. Deze statistische significantie bleef ook bestaan nadat gecorrigeerd werd voor eventuele andere factoren zoals leeftijd, schooltype, etniciteit, geslacht, huidig gebruik van cannabis en gebruik van andere soorten drugs. Het verhoogd risico werd niet gezien in de personen die begonnen met het gebruik van cannabis na hun $14^{\mathrm{e}}$ jaar. De resultaten van deze studie, in deze niet Westerse samenleving, bevestigt twee recente epidemiologische studies (in goed ontwikkelde landen) dat vroeg gebruik van cannabis geassocieerd is met een groter risico in het ontwikkelen van psychotische symptomen in vergelijking met later gebruik van cannabis. Al deze studies impliceren dat het risico van gebruik van cannabis ontwikkelingsgevoelig is, waarbij leeftijd van gebruik van cannabis belangrijk is en waarbij cannabis gebruik op vroege leeftijd een andere impact kan hebben op de hersenen, met meer schade wanneer er dus vroeg wordt gebruikt.

In dit hoofdstuk worden verdere aanwijzingen voor deze hypothese van verschillend impact op de hersenen met verschillende leeftijd van gebruik beschreven aan de hand van dieren studies, waar blootstelling aan THC leidt tot gedrags- en cognitieve problemen in ratten in hun pubertijd maar niet bij volwassen ratten. Als mogelijke verklaring voor het bestaan van zo'n kwetsbare periode wordt opnieuw het endocannabinoid en dopamine systeem besproken. Met name gedurende de pubertijd verandert de synaptische dopamine activiteit in de prefrontale cortex (wat een belangrijk gebied is aangezien het direct betrokken lijkt bij de etiologie van psychose) en dit gebied is kwetsbaar voor toxische factoren als cannabis.

Hoofdstuk VI beschrijft een epidemiologische studie van twee verschillende data sets (de Griekse Perinatal Study en de Nederlandse MEMESIS studie) om zo te onderzoeken of blootstelling aan verschillende omgevings- risicofactoren het risico op het ontwikkelen van psychose veel meer verhoogt in vergelijking met blootstelling aan één risicofactor. Daarom werden, in deze twee verschillende data sets, het 
verhoogd risico op psychose berekend bij alle personen die vroeg kinderlijke traumatische ervaringen (mishandeling) hadden meegemaakt gecombineerd met of zonder latere blootstelling aan cannabis. Er werd een duidelijke interactie gevonden tussen mishandeling en later cannabis gebruik en dit was ook statistische significant. Dus personen die vroeg kinderlijke traumatische ervaringen hebben doorgemaakt en later in hun leven cannabis gebruiken, laten een veel groter risico zien om psychose te ontwikkelen in vergelijking met personen die of alleen aan cannabis of vroeg kinderlijke trauma zijn blootgesteld of in vergelijking met die personen die niet zijn blootgesteld aan beide factoren. Het is niet waarschijnlijk dat processen zoals "mediation" (getraumatiseerde jonge mensen hebben een groter risico om cannabis te gebruiken) een significante rol spelen omdat alleen in de NEMESIS studie en niet in de Griekse studie, een significante, maar kleine, associatie kon worden gevonden tussen trauma op kinderleeftijd en later cannabis gebruik. Deze bevindingen komen overeen met twee andere studies waar ook interactie tussen trauma op kinderleeftijd en vroeg cannabis gebruik werd gezien. In dit hoofdstuk wordt het model van "cross-sensitization" besproken en verder onderzocht als mogelijke verklaring voor de bevindingen. In dit model worden mensen toenemend gevoelig voor de schadelijke effecten van bv cannabis nadat ze blootgesteld zijn aan trauma op kinderleeftijd. Bewijs voor het model van "(cross)sensitzation" wordt gevonden in verschillende dieren studies en studies met andere drugs en deze studies worden in dit hoofdstuk besproken. Er zijn ook studies met cannabis die dit mechanisme suggereren waarbij langerdurende blootstelling aan cannabis het risico voor psychose verhoogt op een dosisresponse manier wat de rol van sensitisatie suggereert. De huidige bevinding dat de psychose inducerende effecten van cannabis worden beïnvloed door vroege ervaringen van kindermishandeling suggereert dat "crosssensitzation" tussen stress en cannabis betrokken is bij het vromen van een risico voor psychose.

In hoofdstuk VII, worden de resultaten van dit proefschrift, inclusief de data van de genoemde studies, besproken en verder geïntegreerd. De adolescentie periode wordt benadrukt, maar ook de culturele aspecten en er wordt een poging gedaan om een model te beschrijven om de weg van cannabis naar psychose te verklaren. Het hoofdstuk eindigt met klinische implicaties met ook aanwijzingen voor toekomstig onderzoek. 



\section{Dankwoord}

Het maken van dit proefschrift was geen gemakkelijke opgaaf. Zeker niet met al mijn andere werkzaamheden als psychiater die ik altijd erbij heb gehad, maar ik heb het als een enorme uitdaging gezien. Het is erg intensief om met een proefschrift bezig te zijn waarbij ik veel geleerd heb, zowel op wetenschappelijk als persoonlijk vlak. Het onderwerp boeide me erg en ik vind het ook een erg belangrijk onderwerp. Dit proefschrift is mogelijk geworden door het enthousiasme en de inspanning van veel mensen.

Als eerste wil ik graag Prof. Dr. Jim van Os, mijn promotor, bedanken. Jim, jij was mijn opleider in de opleiding tot psychiater en je bent altijd een opleider geweest die altijd veel enthousiasme en steun getoond heeft tijdens de opleiding en zeker in mijn plan om naar Trinidad te gaan en daar onderzoek te gaan doen. Door jouw begeleiding en energie is het mogelijk geweest om daar een jaar te werken. Ik zal nooit vergeten hoe je me, tijdens de periode daar, hebt gesteund en vertrouwen had in mijn activiteiten. Je beantwoorde altijd trouw mijn emails als ik je weer op de hoogte bracht van iets dat iets niet goed liep en je probeerde me altijd weer gerust te stellen. Ik zal ook nooit vergeten, Jim, hoe je besloot, nadat ik weer terug was, dat ik zou gaan promoveren en dat je daarbij mijn tegenargumenten helemaal negeerde. Hiervoor allemaal mijn hartelijke dank.

Verder wil ik heel erg graag Cécile Henquet bedanken, mijn co promotor die mij begeleidde in dit onderzoek. Cécile, jij bent altijd heel enthousiast en toegankelijk geweest en je hebt me enorm bijgestaan in onder andere al die statistische berekeningen. Je hebt enorm veel kennis over het onderwerp cannabis en psychose, waardoor je me altijd weer stimuleerde en enthousiast maakte. Je bent enthousiast en vol energie en je zette me weer aan het denken met jouw vragen ! Je confronteerde me ook met bepaalde zaken, zoals mijn snelle denken en hierdoor wat te snel over bepaalde onderwerpen heengaan en daar ben ik je, hoe raar het ook klinkt, dankbaar voor. Ook in het laatste jaar van dit project, waarbij je naar een andere baan bent gegaan en ik niet meer op de Universiteit kon komen, bleef je betrokken en ben je een grote hulp voor me geweest. Cécile, heel erg bedankt voor jouw begeleiding en onze prettige gesprekken waarin je me enthousiast bleef maken voor het onderzoek en me weer inspiratie gaf.

I would also like to thank dr Hari Maharajh. Hari, I want to thank you for your hospitality by introducing me to your practice in Trinidad and letting me participate in research. It was very interesting to be able to know a bit more about your culture and I am very pleased that you introduced me to your patients, assistants and other colleagues. You have opened my eyes for your beautiful country with all its cultural aspects, which differ so much from the Netherlands and I have very much enjoyed 
working with you. You made it possible for me to visit all these schools and to see the children who filled in the questionnaires which we could use for our data sampling. I also enjoyed being able to see psychiatry in a developing country. Hari, thanks a lot.

I also want to thank another collegue from Trinidad, Prof. Dr. Gerard A Hutchinson. He made it possible for me to come to Trinidad, to participate in education and to do this research. I also had the possibility to teach medical students which was a nice experience. I am very grateful for him to have given me all these chances. Thanks a lot for making this all possible.

Graag wil ik ook alle co-auteurs bedanken voor de fijne samenwerking. Rebecca, fijn dat je jouw kennis van cannabis heb toegevoegd aan verschillende artikelen en dat ik van jouw kennis gebruik kon maken.

I also would like to thank Dr Nikos Stefanus. Thank you for the interesting Greek data. I loved to work with these data and this theme.

Natuurlijk wil ik ook de GGzE bedanken. Dankzij hun inzet, was het mogelijk voor mij om, gedurende 2 jaar, regelmatig op de Universiteit van Maastricht te zijn. Ik ben dankbaar dat ze me die kans hebben gegeven.

Graag wil ik ook mijn ouders, vrienden en vriendinnen bedanken die altijd belangstelling hebben getoond voor mijn onderzoek en die me daarin ook gesteund hebben. Daarin wil ik graag ook mijn paranimf Miriam bedanken, die zelf ook besloten heeft tot het maken van een proefschrift in haar vakgebied. Miriam, heel veel plezier en succes hierin.

In het bijzonder wil ik graag uiteindelijk mijn echtgenoot Antoine, bedanken. Antoine, dank je wel voor al jouw steun en rustige aanwezigheid in deze drukke periode van mijn proefschrift, gecombineerd met mijn andere werkzaamheden. Je bent mij altijd heel erg blijven steunen in de keuzes die ik maak en blijft altijd rustig en positief. Ik heb dit proefschrift dan ook aan jou opgedragen omdat je me altijd zo steunt. Toen ik dat jaar in Trinidad verbleef, ben jij me komen opzoeken en dat was erg fijn ! Je bent iemand die me altijd aanmoedigt alle uitdagingen aan te gaan, dank je wel daarvoor. 


\section{Curriculum Vitae}

Monique Konings werd op 15 mei 1975 geboren in Ell (gemeente Hunsel). Na het Gymnasium aan de Philips van Horne School te Weert ging ze in 1993 geneeskunde studeren aan de Rijksuniversiteit Limburg (nu Universiteit Maastricht) waar ze in 1999 haar artsexamen behaalde. Tijdens deze studie geneeskunde heeft ze in 1995 gedurende een jaar psychologie gestudeerd aan de Universiteit Maastricht, waar ze in 1996 de propadeuse behaalde. Aansluitend aan het artsexamen, is ze gaan werken als AGNIO binnen de psychiatrie en in 2001 is Monique begonnen met de opleiding tot de psychiater in Maastricht (PMS Vijverdal/ RIAGG Maastricht). In het laatste jaar van deze opleiding, ging ze naar Trinidad en Tobago om daar werkzaam te zijn in verschillende poliklinische activiteiten en ook te participeren in onderwijsactiviteiten aan zowel medische studenten als psychiaters in opleiding van de University of West Indies, St Augustine. Ook startte ze hier met verzamelen van data over het onderwerp cannabis bij adolescenten. Ook onderzocht en publiceerde ze diverse artikelen met verschillende (cultureel) psychiatrische onderwerpen. In 2005 rondde ze de opleiding tot psychiater af waarna ze werkzaam was als psychiater binnen de GGZ Oost Brabant, regio Helmond. Vervolgens ging ze in 2007 werken als psychiater binnen de crisisdienst van de GGzE. In 2008 startte ze met promotie onderzoek met als onderwerp "culturele studies over cannabis en psychose" in samenwerking met de Universiteit Maastricht en de GGzE. Verder startte ze met een oud collega in 2007 een vrijgevestigd psychiatrie praktijk waar ze vanaf 2011 full time in werkzaam is. 



\section{List of publications}

\section{International journals}

Konings M, Stefanis N, Kueooer R, de Graaf R, ten Have M, van Os J, Bakoula C and Henquet $C$. Replication in two independent population-based samples that childhood maltreatment and cannabis use synergistically impact on psychosis risk. Psychological Medicine. 2011.

Konings M, Henquet C, Maharajh HD, Hutchinson HD, van Os J. Early exposure to cannabis and risk for psychosis in young adolescents in Trinidad. Acta Psychiatr Scand 2008 Sep : 118 (3) : 209 - 13.

Konings M, Maharajh HD, Gopeesingh S. Injuries from arthropod, reptile and marine bites and stings in South Trinidad. 2007. Journal of Rural and Tropical Public Health 6:1-5.

Maharajh HD, Konings M. Dancing frotteurism and courtship disorder in Trinidad and Tobago. Journal of Chinese Clinical Medicine. 2007;vol2(7): 407-411.

Konings M, Maharajh HD. Substance abuse in different school systems in Trinidad and Tobago: A controlled study of children with disabilities and their drug use. Int J Disabil Hum Dev 2007;6(1):3-10.

Konings $M$, Bak M, Hanssen M, van Os J, Krabbendam L. Validity and reliability of the CAPE: a self-report instrument for the measurement of psychotic experiences in the general population. Acta Psychiatr Scand. 2006 Jul;114(1):55-61.

Maharajh HD, Konings M. Fire setting in a patient with hyperglycaemic delirium. J Forensic Sci. 2006 Jul;51(4):940

Konings M, Maharajh HD. Cannabis use and mood disorders: patterns of clinical presentations among adolescents in a developing country. Int J Adolesc Med Health. 2006 Apr-Jun;18(2):221-33.

Maharajh HD, Ali A, Konings M. Adolescent depression in Trinidad and Tobago.Eur Child Adolesc Psychiatry. 2006 Feb;15(1):30-7. 
Maharajh HD, Konings M, Baboolal NS. Gender and ethnic differences in urban and rural first-contact schizophrenia outpatients in Trinidad. Rev Environ Health. 2006; Jan-Mar; 21(1):69-79.

Maharajh HD, Konings M. Cannabis and suicidal behaviour among adolescents: a pilot study from Trinidad. ScientificWorldJournal. 2005 Aug 8;5:576-85.

Baboolal NS, Konings M, Maharajh HD. Sexual Abuse Resulting in HIV Positivity in a Patient with Alzheimer's DiseaseA Case Report from Trinidad and Tobago.

J Elder Abuse Negl. 2005;17(2):77-82

\section{National journals}

Konings, $\mathrm{M}$ en van der kallen, S. Suïcidepreventie internationaal : wat er al bekend is. Metaforum Wetenschappelijk Tijdschrift van GGzE \& GGZ Brebrug groep. 2009 Dec :7-16.

Konings M. Suïcidepreventie internationaal. Tijdschrift voor Psychiatrie. 2008 ;50 (suppl 1):5202.

Konings M, Debetes JM, Baeten CG. Rubberband ligation of hemorrhoids: symptoms almost gone after 6 weeks, but many patients need retreatment in the long run. Ned Tijdschr Geneeskd. 1999;Jun 12;143(24):1265-8

\section{Chapters in books}

Maharajh HD, Konings M. Chapter 2.9 Suicidal behaviour and cannabis-related disorders among adolescents in : Suicidal Behaviour in Adolescence An international perspective. Freund Publishing House LTD, London and Tel Aviv. 2005.

Konings M, Kuepper R, Smits M, Henquet C. Hoofdstuk 14 Biologische risicofactoren (1): cannabisgebruik in : Handboek schizofrenie. De Tijdstroom uitgeverij, Utrecht. 2011. 